Betina Stifelman Katz

\title{
Estudo dos genes e microRNAs relacionados à transição epitélio-mesenquimal no adenocarcinoma de próstata
}

\author{
Tese apresentada à Faculdade de \\ Medicina da Universidade de São Paulo \\ para obtenção de título de Doutor em \\ Ciências \\ Programa de Urologia \\ Orientadora: Prof. Dra. Katia Ramos \\ Moreira Leite
}

São Paulo, 2014 
Dados Internacionais de Catalogação na Publicação (CIP)

Preparada pela Biblioteca da

Faculdade de Medicina da Universidade de São Paulo

@reprodução autorizada pelo autor

Katz, Betina Stifelman

Estudo dos genes e microRNAs relacionados à transição epitélio-mesenquimal no adenocarcinoma de próstata / Betina Stifelman Katz. -- São Paulo, 2014.

Tese(doutorado)--Faculdade de Medicina da Universidade de São Paulo. Programa de Urologia.

Orientadora: Katia Ramos Moreira Leite.

Descritores: 1 .Neoplasias da próstata 2 .Transição epitelial-mesenquimal 3.MicroRNAs 4.Marcadores biológicos de tumor 5.Prognóstico 6.Biologia molecular

USP/FM/DBD-137/14 
Dedico este trabalho à minha amada avó Ida Katz, cuja perda ocorrida durante a realização da minha tese me motivou ainda mais a buscar uma esperança na ciência. 


\section{Agradecimentos}

À Prof. Dra. Katia Leite, minha maior mentora de todos os tempos, por ter me proporcionado um crescimento científico e pessoal inestimável e por me encantar diariamente com sua capacidade ímpar de ser direta e verdadeira e, ainda assim, vasta e profunda.

Ao Prof. Dr. Miguel Srougi, pelo caráter magnânimo e por todo apoio dado a mim e à minha família ao longo dos anos.

Às pessoas mais importantes da minha vida, meus pais Gildo e Silvia, pelo imenso amor atemporal e pela segurança de uma amizade eterna.

Às minhas irmãs Fernanda e Fabiana, por todos os momentos que compartilhamos e por enriquecerem a minha vida através das suas personalidades tão diferentes e tão fascinantes.

Til min Anders, min største kjærlighet. For å vise meg at vi var skapt for denne verden og livet i sitt fulle.

Às minhas “irmãs" mineiras Sabrina e Nayara, pelo admirável dom de solidariedade e pela brilhante amizade, que foi indubitavelmente uma das mais gratificantes conquistas que obtive nesse período em São Paulo.

Aos meus queridos colegas e amigos do LIM55, José Pontes, Iran, Denis, Caio, Nelson, Alexandre, Vanessa, Rita e Ísis, por me acolherem carinhosamente e por todo o auxílio durante o desenvolvimento da minha tese.

A todos os colegas médicos e funcionários da Disciplina de Urologia, especialmente ao Prof. Dr. Homero Bruschini e ao Prof. Dr. Alberto Antunes, pela seriedade e competência com que conduzem o programa de Pós-Graduação, e à equipe da secretaria Elisa, Tereza, Iones, Inisabete e Aparecida, pela disposição e presteza em sempre me ajudar.

A todos do Laboratório de Patologia Cirúrgica e Molecular, em especial ao Dr. Camara Lopes, por ter me dado a oportunidade de conviver com esse grupo incrível, e ao Dr. Ricardo Souza e à Dra. Juliana Canavez, pela generosa atenção e pela agradável convivência.

À Dra. Liane Golbspan, por ter sido meu modelo de patologista durante minha residência com a sua energia radiante e inspiradora que faz dessa especialidade um mundo ainda mais fantástico.

À Dra. Cristina Mitteldorf, pelo apoio incessante durante a minha estreia como patologista e por ter compartilhado comigo seu fabuloso conhecimento na área. 
Ao Dr. Fabio Tavora, por ter acreditado no meu potencial e por ter feito a gentileza de me introduzir à minha estimada orientadora.

Por fim, à minha preciosa Emily, pelo amor totalmente incondicional e pela fidelidade canina incontestável. 
"Tudo, absolutamente tudo que eu sei apenas sei porque amo."

Liev Tolstói 
Esta tese está de acordo com as seguintes normas, em vigor no momento desta publicação:

Referências: Adaptado de International Committe of Medical Journals Editors (Vancouver).

Universidade de São Paulo. Faculdade de Medicina. Serviço de Biblioteca e Documentação. Guia de apresentação de dissertações, teses e monografias. Elaborado por Anneliese Carneiro da Cunha, Maria Julia de A. L. Freddi, Maria F. Crestana, Marinalva de Souza Aragão, Suely Campos Cardoso, Valéria Vilhena. $3^{\text {a }}$ ed., São Paulo: Serviço de Biblioteca e Documentação, 2011.

Abreviaturas dos títulos dos periódicos de acordo com List of Journals Indexed in Index Medicus. 


\section{Sumário}

Lista de abreviaturas

Lista de figuras

Lista de tabelas

Resumo

Summary

1. Introdução

1.1. Câncer de próstata - Generalidades ___ 2

1.2. Transição epitélio-mesenquimal __ 7

1.3. Genes envolvidos na transição epitélio-mesenquimal ___ 9

1.4. A transição epitélio-mesenquimal no câncer de próstata ___ 11

1.5. Os microRNAs __ 13

1.6. Os microRNAs no câncer de próstata ___ 14

1.7. Os microRNAs e a transição epitélio-mesenquimal ___ 14

1.8. Justificativa _ 17

2. Objetivos _ 18

3. Material e métodos — 20

3.1. Casuística __ 21

3.1.1. Pacientes __ 21

3.1.2. Linhagens celulares__ 23

3.2. Ética _ 23

3.3. Manipulação do espécime cirúrgico - Prostatectomia radical___ 23

3.4. Processamento do RNA _ 24

3.4.1. Extração do RNA __ 24

3.4.2. Isolamento do miRNA _ 25

3.5. Síntese do DNA complementar (cDNA) _ 26

3.5.1. Síntese de cDNA para análise de expressão dos genes___ 26

3.5.2. Síntese de cDNA para análise de expressão dos miRNAs __ 26

3.6. Análise da expressão dos miRNAs e genes alvo ___ 27

3.7. Seleção dos miRNAs e seus genes alvo___ 31

3.8. Análise estatística___ 34 
3.8.1. Subdivisão dos pacientes em grupos 34

3.8.2. Avaliação dos casos metastáticos __ 34

3.8.3. Testes estatísticos _ـ 35

4. Resultados 36

4.1. Perfil de expressão geral dos miRNAs no câncer de próstata localizado ___ 37

4.2. Perfil de expressão geral dos genes no câncer de próstata localizado ___ 41

4.3. Expressão dos miRNAs e a graduação histológica de Gleason ___ 45

4.4. Expressão dos miRNAs e o estadiamento patológico ___ 45

4.5. Expressão dos genes e a graduação histológica de Gleason ___ 47

4.6. Expressão dos genes e o estadiamento patológico___ 47

4.7. Expressão dos miRNAs e os níveis de PSA pré-operatório___ 48

4.8. Expressão dos miRNAs e a recidiva bioquímica___ 48

4.9. Expressão dos miRNAs e grupos de baixo e alto risco ___ 48

4.10. Expressão dos genes e os níveis de PSA pré-operatório ___ 50

4.11. Expressão dos genes e a recidiva bioquímica _ 50

4.12. Expressão dos genes e grupos de baixo e alto risco__ 50

4.13. Análise de sobrevida livre de recorrência bioquímica dos microRNAs 200b,

$30 \mathrm{a}$ e 1 _ 51

4.14. Comparação entre o câncer de próstata localizado e as linhagens celulares metastáticas _ 53

4.15. Correlação entre os genes e miRNAs__ 57

5. Discussão — 58

5.1. O câncer de próstata localizado mantém o fenótipo epitelial ___ 59

5.2. O início da transição epitélio-mesenquimal____ 64

5.3. A superexpressão de Twist1 nos tumores localizados ___ 66

5.4. O miR-183 e o gene Twist1 estão envolvidos no processo de disseminação da doença _ 67

5.5. Aplicação prática: associação com parâmetros clínico-patológicos _ـ 70

5.6. Considerações finais___ 72

6. Conclusão _ 76

7. Anexos 78

8. Referências __ 81

Apêndices 


\section{Lista de abreviaturas}

AJCC - American Joint Committee on Cancer

ATCC - American Type Culture Collection

Bcl-2 - B-cell lymphoma 2

BMP - Bone morphogenic protein

B2M - Beta-2-microglobulin

CaP - Câncer de próstata

cDNA - Complementary deoxyribonucleic acid

DKK3 - Dickkopf WNT signaling pathway inhibitor 3

dNTP - Deoxynucleotide

EGR1 - Early growth response 1

ERG - ETS-related gene

FGF - Fibroblast growth factor

FOXP1 - Forkhead box P1

HDAC1 - Histone deacetylase 1

HDAC4 - Histone deacetylase 4

HGF - Hepatocyte growth factor

HOXD10 - Homeobox D10

HPB - Hiperplasia prostática benigna

IGF-1 - Insulin-like growth factor 1

ITGB1 - Integrin, beta 1 
KIF2A - Kinesin heavy chain member $2 A$

KLF4 - Kruppel-like factor 4

miRNA - microRNA

MMP2 - Matrix metalloproteinase 2

$\mathrm{NF \kappa B}$ - Nuclear factor of kappa light polypeptide gene enhancer in B-cells 1

NKX3.1 - NK3 homeobox 1

PCR - Polymerase chain reaction

PDGF - Platelet derived growth factor

PDGF-D - Platelet derived growth factor D

PI3K - Phosphatidylinositol-4,5-bisphosphate 3-kinase

PIN - Prostatic intraepithelial neoplasia

$\mathrm{PKC} \varepsilon-$ Protein kinase C, epsilon

PNP - Purine nucleoside phosphorylase

PSA - Prostate-specific antigen

PTEN - Phosphatase and tensin homolog

qRT-PCR - Quantitative real-time polymerase chain reaction

RHOC - Ras homolog family member C

RISC - RNA-induced silencing complex

RKIP - Raf kinase inhibitor protein

RNA - Ribonucleic acid

RNAm - RNA mensageiro

SEC23A - Sec23 homolog A 
SIP1 - Smad interacting protein 1

SMAD - Mothers against decapentaplegic homolog

SMAD 4 - Mothers against decapentaplegic homolog 4

TCF8 - Transcription factor 8

TEM - Transição epitélio-mesenquimal

TME - Transição mesênquima-epitelial

TGF- $\beta 1$ - Transforming growth factor beta 1

TIMP2 - Tissue inhibitor of metalloproteinase 2

TMA - Tissue microarray

UTR - Untranslated region 


\section{Lista de figuras}

Figura 1 - Principais genes envolvidos na transição epitélio-mesenquimal e suas funções

Figura 2 - Biogênese do miRNA

Figura 3 - Reprodução esquemática da alça de retroalimentação duplamente negativa ZEB/miR-200 e seu papel na transição epitélio-mesenquimal

Figura 4 - Amplificação dos miRNAs e genes pelo método TaqMan®

Figura 5 - Modelo esquemático dos miRNAs e genes envolvidos na transição epitélio-mesenquimal e suas possíveis funções

Figura 6 - Perfil de expressão dos miRNAs com predomínio de superexpressão em 51 pacientes com câncer de próstata 38

Figura 7 - Perfil de expressão dos miRNAs com predomínio de subexpressão em 51 pacientes com câncer de próstata

Figura 8 - Perfil de expressão dos miRNAs que exibiram padrão variável em 51 pacientes com câncer de próstata

Figura 9 - Perfil de expressão dos genes com predomínio de superexpressão em 51 pacientes com câncer de próstata

Figura 10 - Perfil de expressão dos genes com predomínio de subexpressão em 51 pacientes com câncer de próstata

Figura 11 - Perfil de expressão dos genes que exibiram padrão variável em 51 pacientes com câncer de próstata

Figura 12 - Curva de sobrevida livre de recorrência bioquímica de acordo com a expressão do miR-200b

Figura 13 - Curvas de sobrevida livre de recorrência bioquímica de acordo com a expressão do miR-30a e do miR-1

Figura 14 - Perfil de expressão dos miRNAs nos tumores pT3 e nas linhagens celulares metastáticas

Figura 15 - Perfil de expressão dos genes nos tumores pT3 e nas linhagens celulares metastáticas 56

Figura 16 - Fenótipo molecular do câncer de próstata localizado 64

Figura 17 - Gene Snail e seus miRNAs reguladores 66

Figura 18 - Interpretação dos resultados da expressão dos miRNAs e genes reguladores da transição epitélio-mesenquimal no câncer de próstata localizado 
Figura 19 - Principais miRNAs e genes envolvidos na transição epitéliomesenquimal no câncer de próstata 


\section{Lista de tabelas}

Tabela 1 - Classificação TNM/AJCC 2010

Tabela 2 - Características clínico-patológicas dos 51 pacientes com câncer de próstata localizado tratados com prostatectomia radical 22

Tabela 3 - Primers utilizados para quantificação da expressão dos genes 29

Tabela 4 - Primers utilizados para quantificação de expressão dos miRNAs 30

Tabela 5 - microRNAs estudados e seus possíveis genes alvo

Tabela 6 - Média de expressão dos microRNAs estudados nos 51 pacientes com câncer de próstata, comparada com o grupo controle

Tabela 7 - Média de expressão dos genes estudados nos 51 pacientes com câncer de próstada, compara com o grupo controle

Tabela 8 - Expressão dos microRNAs de acordo com o escore de Gleason e estadiamento patológico 46

Tabela 9 - Expressão dos genes de acordo com o escore de Gleason e estadiamento patológico

Tabela 10 - Expressão dos microRNAs de acordo com o valor do PSA préoperatório, presença ou não de recorrência bioquímica, e grupos de risco

Tabela 11 - Expressão dos genes de acordo com o valor do PSA pré-operatório, presença ou não de recorrência bioquímica, e grupos de risco

Tabela 12 - Expressão dos microRNAs e genes nos tumores pT3 e nas linhagens celulares metastáticas 


\section{RESUMO}

Katz BS. Estudo dos genes e microRNAs relacionados à transição epitéliomesenquimal no adenocarcinoma de próstata [tese]. São Paulo: Faculdade de Medicina, Universidade de São Paulo; 2014.

Introdução: $\mathrm{O}$ câncer de próstata $(\mathrm{CaP})$ é o tumor mais comum em homens e a segunda causa de óbito por câncer no Brasil. Com a adoção do rastreamento, a maioria dos pacientes apresenta doença localizada ao diagnóstico, enquanto apenas 4\% têm doença metastática. Um dos principais mecanismos responsáveis pela progressão tumoral é a transição epitélio-mesenquimal (TEM). Esse é um programa celular reversível no qual a célula epitelial perde a capacidade de aderência intercelular e assume um fenótipo mesenquimal com potencial invasivo e metastático. A principal característica da TEM é a repressão da E-caderina através de fatores de transcrição que incluem ZEB1, ZEB2, Snail, Slug e Twist1. Os microRNAs também estão envolvidos na regulação do processo, sendo a família do miR-200 uma das mais importantes e uma potente indutora da diferenciação epitelial. Assim sendo, o conhecimento dos fatores envolvidos na TEM no CaP é fundamental para a compreensão do comportamento biológico dessa neoplasia. Objetivos: Analisar a expressão dos genes e microRNAs envolvidos na transição epitéliomesenquimal em espécimes de câncer de próstata localizado e em linhagens celulares de câncer de próstata metastático. Além disso, correlacionar o perfil de expressão dos genes e microRNAs com parâmetros clínico-patológicos. Material e métodos: $\mathrm{O}$ estudo consistiu na análise de espécimes de 51 pacientes com CaP localizado tratados por prostatectomia radical e de linhagens celulares de $\mathrm{CaP}$ metastático (LNCaP, DU145 e PC3). O grupo controle foi composto por 10 casos de hiperplasia prostática benigna. A expressão dos genes E-caderina, N-caderina, Vimentina, TGF$\beta 1$, ZEB1, ZEB2, Snail, Slug, Twist1 e PDGF-D e dos microRNAs 200a, 200b, 200c, 429, 141, 203, 205, 183, 373, 21, 9, 1, 495, 29b, 30a, 34a, 155 e 10b foi avaliada através da técnica de PCR em tempo real (qRT-PCR) nos espécimes e nas linhagens. Para correlação com parâmetros clínico-patológicos, os pacientes foram divididos em grupos em relação ao escore de Gleason, estadiamento patológico, PSA pré-operatório, recorrência bioquímica e doença de baixo e alto risco. Para avaliação do tumor metastático, agrupamos as linhagens celulares e comparamo-las com tumores pT3. Resultados: A grande maioria dos casos apresentou superexpressão de E-caderina e Twist1 e subexpressão de N-caderina, Vimentina, TGF- $\beta 1$, ZEB1 e Slug. ZEB2, Snail e PDGF-D apresentaram expressão variável. A família do miR200 e os miRNAs 203, 205, 183, 373 e 21 apresentaram superexpressão, enquanto que os miRNAs 9, 495, 29b e 1 apresentaram subexpressão. Os demais miRNAs apresentaram perfil de expressão variável. Níveis menores de expressão dos miRNAs 200b, 30a e 1 associaram-se significativamente com estadiamento patológico. Os pacientes com expressão reduzida do miR-200b também apresentaram associação com escore de Gleason $\geq 8$ e com menor tempo de sobrevida livre de recorrência bioquímica. Ainda, níveis baixos do miR-30a e níveis elevados de Vimentina e Twist1 associaram-se com grupo de alto risco. As linhagens metastáticas apresentaram níveis de expressão do miR-183 e do Twist1 significativamente maiores quando comparadas ao tumor localizado. Conclusão: O CaP localizado 
mantém um fenótipo molecular epitelial. Menor expressão dos miRNAs 200b, 30a e 1 está associada com estadiamento mais avançado, sendo que o miR-200b também associou-se com maior escore de Gleason e menor tempo de sobrevida livre de recorrência bioquímica, e o miR-30a, com grupo de alto risco. A maior expressão de Vimentina e Twist1 apresentou associação com o grupo de alto risco. miR-183 e Twist1 apresentam maiores níveis de expressão em linhagens celulares metastáticas em relação ao tumor primário. De acordo com nossos resultados, os miRNAs 200b, 30a, 1 e 183 e os genes Twist1 e Vimentina podem ter um papel importante na progressão do $\mathrm{CaP}$, além de serem potenciais marcadores prognósticos.

Descritores: Neoplasias da próstata; Transição epitelial-mesenquimal; microRNAs; Marcadores biológicos de tumor; Prognóstico; Biologia molecular. 


\section{SUMMARY}

Katz BS. Study of gene and miRNA expression profiles related to epithelialmesenchymal transition in prostate adenocarcinoma [thesis]. São Paulo: Faculdade de Medicina, Universidade de São Paulo; 2014.

Introduction: Prostate cancer (PCa) is the most common cancer in men and the second leading cause of cancer-related mortality in Brazil. After the adoption of screening, most patients present with localized disease at the time of diagnosis, while only $4 \%$ have metastatic disease. One of the main mechanisms of tumor progression is the epithelial-mesenchymal transition (EMT). This is a reversible cell-biological program in which an epithelial cell loses intercellular adhesion and acquires a mesenchymal phenotype with invasiveness and metastatic potential. The main event in EMT is the repression of E-cadherin by transcriptional factors, including ZEB1, ZEB2, Snail, Slug, and Twist1. microRNAs are also involved in the regulation of this process, and one of the most important ones is the miR-200 family, which is a powerful inducer of epithelial differentiation. Therefore, the knowledge of the factors involved in EMT in PCa is essential to understand the biological behavior of this neoplasia. Objectives: Analysis of gene and miRNA expression involved in epithelial-mesenchymal transition in specimens of localized prostate cancer and metastatic prostate cancer cell lines. Correlation between the gene and miRNA expression profiles and clinicopathological features. Material and Methods: This study consisted in the analysis of specimens from 51 patients with localized PCa treated by radical prostatectomy and of metastatic PCa cell lines (LNCaP, DU145, PC3). The control group was composed by 10 cases of benign prostatic hyperplasia. Gene expression of E-cadherin, N-cadherin, Vimentin, TGF- $\beta 1$, ZEB1, ZEB2, Snail, Slug, Twist1, and PDGF-D as well as miRNA expression of 200a, 200b, 200c, 429, 141, 203, 205, 183, 373, 21, 9, 1, 495, 29b, 30a, 34a, 155, and 10b were assessed by Real-Time PCR (qRT-PCR). The patients were divided into groups according to Gleason score, pathological stage, preoperative PSA, biochemical recurrence, and low and high-risk disease. For evaluation of metastatic tumor, the cell lines were grouped and compared to pT3 tumors. Results: The vast majority of the cases showed overexpression of E-cadherin and Twist1 and underexpression of $\mathrm{N}$ cadherin, Vimentin, TGF- $\beta 1$, ZEB1, and Slug. ZEB2, Snail, and PDGF-D showed a variable expression pattern. miRNA-200 family and miRNAs 203, 205, 183, 373, and 21 were overexpressed, while miRNAs 9, 495, 29b, and 1 were underexpressed. The remaining miRNAs showed a variable expression pattern. Lower expression levels of miRNAs 200b, 30a, and 1 were significantly associated with pathological stage. Patients with lower expression of miR-200b also showed association with Gleason score $\geq 8$ and biochemical recurrence-free survival (BRFS). Furthermore, low expression levels of miR-30a and high expression levels of Vimentin and Twist1 were associated with high-risk group. The metastatic PCa cell lines showed significantly higher expression levels of miR-183 and Twist1 in comparison to the primary tumor. Conclusion: Localized prostate cancer maintains a molecular epithelial phenotype. Lower expression of miRNAs 200b, 30a, and 1 was associated with higher stage. Low levels of miR-200b were also associated with high Gleason score and shorter BRFS, and miR-30a, with high-risk group. High expression levels of Vimentin and Twist1 were associated with high-risk group. miR-183 and Twist1 
levels were higher in metastatic cell lines than in the primary tumor. According to our results, miRNAs 200b, 30a, 1, and 183 and the genes Twist1 and Vimentin might play an important role in the progression of PCa and may turn to be important prognostic markers.

Descriptors: Prostate neoplasms; Epithelial-mesenchymal transition; microRNA; Tumor markers, biological; Prognosis; Molecular biology. 
I.INTRODUÇÃO 


\section{INTRODUÇÃO}

\subsection{Câncer de próstata - Generalidades}

O câncer de próstata $(\mathrm{CaP})$ é o tumor não cutâneo mais comum em homens e a segunda causa de óbito por câncer no Brasil (www.inca.gov.br). É responsável por 13,8\% das mortes decorrentes de câncer no sexo masculino, similar ao que ocorre com o câncer de mama no sexo feminino, que corresponde a 15,8\% das mortes por câncer em mulheres. Para o ano de 2014, estimam-se 68.800 casos novos, tendo ocorrido 13.129 óbitos em 2011. Nos Estados Unidos, o CaP corresponde a 29\% dos cânceres diagnosticados em homens ${ }^{1}$, e estima-se que um em cada sete homens será diagnosticado com este tumor ao longo da vida (seer.cancer.gov).

A incidência do $\mathrm{CaP}$ apresenta variações geográficas e raciais significantes que podem ser influenciadas por fatores genéticos - como etnia e história familiar -, alimentares e ambientais ${ }^{2}$. Pacientes da raça negra apresentam as maiores taxas de $\mathrm{CaP}$ e tendem a apresentar evolução mais agressiva da doença, enquanto que asiáticos têm a menor prevalência. Presença de pai ou irmão com $\mathrm{CaP}$ antes dos 60 anos aumenta o risco em 3 a 10 vezes em relação à população geral ${ }^{3}$.

A suspeita clínica se dá através do toque retal e da dosagem dos níveis séricos do antígeno prostático específico (PSA) ${ }^{4,5}$, sendo o diagnóstico realizado mediante biópsia por agulha. Com a adoção do rastreamento, a grande maioria dos pacientes com $\mathrm{CaP}$ apresenta doença localizada e tem um prognóstico excelente quando manejada adequadamente. Atualmente, apenas $4 \%$ a $6 \%$ dos pacientes têm doença metastática no momento do diagnóstico ${ }^{6}$.

O prognóstico depende fundamentalmente do escore de Gleason ${ }^{7,8}$ e do estadiamento patológico. O sistema de graduação de Gleason baseia-se na avaliação da arquitetura da neoplasia e é dividido em cinco padrões, de 1 a 5 . Em espécimes de prostatectomia radical e de ressecção transuretral, o escore é obtido através da soma do padrão mais prevalente com o segundo mais prevalente. Já em biópsias, o escore é o resultado da soma do padrão mais prevalente com o padrão de mais alto grau. 
Tumores com escore 6 são considerados de baixo grau, enquanto que tumores com escore 8, 9 e 10, de alto grau. O escore 7 é considerado de grau intermediário, e seu comportamento é bastante variável. Os escores 2 a 4 são extremamente raros e praticamente nunca devem ser dados em material de biópsia. $\mathrm{O}$ estadiamento segue a classificação TNM recomendada pela AJCC (2010), conforme ilustrado na Tabela 1. Embora esses parâmetros sejam fundamentais para a decisão terapêutica, eles não são perfeitos, tampouco suficientemente acurados para discriminar o comportamento dos tumores.

$\mathrm{O}$ tratamento do $\mathrm{CaP}$ inclui desde a vigilância ativa até o tratamento sistêmico com bloqueio hormonal e quimioterapia. Para definir a forma de tratamento mais adequada, deve-se levar em consideração o estadiamento, as comorbidades e a expectativa de vida, assim como os possíveis efeitos colaterais do tratamento. De acordo com a NCCN (nccn.org), a vigilância ativa como primeira opção pode ser realizada em pacientes que preenchem os critérios de doença de baixo risco de D’Amico $^{1}$ (quando a expectativa de vida é menor que 10 anos) ou de Epstein ${ }^{2}$ (se menor de 20 anos) ${ }^{9,10}$. Nos pacientes com CaP de baixo risco que não preenchem esses critérios ou que não desejam realizar o tratamento conservador, e aqueles com risco intermediário, a opção de tratamento é a prostatectomia radical ou a radioterapia. Já em pacientes de alto risco, o tratamento deve ser mais agressivo, devido ao maior potencial metastático da doença nesses casos ${ }^{11}$.

Nos pacientes que já possuem doença metastática, o objetivo da terapia visa somente ao controle da doença e à manutenção da qualidade de vida, uma vez que a metástase torna o CaP incurável. O tratamento consiste na castração clínica ou cirúrgica, conhecida como terapia antiandrogênica, a qual é altamente efetiva na diminuição do tumor e nos níveis séricos do PSA ${ }^{12}$. Cerca de $60 \%$ a $80 \%$ dos pacientes respondem inicialmente ao tratamento clínico que promove níveis de testosterona plasmática semelhantes aos obtidos com a castração cirúrgica ${ }^{13}$.

\footnotetext{
${ }^{1}$ Critérios de D'Amico: escore de Gleason $\leq 6$, estadiamento clínico T1 ou T2a e PSA $\leq 10 \mathrm{ng} / \mathrm{mL}$

${ }^{2}$ Critérios de Epstein: escore de Gleason $\leq 6$, estadiamento clínico T1c, densidade do PSA $<0,15$ e biópsia contendo tumor em não mais que dois fragmentos, sendo que nenhum compromete mais que $50 \%$ do fragmento acometido
} 
Apesar das altas taxas de resposta à terapia antiandrogênica, quase todos os pacientes com $\mathrm{CaP}$ metastático apresentarão progressão da doença, sendo então considerados resistentes à castração ${ }^{12,14,15}$. No entanto, esses pacientes podem ainda apresentar resposta clínica a outras manipulações hormonais, conhecidas como terapia hormonal secundária. O tratamento com quimioterapia e/ou imunoterapia é reservado a pacientes que não respondem mais à terapia hormonal.

A terapia hormonal para o $\mathrm{CaP}$ metastático não é curativa e, embora aumente a sobrevida livre de progressão da doença, não há evidências de aumento na sobrevida global ${ }^{12}$. Ademais, os efeitos colaterais decorrentes da terapia antiandrogênica são deletérios à qualidade de vida dos pacientes. Além de causar disfunção sexual, perda da libido e perda da massa muscular e óssea, um dos mais preocupantes efeitos adversos está relacionado a alterações metabólicas ${ }^{16}$. Vários estudos observaram um aumento nos níveis de colesterol e triglicerídeos e um aumento no risco de desenvolvimento de diabetes melito e doença cardiovascular ${ }^{17}$, 18 .

Embora a conduta do CaP seja bem estabelecida na maioria dos casos, em determinadas situações não há consenso sobre o manejo mais adequado. Nos tumores de alto risco ainda localizados, a cirurgia isolada muitas vezes não é suficiente para fins curativos, o que faz com que esses pacientes tenham maior risco de recorrência bioquímica. Em alguns casos, a adjuvância com terapia antiandrogênica é necessária, propiciando um aumento significativo na sobrevida livre de doença em 5 anos e na sobrevida geral ${ }^{19,20}$. Entretanto, seu uso é restrito a certos pacientes, sendo os fatores prognósticos clássicos insuficientes para discriminar quais deles realmente necessitam da terapia antiandrogênica adjuvante.

De forma semelhante, nos casos de baixo risco também podemos nos deparar com uma situação amiúde conflitante. Embora a vigilância ativa seja cada vez mais adotada nesses pacientes ${ }^{21}$, aproximadamente um terço deles necessitará de tratamento em algum momento ${ }^{22}$. Acredita-se que a reclassificação do tumor em maior risco não se deva à progressão biológica, mas, sim, à amostragem mais acurada $^{23}$. Ainda, grande parte dos pacientes tende a optar, em algum momento, pelo tratamento cirúrgico ou radioterápico devido à aflição e à ansiedade sobre a eventual 
progressão da doença ${ }^{24}$, a qual, de fato, desconhecemos. Em contrapartida, de acordo com revisão recente da literatura, o número de cirurgias descenessárias varia de $5 \%$ a $30 \%{ }^{25}$.

Diante dessas situações, observamos não só a carência de marcadores moleculares relacionados ao comportamento biológico do $\mathrm{CaP}$, mas a necessidade e a importância da identificação dos mesmos. Portanto, o conhecimento dos processos biológicos que participam da progressão da doença torna-se fundamental. 
Tabela 1. Classificação TNM/AJCC 2010

\begin{tabular}{|c|c|c|}
\hline \multicolumn{3}{|c|}{ Tumor primário (T) } \\
\hline $\mathrm{Tx}$ & & O tumor primário não pode ser avaliado \\
\hline T0 & & Não há evidência de tumor primário \\
\hline \multirow[t]{4}{*}{ T1 } & & $\begin{array}{l}\text { Tumor não diagnosticado clinicamente, não palpável ou não visível } \\
\text { por meio de exame de imagem }\end{array}$ \\
\hline & T1a & Achado histológico incidental em $5 \%$ ou menos do tecido ressecado \\
\hline & $\mathrm{T} 1 \mathrm{~b}$ & Achado histológico incidental em mais de $5 \%$ do tecido ressecado \\
\hline & T1c & $\begin{array}{l}\text { Tumor identificado por biópsia por agulha (por exemplo, devido a } \\
\text { PSA elevado) }\end{array}$ \\
\hline \multirow[t]{4}{*}{$\mathrm{T} 2$} & & Tumor confinado à próstata \\
\hline & $\mathrm{T} 2 \mathrm{a}$ & Tumor que envolve uma metade ou menos de um dos lobos \\
\hline & $\mathrm{T} 2 \mathrm{~b}$ & $\begin{array}{l}\text { Tumor que envolve mais da metade de um dos lobos, mas não } \\
\text { ambos os lobos }\end{array}$ \\
\hline & $\mathrm{T} 2 \mathrm{c}$ & Tumor que envolve ambos os lobos \\
\hline \multirow[t]{3}{*}{$\mathrm{T} 3$} & & Tumor com extensão extraprostática \\
\hline & T3a & Extensão extraprostática ou invasão microscópica do colo da bexiga \\
\hline & $\mathrm{T} 3 \mathrm{~b}$ & Invasão das vesículas seminais \\
\hline $\mathrm{T} 4$ & & $\begin{array}{l}\text { Tumor invade estruturas adjacentes que não as vesículas seminais: } \\
\text { reto, músculos elevadores do ânus, parede pélvica }\end{array}$ \\
\hline
\end{tabular}

\section{Linfonodos regionais $(\mathbf{N})$}

$\mathrm{Nx}$

Os linfonodos regionais não podem ser avaliados

$\begin{array}{ll}\text { N0 } & \text { Ausência de metástase em linfonodo regional } \\ \text { N1 } & \text { Metástase em linfonodo regional }\end{array}$

\section{Metástase à distância (M)}

$\mathrm{Mx}$

M0

M1

$\begin{array}{lll}\text { M1 } & \begin{array}{l}\text { Metástase à distância } \\ \text { Linfonodo(s) não regional(ais) }\end{array} \\ \text { M1b } & \text { Osso(s) } \\ \text { M1c } & \text { Outra(s) localização(ões) }\end{array}$




\subsection{Transição epitélio-mesenquimal}

A transição epitélio-mesenquimal (TEM) é um programa biológico celular reversível que permite a transição parcial ou completa entre esses dois fenótipos. A célula epitelial, que normalmente interage com a membrana basal, perde a capacidade de aderência intercelular e, através de uma série de processos moleculares, assume um fenótipo mesenquimal. Ao obter tais características, a célula adquire um aumento da capacidade migratória e invasora, com capacidade de romper os componentes da membrana basal, além de se tornar mais resistente à apoptose. A ativação de fatores de transcrição, a expressão de proteínas da superfície celular e do citoesqueleto e as alterações na expressão de certos microRNAs (miRNAs) são fenômenos envolvidos na TEM ${ }^{26}$.

A TEM foi descrita em 1968 pela pesquisadora Elizabeth Hay, que observou a importância desse processo no movimento celular de embriões, denominando-o inicialmente de transformação epitélio-mesenquimal. Em 1982, Greenburg e Hay demonstraram pela primeira vez a transição fenotípica in vivo ${ }^{27}$. Acredita-se que as células do corpo humano sejam derivadas de outras células menos especializadas através de um processo de diferenciação. Para tal, as células devem passar por transformações durante o desenvolvimento, assumindo vários fenótipos, e é por essa razão que a transição epitélio-mesenquimal ocorre. As células com aparência epitelial exibem plasticidade e podem transitar entre os estados epitelial e mesenquimal através desse fenômeno ${ }^{28}$. Após o término do desenvolvimento, as células epiteliais exercem funções específicas relacionadas a cada tecido, enquanto que as células mesenquimais têm papel de suporte, sendo ambas mantidas num estado permanente de diferenciação ${ }^{26}$. Esse conceito foi muito contestado após inúmeras observações de que células epiteliais já diferenciadas podem mudar de fenótipo através da ativação da TEM quando influenciadas por certas situações, como o reparo tecidual e o câncer. Atualmente, a TEM constitui um mecanismo envolvido não só na embriogênese, mas também no reparo tecidual e na carcinogênese, sendo classificada em três tipos, cada uma com funções diferentes ${ }^{29}$.

A TEM tipo 1 está associada com a implantação e formação do embrião e desenvolvimento dos órgãos. Seu papel é gerar células com fenótipo mesenquimal 
para a criação de novos tecidos com distintas funcionalidades. Esse fenômeno é encontrado em processos como a gastrulação ${ }^{26}$, delaminação da crista neural ${ }^{26} \mathrm{e}$ formação do palato e das valvas cardíacas ${ }^{30}$.

A TEM tipo 2 participa da cicatrização, regeneração tecidual e fibrose, através da produção de fibroblastos que reconstroem e reparam o tecido após trauma ou dano inflamatório. A fibrose que ocorre no rim, como resposta ao dano renal causado por condições como diabetes melito, hipertensão, glomerulopatias e toxicidade, é um exemplo de fenômeno decorrente da TEM ${ }^{31}$.

A TEM tipo 3 é a que ocorre no câncer. A aquisição do comportamento invasivo e metastático de uma neoplasia parece ser ativada por este programa, que está intimamente relacionado à progressão tumoral. A TEM tipo 3 está associada com alterações morfológicas celulares e mudança concomitante de um estado séssil para um estado migratório. Dois elementos fundamentais que caracterizam a TEM são a perda da aderência celular e a perda da polaridade celular. Há, ainda, uma reorganização completa do citoesqueleto de actina, que aumenta a locomoção da célula. No entanto, a presença de fenótipos intermediários que conservam marcadores específicos tanto epiteliais quanto mesenquimais demonstra que a TEM ocorre muitas vezes de forma parcial ou incompleta. Como exemplo prático, temos o carcinossarcoma da mama, cujo componente epitelial expressa alguns marcadores da TEM, mesmo mantendo características histológicas epiteliais ${ }^{32}$.

É importante ressaltar que o processo de invasão e progressão tumoral é complexo e provavelmente envolve mais de um caminho. Acredita-se que as célulastronco tumorais também sejam cruciais para o desenvolvimento da metástase. Essas células possuem capacidade de autorrenovação, iniciação e disseminação tumoral, além de apresentarem resistência à apoptose. Contudo, ambos os processos parecem estar relacionados entre si, pois a ativação da TEM é capaz de induzir células tumorais a entrarem em um estado de células-tronco ${ }^{33,34}$. Dessa forma, a TEM confere às células não apenas o fenótipo mesenquimal, mas também a aquisição de propriedades de células-tronco, prestando-lhes todos os traços necessários para a disseminação do tumor primário e para o crescimento à distância ${ }^{35}$. 
Existem também outros mecanismos que não a TEM através dos quais as células se movimentam no câncer. Dependendo do tipo celular e do ambiente tecidual, as células podem migrar individualmente quando as junções celulares estão ausentes, como é o caso da TEM, ou coletivamente, na forma de grupos multicelulares cuja adesão está mantida ${ }^{36}$. Neste último, denominado migração coletiva, a adesão entre as células é mantida em função da expressão de E-caderina, o que facilita a coordenação do movimento em grupo. Essa forma de invasão é frequentemente observada no carcinoma epidermoide invasivo, o qual expressa Ecaderina na sua fronte de invasão. Diferentemente da TEM, portanto, a polarização e a aderência celular estão mantidas na migração coletiva ${ }^{37}$.

\subsection{Genes envolvidos na transição epitélio-mesenquimal}

Para que ocorra a transição epitélio-mesenquimal, espera-se que a expressão gênica de marcadores epiteliais seja reprimida, enquanto que a expressão de marcadores mesenquimais seja estimulada. A principal característica da TEM é a repressão do gene da E-caderina, uma proteína de adesão celular dependente de cálcio que tem papel na regulação da morfogênese e da diferenciação epitelial ${ }^{38,39}$.

Inicialmente, a ativação da TEM requer uma sinalização entre células tumorais e células do estroma vizinho ${ }^{33}$. As células tumorais recrutam uma variedade de células estromais, como fibroblastos, miofibroblastos, granulócitos, macrófagos, células-tronco mesenquimais e linfócitos. Essas células criam um estroma reativo: um microambiente inflamatório que resulta no lançamento de sinais indutores da TEM. As células tumorais sofrem ação desses fatores, que incluem FGF, EGF, PDGF e TGF- $\beta$, e de vias sinalizadoras, como a via Wnt e a via Notch ${ }^{40}$, ${ }^{41}$. As células tumorais respondem a esses sinais ativando fatores de transcrição, que serão os responsáveis por alterações na expressão de genes que carregam comportamentos relacionados a TEM.

O TGF- $\beta 1$ é um dos principais responsáveis pela ativação dos fatores de transcrição repressores da E-caderina (Figura 1). Contudo, no CaP, age tanto como supressor tumoral quanto como oncogene, dependendo do estágio do tumor ${ }^{42}$. 
Inicialmente, o TGF- $\beta 1$ suprime o desenvolvimento tumoral ao impedir a proliferação e induzir a morte celular. Mais tardiamente, porém, contribui para a progressão tumoral ao promover invasão e metástase, e este papel está associado à sua potente capacidade de induzir a TEM.

O processo é fundamentalmente controlado por três famílias de fatores de transcrição: ZEB, Snail e hélice-alça-hélice (Twist1). Os fatores de transcrição ativados são repressores da E-caderina, cuja perda facilita a dissociação das células tumorais promovendo metástase. Uma descoberta crucial no entendimento da regulação transcricional da TEM surgiu em 2000, quando o gene Snail (Snai1) foi identificado como um repressor transcricional direto da E-caderina ${ }^{43,44}$. Aquele se liga à caixa $\mathrm{E}$, localizada no promotor desta, o que causa sua perda temporal e reversível. Desde então, outros fatores repressores foram descobertos, como Slug (Snai2), ZEB1, ZEB2, E47 e Twist1, o último agindo provavelmente de forma indireta sobre a E-caderina ${ }^{45}$.

Além da repressão da E-caderina, ocorre também uma superexpressão de marcadores mesenquimais, como a Vimentina, a N-caderina e a Caderina-11, processo conhecido como cadherin switching ${ }^{46}$. Alguns dos fatores repressores podem agir também como ativadores transcricionais, como no caso do Twist1, o qual induz a expressão de $\mathrm{N}$-caderina aumentando a motilidade celular ${ }^{47}$. 


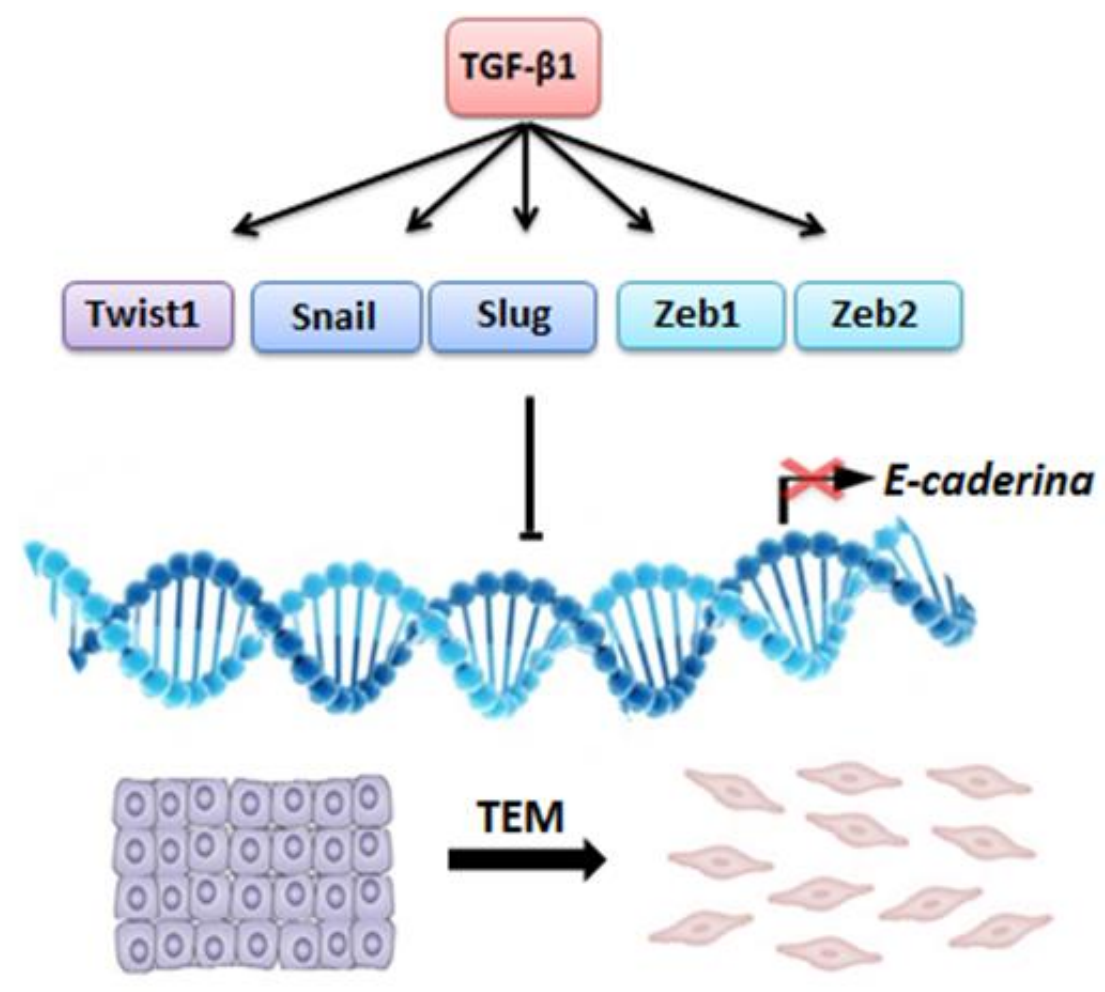

Figura 1. Principais genes envolvidos na transição epitélio-mesenquimal e suas funções

\subsection{A Transição epitélio-mesenquimal no câncer de próstata}

Um dos aspectos mais controversos da TEM no câncer é a dificuldade de encontrar evidências práticas desse evento em espécimes cirúrgicos avaliados por estudo anatomopatológico. No CaP, a graduação histológica de Gleason pode ser vista como uma evidência morfológica da TEM, e o aumento do grau está associado à perda progressiva da arquitetura epitelial glandular e ao padrão invasivo ${ }^{41}$. Já no âmbito molecular, a TEM pode ser observada através da perda da expressão da Ecaderina ${ }^{48}$, acompanhada de um aumento da N-caderina, Caderina-11 e Vimentina, processo que pode ser avaliado pelo método imuno-histoquímico ${ }^{46}$.

Em estudo realizado pelo nosso grupo, observamos perda da expressão imuno-histoquímica de E-caderina em tumores de próstata metastáticos em osso ${ }^{49}$. A $\mathrm{N}$-caderina parece estar superexpressa nos tumores resistentes à castração, tanto em modelos animais quanto humanos, e participa da regulação do Bcl-2, proteína com função antiapoptótica ${ }^{41}$. 
Vários fatores de crescimento são indutores da TEM no CaP, incluindo FGF, TGF- $\beta 1$, HGF, IGF-1 e PDGF ${ }^{50,51}$, sendo o TGF- $\beta 1$ um dos mais importantes nessa neoplasia. Zhang e col descobriram que o TGF- $\beta 1$ induz acúmulo nuclear do NFkB e

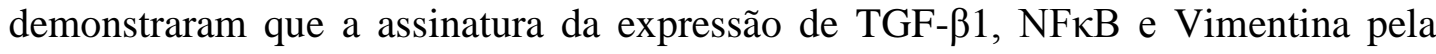
técnica de tissue microarray (TMA) apresentava correlação com recorrência bioquímica, independentemente do grau de Gleason ${ }^{52}$.

Alguns fatores de transcrição também participam do CaP, como a família do ZEB e do Snail e o Twist1. Os fatores de transcrição ZEB1 e ZEB2 são codificados pelos genes ZFHX1a e ZFHX1b. O aumento da expressão dos fatores ZEB nas células epiteliais resulta em uma rápida TEM associada a perda da polaridade celular, perda da adesão celular e indução da motilidade, promovendo invasão e metástase ${ }^{53}$. Ao contrário, uma diminuição dos fatores ZEB em células indiferenciadas induz a transição mesênquima-epitelial (TME). O ZEB1, também conhecido como TCF8, é um ativador crucial da TEM em vários tumores, como próstata, cólon, mama e pâncreas ${ }^{34}$. O ZEB1 reprime a E-caderina através da interação com a sequência CANNTG (caixa E) na região promotora e do recrutamento da histona deacetilase 1 (HDAC1), levando à condensação da cromatina e ao silenciamento do gene. $\mathrm{O}$ ZEB2, também chamado de SIP1, foi descrito como fator colaborativo com a via do TGF- $\beta 1$ e igualmente induz invasão ${ }^{54}$.

O ZEB1 parece ser um regulador crucial na TEM no CaP, e seus níveis de expressão se correlacionam com o escore de Gleason ${ }^{50}$. Graham e col, ao estudarem o papel do IGF-I na TEM e no CaP, demonstraram sua função no tocante ao ZEB1. Os autores observaram que o IGF-I causou um aumento no RNAm e nos níveis proteicos do ZEB1 em células epiteliais e elevou a expressão de marcadores mesenquimais, como a $\mathrm{N}$-caderina e a fibronectina. Ademais, concluíram que a expressão imuno-histoquímica do ZEB1 apresentava forte correlação com o escore de Gleason, sendo que os tumores com grau mais elevado apresentavam maior intensidade na sua expressão. O Snail, por sua vez, reprime diretamente não só a Ecaderina, mas também a RKIP, a qual age como supressora de metástase no $\mathrm{CaP}^{55}$. 


\subsection{Os microRNAs}

Os microRNAs são pequenos RNAs não codificantes de proteínas, constituídos por aproximadamente 22 nucleotídeos, que participam de vários processos biológicos, como desenvolvimento tecidual, diferenciação, apoptose e proliferação celular, incluindo o processo de carcinogênese ${ }^{56}$. Os miRNA são transcritos a partir de RNA precursores de fita dupla, formando estruturas do tipo hairpin com cerca de 70 nucleotídeos, que são reconhecidas e clivadas pela enzima Drosha. O precursor resultante é então transportado para o citoplasma, onde é clivado pela enzima Dicer em sequências menores contendo de 19 a 22 nucleotídeos. Após a clivagem, o miRNA integra-se com o complexo silenciador induzido pelo RNA (RISC), que o conduz ao seu RNAm homólogo recém transcrito. Esta associação promove a degradação ou a repressão transcricional do RNAm, abolindo a expressão da proteína ${ }^{40,57}$. A Figura 2 resume os passos descritos acima.

O primeiro relato sobre as alterações na expressão do miRNA na biologia tumoral foi descrito na leucemia linfoide crônica ${ }^{58}$. Desde então, diferentes perfis de expressão dos miRNAs já foram observados em várias neoplasias, como mama, cólon, pâncreas, fígado e ovário. Em relação ao $\mathrm{CaP}$, os estudos em relação à expressão do miRNA são poucos e apresentam resultados muito variáveis.

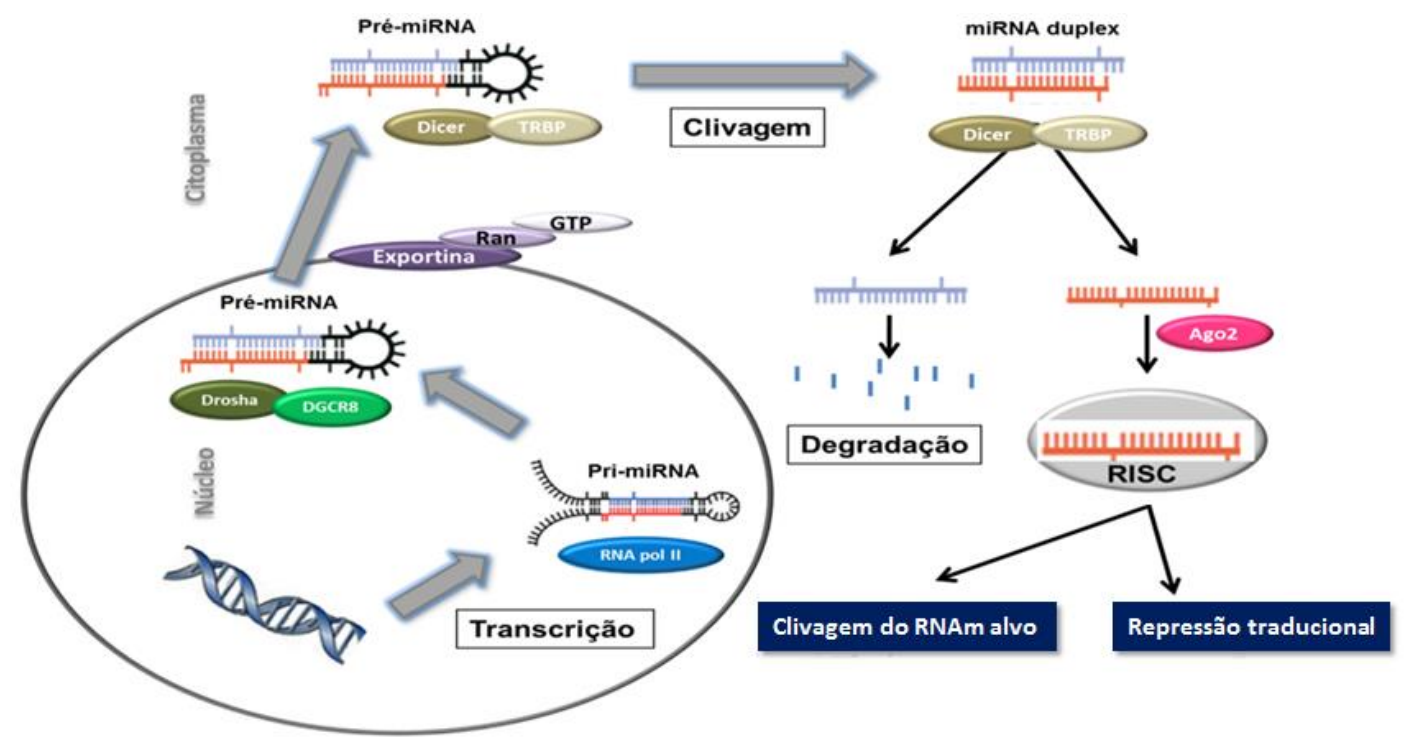

Figura 2. Biogênese do miRNA 


\subsection{Os microRNAs no câncer de próstata}

Os primeiros estudos que avaliaram o perfil dos miRNAs no câncer em humanos e em tumores sólidos incluíam, entre outros tumores, o $\mathrm{CaP}^{59,60}$. Mattie e col foram os primeiros a estudar o perfil de expressão do miRNA no $\mathrm{CaP} \mathrm{em}$ espécimes de biópsia, juntamente com o câncer de mama ${ }^{61}$. Em seguida, Porkka e col estudaram o perfil de expressão de miRNA em espécimes clínicos de $\mathrm{CaP}$ por técnica de microarray ${ }^{62}$. Os autores encontraram subexpressão de 37 miRNAs e superexpressão de 14. Muitos dos 51 miRNAs detectados correspondiam aos mesmos publicados anteriormente, apresentando 33 miRNAs em comum com o estudo de Lu e col ${ }^{59}$ e 11 em comum com o estudo de Mattie e col ${ }^{61}$. No entanto, nenhum miRNA ou perfil de expressão foi igual aos encontrados por Volinia e col ${ }^{60}$.

Posteriormente, os miR-125b e miR-32 ${ }^{63,} 64$ foram descritos no CaP como oncomiRs, e os miR-15a e 16-1, como supressores tumorais ${ }^{65}$, assim como os miRNAs 143 e $145^{66}$. Sun e col observaram superexpressão dos miRNAs 221-222 em linhagem celular de $\mathrm{CaP}$ resistente à castração ${ }^{67}$. O miR-21 também está expresso no CaP e tem função de oncogene ${ }^{68-70}$. Em estudo publicado pelo nosso grupo, demonstramos perda da expressão de miR-let7c, miR-100 e miR-218 no processo de transição entre o CaP localizado e o carcinoma metastático ${ }^{71}$.

\subsection{Os microRNAs e a transição epitélio-mesenquimal}

Acredita-se que um importante regulador da TEM sejam os miRNAs. Os miRNAs mais estudados nesse processo são a família do miR-200 e o miR-205 ${ }^{30,72-}$ 74 .

A família do miR-200 tem sido muito pesquisada por ser uma potente indutora da diferenciação epitelial capaz de reverter a TEM, participando de uma via sinalizadora que envolve a família do ZEB, seu principal alvo, e do TGF- $\beta 1^{74}$. A família do miR-200 é constituída por cinco membros: miR-200a, miR-200b, miR429, miR-200c e miR-141. Os membros miR-200a, miR-200-b e miR-429 estão localizados no cromossomo 1; já o miR-200c e o miR-141, no cromossomo 12. 
Todos os membros são fortemente relacionados em termos de sequência, especialmente nos nucleotídeos 2-8 da denominada seed region, que determina a especificação do RNAm alvo, indicando que eles provavelmente agem no RNAm com complementariedade similar ${ }^{75}$. Recentemente, o p53 foi descrito como um importante indutor do miR-200, inibindo o processo da TEM ${ }^{76}$. O miR-205 também tem como alvo a família do ZEB, porém liga-se em sequência distinta da 3'UTR deste, contribuindo de maneira sinérgica no aumento dos níveis de repressão do ZEB.

O ZEB e o miR-200 apresentam funções opostas e são eventos mutuamente exclusivos. Ambos formam uma alça de retroalimentação duplamente negativa: a ativação de um grupo afeta negativamente a expressão do outro (Figura 3) ${ }^{77}$. Dependendo do sinal extracelular, uma alça pode facilmente alterar sua direção e estabilizar um fenótipo epitelial ou mesenquimal. O miRNA-200 inibe a expressão pós-transcricional do ZEB ao se ligar a sequências nas terminações 3'UTR. Por sua vez, o ZEB1 inibe diretamente a transcrição dos genes miR-141 e miR-200c ao se ligarem a sequências em seus promotores.

Em estudo recente, Brabletz e Brabletz observaram que a alça ZEB/miR-200 tem papel nos dois conceitos emergentes no câncer: na TEM e na manutenção das propriedades de célula-tronco ${ }^{34}$. Além de regular a TEM, a alça ZEB/miR-200 controla outras funções celulares cruciais, como a diferenciação celular, a longevidade e a senescência, a sobrevivência e a apoptose, e a participação no ciclo celular. As células-tronco embrionárias expressam ZEB1 e reduzem seus níveis ao longo da diferenciação.

No processo da TEM, as células apresentam uma capacidade maior de sobrevivência e são mais resistentes à apoptose, enquanto que a expressão do miR200 favorece a apoptose e a sensibilidade a agentes tóxicos. Embora a sobrevivência e a longevidade estejam associadas a TEM, durante esse estado observa-se uma redução da atividade proliferativa celular. Acredita-se que seus ativadores afetem diretamente o ciclo celular através do controle sobre a transição G1/S ${ }^{78,79}$. Ademais, a conversão para o fenótipo mesenquimal implica uma intensa reorganização do 
citoesqueleto que provavelmente é incompatível com um estado altamente proliferativo ${ }^{80,81}$.

Uma vez que o fenótipo TEM está associado com a parada do crescimento das células invasoras, para que ocorra proliferação fora do sítio primário, essas células devem reverter a alça em direção ao miR-200 ${ }^{82,83}$. Este retoma o fenótipo epitelial, justificando como e por que a maioria das metástases readquire o estado diferenciado do tumor primário. A natureza reversível dessa alça e a habilidade aberrante das células tumorais em utilizar ambas as direções é o que permite que as células que sofreram a TEM e escaparam do tumor primário retornem ao seu estado epitelial no local remoto para formar um tumor secundário. Essa adaptação às condições que o ambiente exige parece ser a base para o desenvolvimento da metástase. A modulação da alça ZEB/miR-200, através da expressão do miR-200 e da prevenção da TEM, pode ser uma estratégia para impedir a invasão e a disseminação do tumor primário.

Há, ainda, outros miRNAs que também participam da TEM. O miR-29b e o miR-30a têm como alvo o Snail e agem como supressores tumorais ${ }^{84,85}$. O miR-34a também parece inibir o Snail, causando, ainda, repressão de Slug e ZEB1, mas não do ZEB2 ${ }^{86}$. O miR-1, juntamente com o miR-200b, age no Slug em estudo com células prostáticas tumorais ${ }^{87}$. O Slug, por sua vez, reprime de forma transcricional o miR-1 e o miR-200b, formando igualmente uma alça de retroalimentação duplamente negativa. O miR-9 também foi descrito como regulador do processo de carcinogênese e da metástase, e está superexpresso nas células tumorais, onde age diretamente na E-caderina ${ }^{88}$. 


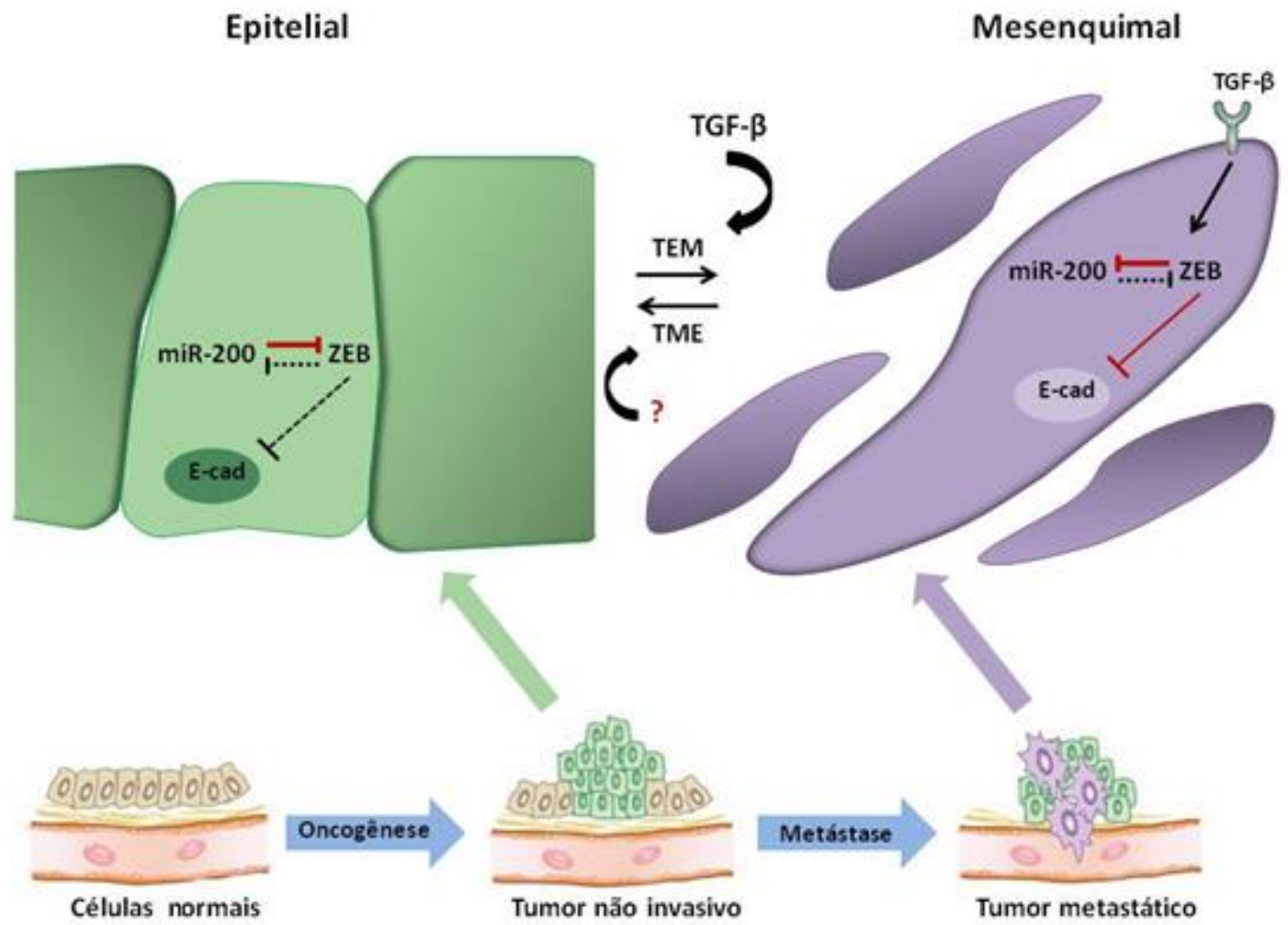

Figura 3. Reprodução esquemática da alça de retroalimentação duplamente negativa ZEB/miR-200 e seu papel na transição epitélio-mesenquimal, adaptado de Korpal e Kang 72

\subsection{Justificativa}

No CaP, o funcionamento da TEM e da alça ZEB/miR-200 ainda permanece incerto. Alguns dos miRNAs e genes envolvidos no processo já foram estudados no $\mathrm{CaP}$, porém nenhum trabalho avaliou-os de forma conjunta.

Assim sendo, a escassez de dados sobre este tema e a sua relevância para a progressão tumoral tornam necessária uma investigação mais ampla e completa dos fatores envolvidos na transição epitélio-mesenquimal no CaP, incluindo os miRNAs. Ainda, a presença de novos marcadores pode contribuir para a decisão terapêutica, visto que, em certas ocasiões, a compreensão mais precisa do comportamento biológico da neoplasia é essencial para que seja adotada a melhor conduta. 
2. OBJETIVOS 


\section{OBJETIVOS}

\subsection{Objetivo primário}

Análise da expressão dos genes e miRNAs envolvidos no processo de transição epitélio-mesenquimal em espécimes de câncer de próstata localizado de pacientes submetidos a prostatectomia radical e em linhagens celulares de adenocarcinoma de próstata metastático.

\subsection{Objetivo secundário}

Correlação do perfil de expressão dos genes e miRNAs com fatores prognósticos clássicos do câncer de próstata e com dados clínicos: graduação histológica de Gleason, estadiamento patológico, PSA pré-operatório, recidiva bioquímica e grupos de risco. 
3. MATERIAL E MÉTODOS 


\section{MATERIAL E MÉTODOS}

\subsection{Casuística}

\subsubsection{Pacientes}

O estudo consistiu na análise de espécimes cirúrgicos de 51 pacientes com CaP localizado tratados por prostatectomia radical, entre os anos 2000 e 2002, pela equipe do Prof. Dr. Miguel Srougi. Nesse período, 419 pacientes com CaP realizaram prostatectomia radical. No entanto, apenas pacientes com doença clinicamente localizada foram selecionados. Ainda, os pacientes com os seguintes critérios foram excluídos da nossa casuística: presença de terapia prévia ou tratamento neoadjuvante; ausência de informações clínicas pré-operatórias; e quantidade inferior a 75\% de neoplasia na amostra coletada para o banco de tumor. Os dados clínicos e patológicos estão expostos na Tabela 2. A amostra inclui pacientes com escores de Gleason baixos, intermediários e altos. Todos os pacientes possuíam doença clinicamente localizada, sendo que 22 pacientes tinham doença pT2 e vinte e nove, doença pT3. Dezessete pacientes apresentaram recidiva bioquímica da doença num período médio de seguimento de 63,06 meses.

O cálculo do tamanho da amostra foi realizado pelo método descrito por Armitage e Berry. Considerando o desvio padrão igual a 2, cada grupo deveria ser constituído por 25 pacientes para um teste bicaudal com poder estatístico de $85 \%$ e nível de significância de $\mathrm{P}<0,05$.

Como controle, utilizamos dez amostras de pacientes submetidos a ressecção transuretral da próstata para hiperplasia prostática benigna (HPB). Todos os pacientes tinham volume prostático $<50 \mathrm{~cm}^{3}$ em exame ultrassonográfico, nível de PSA sérico < 2,5 ng/mL e ausência de malignidade no exame anatomopatológico do espécime. 
Tabela 2. Características clínico-patológicas dos 51 pacientes com câncer de próstata localizado tratados com prostatectomia radical

\begin{tabular}{|c|c|c|c|}
\hline & $\begin{array}{c}\text { Casos CaP } \\
(51)\end{array}$ & $\begin{array}{l}\text { Controles } \\
\text { HPB (10) }\end{array}$ & $\mathbf{P}$ \\
\hline \multicolumn{4}{|l|}{ Idade (anos) } \\
\hline Média & 64,9 & 71,9 & \\
\hline Mediana & 66 & 72 & \\
\hline \multirow[t]{2}{*}{ Variação } & $49-77$ & $59-88$ & \\
\hline & & & 0,012 \\
\hline \multicolumn{4}{|c|}{ Estadiamento clínico } \\
\hline $\mathrm{T} 1 \mathrm{c}$ & $22(45)$ & & \\
\hline $\mathrm{T} 2 \mathrm{a}$ & $13(27)$ & & \\
\hline $\mathrm{T} 2 \mathrm{~b}$ & $9(18)$ & & \\
\hline $\mathrm{T} 2 \mathrm{c}$ & $5(10)$ & & \\
\hline \multicolumn{4}{|l|}{ PSA $(n g / m L)$} \\
\hline Média & 8,19 & 1,05 & \\
\hline Mediana & 9 & 1,25 & \\
\hline \multirow[t]{2}{*}{ Variação } & $4,1-20$ & $0,06-1,58$ & \\
\hline & & & 0,000 \\
\hline$<10(\mathrm{~N}, \%)$ & $39(76)$ & & \\
\hline$\geq 10(\mathrm{~N}, \%)$ & $12(24)$ & & \\
\hline
\end{tabular}

\section{Escore de Gleason}

Mediana
Escore $\leq 6(\mathrm{~N}, \%)$ $15(30)$
Escore 5 2
Escore 6

Escore 7 (N, \%) $13(25)$

Escore $\geq 8(\mathrm{~N}, \%) \quad 23(45)$

$\begin{array}{lc}\text { Escore } 8 & 18 \\ \text { Escore } 9 & 3 \\ \text { Escore } 10 & 2\end{array}$

\section{Estadiamento patológico (N, \%)}

pT2

pT3

\section{Recorrência bioquímica (N,\%)}

Sim

Não 


\subsubsection{Linhagens celulares}

Para avaliação da expressão de genes e miRNAs na doença metastática, utilizamos linhagens comerciais de adenocarcinoma de próstata humano metastático. As linhagens utilizadas foram LNCaP, DU145 e PC3, obtidas no American Type Culture Collection (ATCC). As células LNCaP são linhagens celulares derivadas de linfonodo supraclavicular andrógeno-dependente. Já as células DU145 e PC3 são linhagens hormônio-resistentes, provenientes de metástase em sistema nervoso central e de metástase óssea, respectivamente.

As células LNCaP, DU145 e PC3 foram acondicionadas em frascos de cultura de $25 \mathrm{~cm}^{2}$ contendo os meios RPMI, DMEM e MEM (Invitrogen, Calrsbad, CA, EUA), respectivamente, sendo suplementadas com soro fetal bovino (SFB) a $10 \%$ e solução antibiótica e antimicótica (Sigma Co, St. Louis, MO, EUA) a 1\%. Os frascos foram mantidos em estufa para cultura de células contendo atmosfera úmida composta por $95 \%$ de ar e $5 \%$ de $\mathrm{CO}_{2}$ à temperatura de $37^{\circ} \mathrm{C}$. O meio de cultivo foi trocado quando atingido o estado de subconfluência em monocamada, com $70 \%$ da área cultivável recoberta por células.

\section{2 Ética}

A todos os pacientes foi solicitada autorização do uso do material para pesquisa científica, sendo o termo de consentimento assinado quando permitido seu uso.

Todas as amostras utilizadas neste estudo foram codificadas, garantindo sua confidencialidade. Esse projeto foi submetido ao comitê de ética em pesquisas do HC-FMUSP, tendo sido aprovado na reunião de 07/03/2012 (protocolo $n^{\circ} 5915$ ).

\subsection{Manipulação do espécime cirúrgico - Prostatectomia radical}

Todos os pacientes foram tratados e acompanhados pela equipe do Prof. Dr. Miguel Srougi. Os espécimes cirúrgicos foram recebidos a fresco e examinados em até 15 minutos após a sua ressecção. A próstata foi palpada em banco, e áreas 
endurecidas foram consideradas suspeitas para tumor. Se a palpação não demonstrava anormalidades, cortes transversais eram realizados na zona periférica na porção posterior da glândula, e áreas com alterações de coloração foram representadas como tumor. Dessas áreas suspeitas, um fragmento de $1 \mathrm{~cm}^{3}$ foi cortado com bisturi e armazenado em criotubo em nitrogênio líquido a $-170{ }^{\circ} \mathrm{C}$ até a realização do experimento.

Dez cortes de $10 \mu \mathrm{m}$ do fragmento armazenado foram cortados em criostato e colocados em microtubo. Um corte foi colocado em lâmina, fixado em formol $10 \%$ por 10 minutos e submetido a coloração de hematoxilina e eosina para comprovação da existência de tumor no material em pelo menos $75 \%$ da amostra.

Os espécimes foram então fixados em formol $10 \%$ tamponado por um período máximo de 8 horas. Toda a glândula foi pintada com tinta nanquim para avaliação de suas margens, e, após sua pesagem e medição, foram ressecadas as vesículas seminais, margens do colo vesical e ápice da próstata. Os lobos direito e esquerdo foram separados e submetidos a cortes transversais à uretra prostática, designados desde as porções proximais junto ao colo vesical até as porções distais. Toda a glândula foi representada para avaliação padronizada do grau histológico de Gleason, volume tumoral, situação das margens cirúrgicas e estadiamento (TNM 2010). Todos os espécimes foram examinados pelo mesmo patologista.

\subsection{Processamento do RNA}

\subsubsection{Extração do RNA}

Para extração do RNA do tecido e das células, utilizamos o kit de isolamento miRVana ${ }^{\circledR}$ miRNA (Ambion, Austin, TX, EUA) de acordo com as recomendações do fabricante. Ao tecido cortado foram adicionadas 10 vezes do seu volume de solução de lise, e às células, $250 \mu 1$ da solução, com igual volume de etanol $64 \%$. Repassamos a solução para uma coluna GFX e centrifugamos a 10.000 rpm por 1 minuto. À coluna adicionamos $700 \mu \mathrm{l}$ de uma solução de lavagem própria do kit. Centrifugamos novamente nas mesmas condições e submetemos a solução a duas 
lavagens com $500 \mu 1$ de outra solução de lavagem do kit. O filtrado foi descartado, e a solução foi centrifugada por mais 1 minuto a $10.000 \mathrm{rpm}$ para secagem da coluna. Repassamos a coluna para um novo tubo e adicionamos $50 \mu 1$ de solução de eluição pré-aquecida no centro da coluna. Após 1 minuto à temperatura ambiente, centrifugamos a coluna, e o RNA foi armazenado a $-80{ }^{\circ} \mathrm{C}$ até sua utilização.

A pureza e concentração do RNA foram mensuradas em espectrofotômetro Nanodrop $^{\circledR}$ (ND-1000, Wilmington, EUA) $(260 / 280 \mathrm{nM})$, e a integridade foi verificada em Agilent 2100 Bioanalyzer (Agilent technologies, CA, USA).

\subsubsection{Isolamento do miRNA}

Para isolamento do miRNA do tecido e das células, também utilizamos o kit de isolamento miRVana ${ }^{\circledR}$ miRNA (Ambion, Austin, TX, EUA) de acordo com as recomendações do fabricante. Os espécimes congelados foram macerados e colocados em tubo estéril de microcentrífuga de 1,5 ml. Ao tubo com os espécimes foram adicionados $500 \mu \mathrm{l}$ do tampão de lise (10 vezes o volume da massa tumoral) e $10 \%(50 \mu \mathrm{l})$ do volume total de aditivo para homogeneização, enquanto que ao tubo contendo as células foram adicionados $250 \mu 1$ do tampão de lise e $25 \mu 1$ do aditivo para homogeneização. Em seguida, eles foram colocados no gelo por 10 minutos. Após, foram adicionados $500 \mu \mathrm{l}$ de fenol-clorofórmio, e as amostras foram agitadas em vórtex e centrifugadas à velocidade máxima $(14.000 \mathrm{rpm})$ por 5 minutos em temperatura ambiente. A fase aquosa foi removida e transferida para um novo tubo, onde foi adicionado um terço do volume de etanol 100\%, e então a solução foi transferida para uma coluna e centrifugada a $10.000 \mathrm{rpm}$ por 15 segundos. A coluna contendo o RNA total foi armazenada. No filtrado que continha o miRNA, foram adicionados $2 / 3$ do volume de etanol $100 \%$. A solução foi transferida para uma nova coluna e centrifugada a $10.000 \mathrm{rpm}$ por 15 segundos, sendo o filtrado descartado. Em seguida, realizamos lavagem com $700 \mu \mathrm{l}$ de wash solution $1 / 3$, sendo a solução centrifugada por 15 segundos a $10.000 \mathrm{rpm}$, seguida por mais duas lavagens com 500 $\mu 1$ de wash solution 2/3, centrifugada nos intervalos por 15 segundos a $10.000 \mathrm{rpm}$. Ao final, foram adicionados $100 \mu \mathrm{l}$ de água livre de RNase a $95{ }^{\circ} \mathrm{C}$ no filtro, e as 
amostras foram novamente centrifugadas a $10.000 \mathrm{~g}$ por 15 segundos. O filtrado contendo o miRNA foi então armazenado em freezer a $-80{ }^{\circ} \mathrm{C}$ até ser utilizado.

A pureza e a concentração foram estimadas em espectrofotômetro Nanodrop ${ }^{\circledR}$ (ND-1000, Wilmington, EUA) (260/280 nM).

\subsection{Síntese do DNA complementar (cDNA)}

\subsubsection{Síntese de cDNA para análise de expressão dos genes}

A síntese do cDNA foi realizada a partir de $5 \mu \mathrm{g}$ de RNA utilizando-se o kit High-Capacity cDNA Reverse Transcription ${ }^{\mathrm{TM}}$ (Applied Biosystems), o qual contém transcriptase reversa MultiScribe ${ }^{\mathrm{TM}}$ e primers randômicos.

O RNA total foi diluído em $\mathrm{H}_{2} \mathrm{O}$ livre de nucleases em um volume final de 20 $\mu \mathrm{L}$. A este volume foram acrescentados $4 \mu \mathrm{L}$ de oligonucleotídeos randômicos (10X), 1,6 $\mu \mathrm{L}$ do mix de dNTPs (25X), $4 \mu \mathrm{L}$ do tampão da enzima (10X), $2 \mu \mathrm{L}$ (50 $\mathrm{U} / \mu \mathrm{l})$ da enzima transcriptase reversa e $8,4 \mu \mathrm{l}$ de água livre de nuclease. A solução foi então submetida a ciclos de temperaturas $\left(25{ }^{\circ} \mathrm{C}\right.$ por 10 minutos, $37{ }^{\circ} \mathrm{C}$ por 120 minutos e $85{ }^{\circ} \mathrm{C}$ por 5 minutos) em um termociclador Veridi (Applied Biosystems). No final da reação, o cDNA foi armazenado a $-20{ }^{\circ} \mathrm{C}$ até o seu uso.

\subsubsection{Síntese de cDNA para análise de expressão dos miRNA}

O DNA complementar (cDNA) foi obtido usando-se o kit TaqMan ${ }^{\circledR}$ miRNA Reverse Transcription (Applied Biosystems, Foster City, CA, EUA). Resumidamente, $10 \mathrm{ng}$ de miRNA foram submetidos a transcrição reversa. O miRNA foi diluído em água livre de nucleases, sendo utilizados $3 \mu \mathrm{l}$ de oligonucleotídeos específicos para cada miRNA estudado. Após, foram adicionados $7 \mu \mathrm{l}$ de um mix contendo $0,15 \mu \mathrm{l}$ de mix de dNTPs (100 $\mathrm{mM}$ total), $0,5 \mu l$ da enzima transcriptase reversa (50 U/ $\mu 1), 1,5 \mu 1$ do tampão da enzima (RT Buffer 10X), 0,19 $\mu 1$ de inibidor de RNAse (20 U/ $\mu 1), 4,66 \mu 1$ de água livre de nuclease e $1 \mu 1$ de primers específicos para cada miRNA, totalizando $10 \mu \mathrm{l}$. As misturas foram submetidas a 16 
${ }^{\circ} \mathrm{C}$ por 30 minutos, $42^{\circ} \mathrm{C}$ por 30 minutos e $85^{\circ} \mathrm{C}$ por 5 minutos para síntese da fita de cDNA em aparelho termociclador Veriti ${ }^{\circledR}$ (Applied Biosystem, Foster City, CA, EUA) e mantidas a $4^{\circ} \mathrm{C}$ até o seu uso.

\subsection{Análise da expressão dos miRNAs e genes alvo}

A expressão dos miRNAs e genes estudados foi realizada por reação em cadeia da polimerase quantitativa em tempo real (qRT-PCR) usando o sistema ABI 7500 Fast no modo standard, com utilização de Master Mix PCR Taqman Universal (Applied Biosystems, Foster City, CA, EUA). Este protocolo utiliza dois iniciadores não fluorescentes e uma sonda com dupla marcação que se anela à região localizada entre os iniciadores. Esta marcação dupla é formada por um fluoróforo que emite luz quando excitado e por um quencher que absorve a luz emitida pelo fluoróforo. Durante os ciclos da PCR, a sonda é quebrada pela Taq polimerase na etapa de extensão do iniciador anelado. Essa quebra da sonda elimina a absorção pelo quencher da fluorescência emitida, que pode ser então medida através de uma câmera situada na parte superior do equipamento. A quantificação da emissão absorvida pela câmera após a quebra da sonda permite a quantificação indireta do RNA alvo contido na reação após cada ciclo da PCR (Figura 4).

Os primers utilizados para amplificação dos miRNAs e genes alvo foram adquiridos da Applied Biosystems (California, EUA) (Tabelas 3 e 4), que desenha primers com as características necessárias para os experimentos de PCR em tempo real (RT-PCR). Como controle endógeno dos genes e miRNAs utilizamos o gene $\beta 2$ microglobulina (B2M) e o RNA nucleolar RNU48, respectivamente.

Para amplificação dos fragmentos desejados, utilizamos as seguintes condições de reação: 5,0 $\mu \mathrm{l}$ do Master Mix Taqman, 0,5 $\mu \mathrm{l}$ de primer (contendo a sonda marcada), 3,5 $\mu \mathrm{l}$ de água destilada deionizada e 1,0 $\mu$ l de cDNA, somando um total de $10 \mu \mathrm{l}$ para cada reação. A condição usual de programação dos ciclos foi um passo a $50{ }^{\circ} \mathrm{C}$ por dois minutos e um passo a $94{ }^{\circ} \mathrm{C}$ por 10 minutos, seguidos de 40 ciclos de $95^{\circ} \mathrm{C}$ por 30 minutos. 
Os níveis de expressão dos genes foram obtidos através da quantificação relativa dos níveis de expressão determinados pelo método $\Delta \Delta \mathrm{C}_{\mathrm{T}}$, que utiliza a seguinte fórmula: $\Delta \Delta \mathrm{C}_{\mathrm{T}}=\left(\mathrm{C}_{\mathrm{T}}\right.$ do gene alvo, amostra de $\mathrm{CaP}-\mathrm{C}_{\mathrm{T}}$ do controle endógeno, amostra de $\mathrm{CaP})-\left(\mathrm{C}_{\mathrm{T}}\right.$ do gene alvo, amostra de $\mathrm{HPB}-\mathrm{C}_{\mathrm{T}}$ do controle endógeno, amostra de HPB). O número de vezes que ocorre a mudança da expressão gênica é calculado como $2^{-\Delta \Delta \mathrm{CT}}{ }^{89}$. No gráfico logarítmico, esse método padroniza a expressão do controle normal como uma linha basal (representada pelo número 1), e a expressão relativa de cada gene para cada amostra tumoral é demonstrada pelo múltiplo do normal para mais, nos casos de superexpressão, ou para menos nos casos de subexpressão. Todas as reações foram feitas em duplicata.

O perfil de expressão dos genes e miRNAs era estabelecido apenas quando mais de $60 \%$ dos casos exibiam o mesmo padrão de expressão. Se determinado gene ou miRNA apresentasse $60 \%$ ou menos de casos com o mesmo perfil, seu padrão de expressão era considerado como sendo variável. 
Tabela 3. Primers utilizados para quantificação da expressão dos genes

\begin{tabular}{cc} 
Gene & Ensaio \\
E-CADERINA & Hs01023892_m1 \\
N-CADERINA & Hs00983056_m1 \\
VIMENTINA & Hs00185584_m1 \\
TGF-ß1 & Hs00998133_m1 \\
ZEB1 & Hs00232783_m1 \\
ZEB2 & Hs00207691_m1 \\
SNAI1 (SNAIL) & Hs00195591_m1 \\
SNAI2 (SLUG) & Hs00950344_m1 \\
TWIST1 & Hs00361186_m1 \\
PDGF-D & Hs00228671_m1 \\
B2M & Hs99999907_m1 \\
\hline
\end{tabular}


Tabela 4. Primers utilizados para quantificação da expressão dos miRNAs

\begin{tabular}{|c|c|}
\hline miRNA & Ensaio \\
\hline hsa-miR-200a & 000502 \\
\hline hsa-miR-200b & 002251 \\
\hline hsa-miR-200c & 002300 \\
\hline hsa-miR-429 & 001024 \\
\hline hsa-miR-141 & 000463 \\
\hline hsa-miR-205 & 000509 \\
\hline hsa-miR-203 & 000507 \\
\hline hsa-miR-183 & 002269 \\
\hline hsa-miR-373 & 000561 \\
\hline hsa-miR-29b & 000413 \\
\hline hsa-miR-1 & 002222 \\
\hline hsa-miR-9 & 000583 \\
\hline hsa-miR-495 & 001663 \\
\hline hsa-miR-21 & 000397 \\
\hline hsa-miR-30a-3p & 000416 \\
\hline hsa-miR-34a & 000426 \\
\hline hsa-miR-10b & 002218 \\
\hline hsa-miR-155 & 002623 \\
\hline RNU48 & 001006 \\
\hline
\end{tabular}




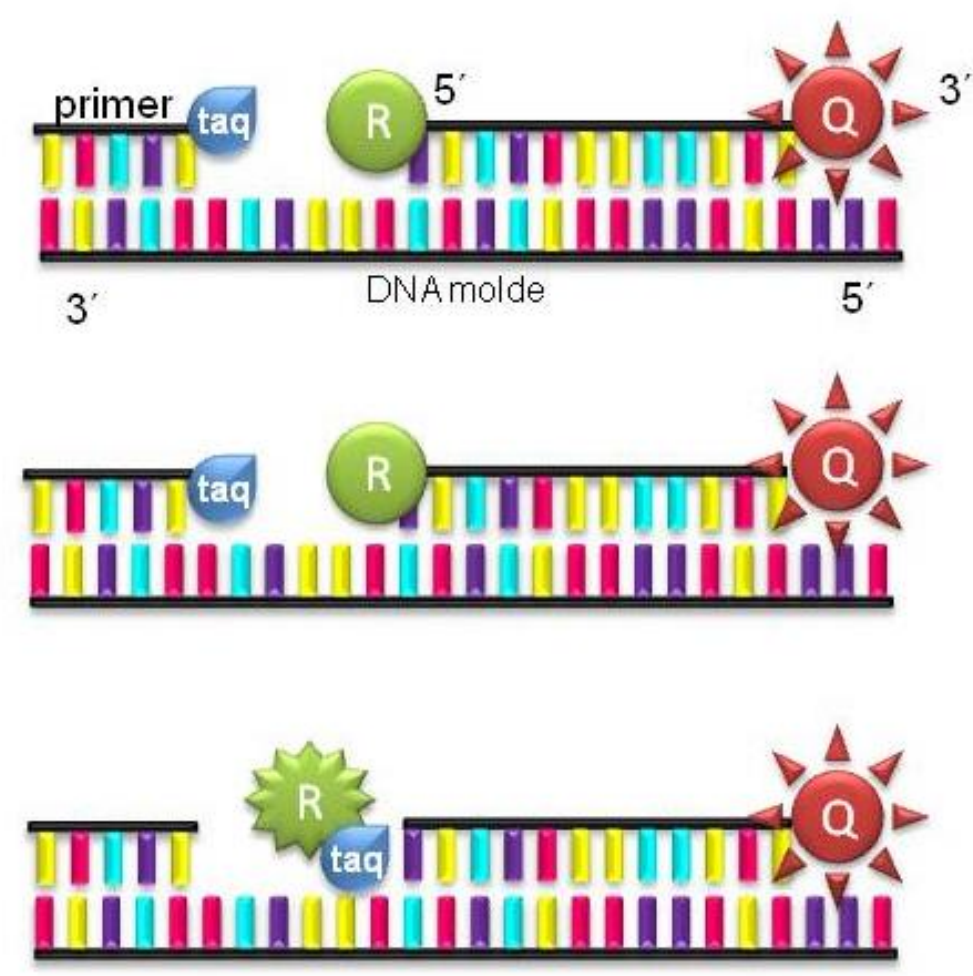

Figura 4. Amplificação dos miRNAs e genes pelo método TaqMan ${ }^{\circledR}$

\subsection{Seleção dos miRNAs e seus genes alvo}

A escolha dos miRNAs para avaliação foi baseada em estudos da literatura que demonstraram um papel fundamental ou promissor na transição epitéliomesenquimal em diferentes neoplasias e identificaram genes alvo responsáveis pelo processo. Realizamos uma busca na literatura nas bases de dados eletrônicas Pubmed e Web of Science utilizando os termos epitelial-mesenchymal transition, cancer e microRNAs. Baseado nos dados publicados, selecionamos 18 miRNAs e seus possíveis genes alvo, que estão ilustrados na Tabela 5, com as respectivas referências. A Figura 5 esquematiza a função desses miRNAs e genes envolvidos na TEM de maneira integrada. 
Tabela 5. microRNAs estudados e seus possíveis genes alvo

\begin{tabular}{|c|c|c|}
\hline microRNA & Gene alvo & Referências \\
\hline miR-200a & ZEB1, ZEB2 & $\begin{array}{c}\text { Bracken e col, 2008; } \\
\text { Gregory e col, 2008; } \\
\text { Korpal e col, } 2008\end{array}$ \\
\hline miR-200b & $\begin{array}{l}\text { ZEB1, ZEB2, Slug, } \\
\text { PDGF-D }\end{array}$ & $\begin{array}{c}\text { Bracken e col, 2008; } \\
\text { Gregory e col, 2008; } \\
\text { Korpal e col, 2008; Kong } \\
\text { e col, 2009; Liu e col, } \\
2012\end{array}$ \\
\hline miR-200c & ZEB1, ZEB2 & $\begin{array}{c}\text { Bracken e col, 2008; } \\
\text { Gregory e col, 2008; } \\
\text { Korpal e col, } 2008\end{array}$ \\
\hline miR-429 & ZEB1, ZEB2 & $\begin{array}{c}\text { Bracken e col, 2008; } \\
\text { Gregory e col, 2008; } \\
\text { Korpal e col, } 2008\end{array}$ \\
\hline miR-141 & ZEB1, ZEB2 & $\begin{array}{c}\text { Burk e col, 2008; Gregory } \\
\text { e col, 2008; Korpal e col, } \\
2008\end{array}$ \\
\hline miR-205 & ZEB1, ZEB2 & Gregory e col, 2008 \\
\hline miR-203 & $\begin{array}{l}\text { ZEB1, ZEB2, } \\
\text { Slug }\end{array}$ & $\begin{array}{l}\text { Wellner e col, 2009; Saini } \\
\text { e col, 2011; Qu e col, } 2013\end{array}$ \\
\hline miR-183 & ZEB1 & Wellner e col, 2009 \\
\hline miR-1 & Slug & $\begin{array}{l}\text { Liu e col, 2012; Tominaga } \\
\text { e col, } 2012\end{array}$ \\
\hline miR-29b & Snail & Ru e col, 2012 \\
\hline miR-9 & E-caderina & Ma e col, 2010 \\
\hline miR-21 & Snail & Bornachea e col, 2012 \\
\hline miR-495 & E-caderina & $\begin{array}{l}\text { Hwang-Verslues e col, } \\
2011\end{array}$ \\
\hline miR-30a & Snail, Vimentina & $\begin{array}{c}\text { Kumarswamy e col, 2011; } \\
\text { Cheng e col, } 2012\end{array}$ \\
\hline miR-34a & ZEB1, Snail & $\begin{array}{c}\text { Fuijta e col, 2008; Kim e } \\
\text { col, 2011; Siemens e col, } \\
2011\end{array}$ \\
\hline miR-155 & TGF- $\beta 1^{*}$ & $\begin{array}{c}\text { Kong e col, 2008; } \\
\text { Johansson e col, } 2013\end{array}$ \\
\hline miR-10b & E-caderina, Twist ${ }^{*}$ & $\begin{array}{l}\text { Ma e col, 2007; Liu e col, } \\
2012\end{array}$ \\
\hline miR-373 & $\begin{array}{c}\text { Ainda não definido na } \\
\text { TEM }\end{array}$ & $\begin{array}{l}\text { Huang e col, 2008; Yang e } \\
\text { col, 2009 }\end{array}$ \\
\hline
\end{tabular}

* Genes reguladores 


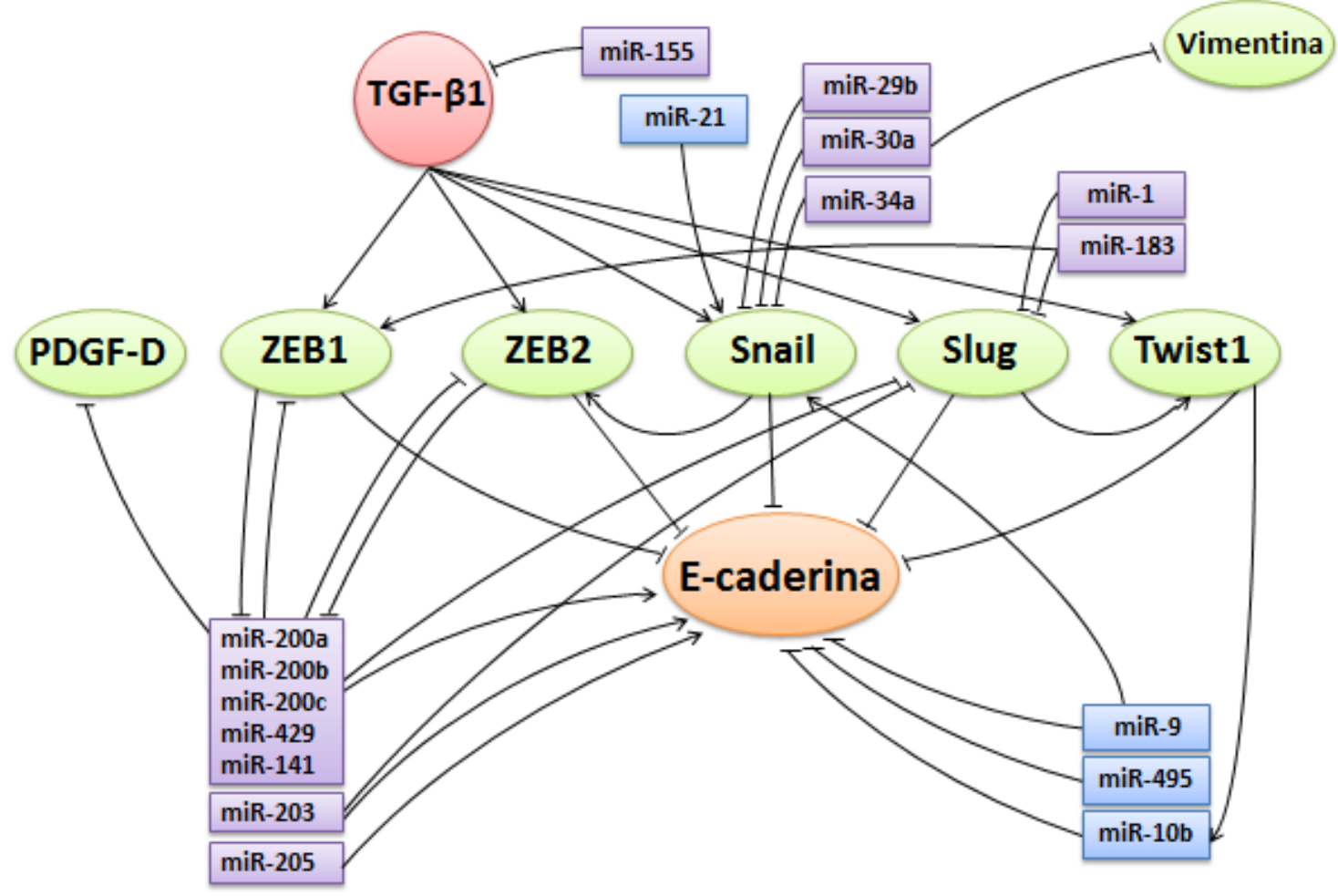

Figura 5. Modelo esquemático dos miRNAs e genes envolvidos na transição epitélio-mesenquimal e suas possíveis funções 


\subsection{Análise estatística}

\subsubsection{Subdivisão dos pacientes em grupos}

Os pacientes foram subdivididos em grupos de acordo com as características clínico-patológicas para fins de análise estatística, assim descritos:

- Grau histológico de Gleason: dividido em tumores de baixo grau (escore $\leq 6)$ e em tumores de grau intermediário ou alto (escore 7 e escore $\geq 7$, respectivamente). Realizamos, ainda, uma segunda divisão em que excluímos os pacientes com escore 7 para que pudéssemos comparar apenas pacientes com tumores bem diferenciados (escore $\leq$ 6) com tumores pouco diferenciados (escore $\geq 8$ );

- Estadiamento patológico: dividido em tumores confinados ao órgão (pT2) e tumores com extensão extraprostática (pT3);

- PSA pré-operatório: dividido em pacientes cujo valor do PSA préoperatório era $<10 \mathrm{ng} / \mathrm{mL}$ ou $\geq 10 \mathrm{ng} / \mathrm{mL}$;

- Recidiva bioquímica: dividido em pacientes que apresentaram ou não recidiva bioquímica, esta definida como valor de PSA sérico igual ou superior a $0,2 \mathrm{ng} / \mathrm{mL}$;

- Grupos de risco: dividido em grupo de baixo e alto risco. Pacientes que apresentavam escore de Gleason $\leq 6$, com doença órgãoconfinada (pT2) e PSA pré-operatório < $10 \mathrm{ng} / \mathrm{mL}$ foram considerados como de baixo risco, enquanto aqueles que apresentavam qualquer fator desfavorável, como escore de Gleason $\geq$ 7, tumores pT3 ou PSA pré-operatório $\geq 10$, foram considerados como de alto risco.

\subsubsection{Avaliação dos casos metastáticos}

Para a avaliação da expressão dos genes e miRNAs na metástase, utilizamos linhagens celulares de $\mathrm{CaP}$ metastático, dada a grande dificuldade em obter espécimes cirúrgicos de pacientes com $\mathrm{CaP}$ metastático. A análise dos marcadores nos tumores metastáticos foi realizada com o intuito de demonstrar um modelo de 
progressão tumoral. Para tal, utilizamos o estadiamento patológico avançado, que é um importante indicador de progressão tumoral, como parâmetro comparativo em relação às células.

Comparamos a expressão dos genes e miRNAs nas três linhagens celulares de forma conjunta em relação à expressão dos mesmos em tumores pT3. No entanto, em vez de utilizarmos o grupo de HPB para o cálculo $\Delta \Delta C_{T}$, usamos os tumores pT2 como $\Delta \mathrm{C}_{\mathrm{T} 2}$, sendo considerado como "grupo controle". Dessa forma, poderíamos observar as alterações que ocorrem quando um tumor pT3 evolui para um tumor metastático em relação aos tumores pT2.

\subsubsection{Testes estatísticos}

A análise estatística foi realizada a fim de comparar o perfil de expressão dos genes e miRNAs com os parâmetros clínico-patológicos nos pacientes com $\mathrm{CaP}$ localizado e entre os tumores localizados e as linhagens metastáticas. Para análise estatística foi utilizado o software SPSS 19.0.

Para fazer a comparação estatística entre dois grupos, utilizamos o teste $\mathrm{T}$ de Student, quando as variáveis eram homogêneas, ou de Mann-Whitney, quando não homogêneas. Em toda análise estatística foi adotado um nível de significância de 5\%, isto é, foram considerados como estatisticamente significantes os resultados que apresentaram valor-p inferior a $5 \%(\mathrm{P}<0,05)$.

Para análise de sobrevida livre de recorrência bioquímica, definida como PSA $\geq 0,2 \mathrm{ng} / \mathrm{mL}$, realizamos curvas de Kaplan-Meier e teste log-rank para mostrar as diferenças entre as curvas.

Para avaliar a correlação entre os genes, entre os miRNAs e entre ambos, utilizamos o coeficiente de correlação de Spearman seguido de correção de Šidák para comparações múltiplas. 
4. RESULTADOS 


\section{RESULTADOS}

\subsection{Perfil de expressão geral dos miRNAs no câncer de próstata localizado}

A análise da expressão dos 18 miRNAs em espécimes cirúrgicos em relação ao grupo controle com HPB está exposta na Tabela 6. Observamos superexpressão dos seguintes miRNAs: miR-200a, miR-200b, miR-200c, miR-141, miR-429, miR203, miR-205, miR-21, miR-183 e miR-373 (Figura 6). Os miRNAs 1, 29b, 9 e 495 estavam subexpressos (Figura 7). Os miRNAs 155, 34a, 10b e 30a apresentaram expressão variável (Figura 8).

Tabela 6. Média de expressão dos miRNAs estudados nos 51 pacientes com câncer de próstata, comparada com o grupo controle

\begin{tabular}{lcccc}
\multicolumn{1}{c}{ microRNA } & Média & Mediana & Superexpressão & Subexpressão \\
\hline miR-200a & 8,12 & 1,72 & $69 \%$ & $31 \%$ \\
\hline miR-200b & 14,69 & 6,83 & $92 \%$ & $8 \%$ \\
\hline miR-200c & 3,67 & 1,85 & $74 \%$ & $26 \%$ \\
\hline miR-429 & 7,75 & 3,73 & $77 \%$ & $23 \%$ \\
\hline miR-141 & 17,92 & 8,10 & $82 \%$ & $18 \%$ \\
\hline miR-205 & 18,18 & 5,19 & $86 \%$ & $14 \%$ \\
\hline miR-203 & 6,54 & 2,16 & $74 \%$ & $26 \%$ \\
\hline miR-183 & 8,92 & 3,35 & $74 \%$ & $26 \%$ \\
\hline miR-21 & 85,30 & 21,19 & $100 \%$ & $0 \%$ \\
\hline miR-373 & 5,16 & 1,79 & $64 \%$ & $36 \%$ \\
\hline miR-1 & 1,26 & 0,45 & $20 \%$ & $80 \%$ \\
\hline miR-29b & 0,55 & 0,24 & $20 \%$ & $80 \%$ \\
\hline miR-9 & 1,26 & 0,47 & $29 \%$ & $71 \%$ \\
\hline miR-495 & 0,90 & 0,35 & $18 \%$ & $82 \%$ \\
\hline miR-34a & 4,49 & 0,89 & $45 \%$ & $55 \%$ \\
\hline miR-155 & 2,29 & 0,95 & $43 \%$ & $57 \%$ \\
\hline miR-30a & 2,62 & 1,02 & $51 \%$ & $49 \%$ \\
\hline miR-10b & 4,71 & 1,00 & $51 \%$ & $49 \%$ \\
\hline
\end{tabular}




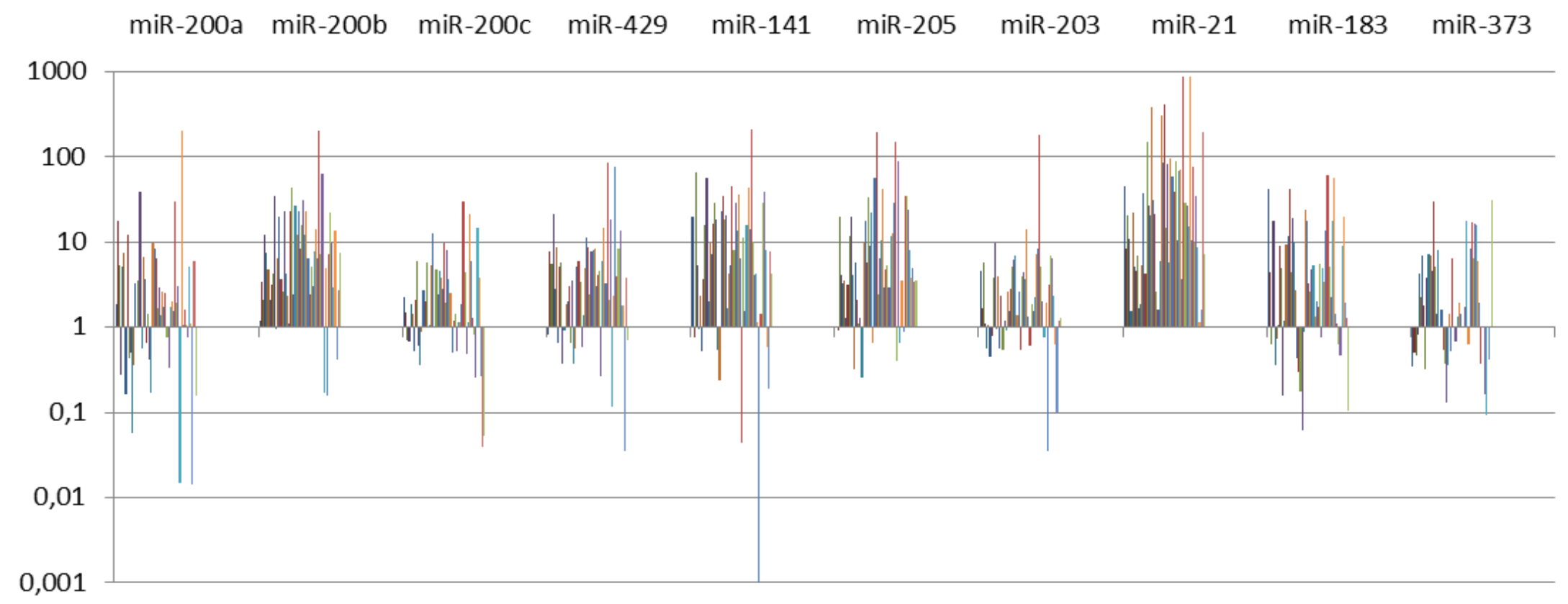

Figura 6. Perfil de expressão dos miRNAs com predomínio de superexpressão em 51 pacientes com câncer de próstata 


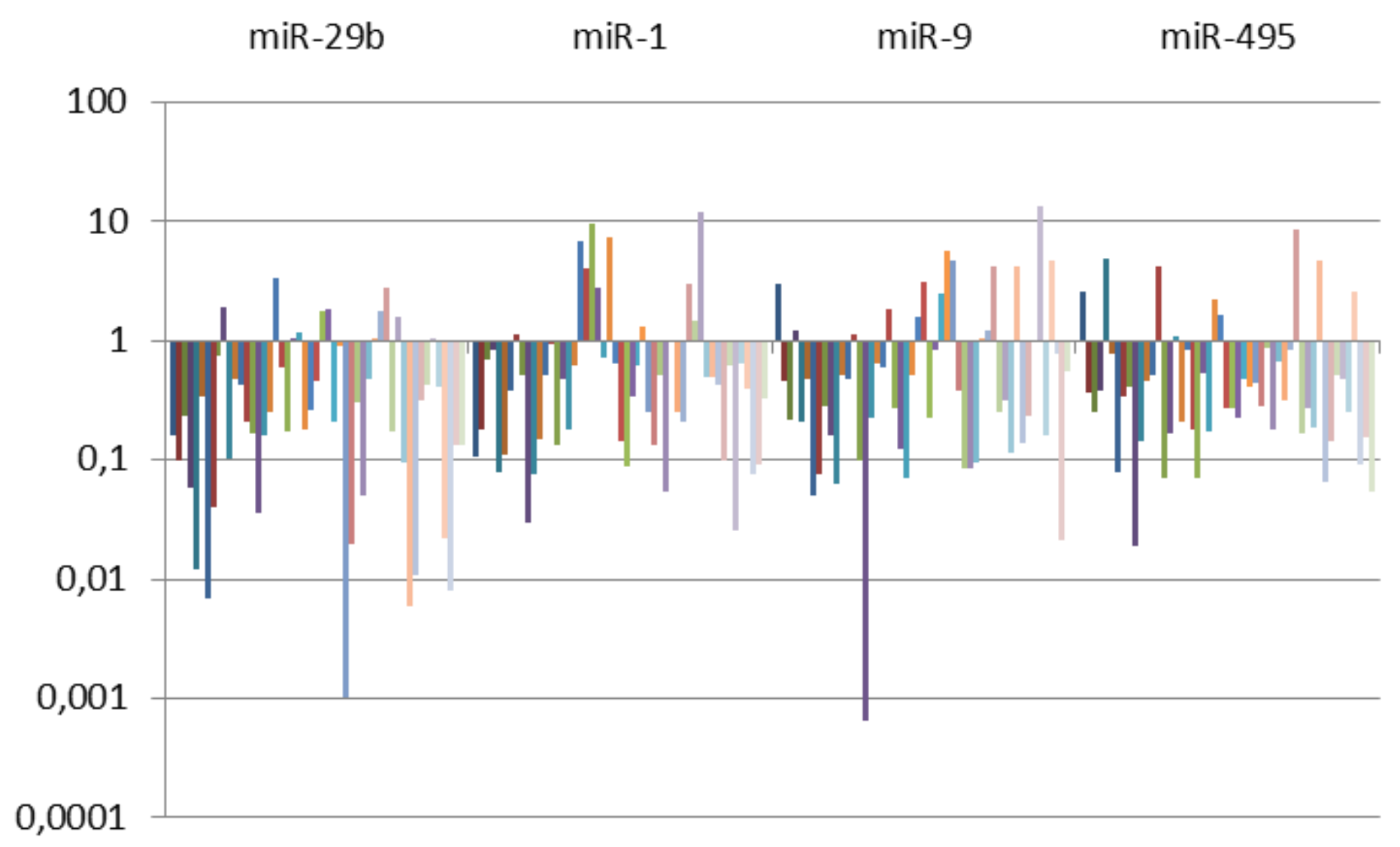

Figura 7. Perfil de expressão dos miRNAs com predomínio de subexpressão em 51 pacientes com câncer de próstata 


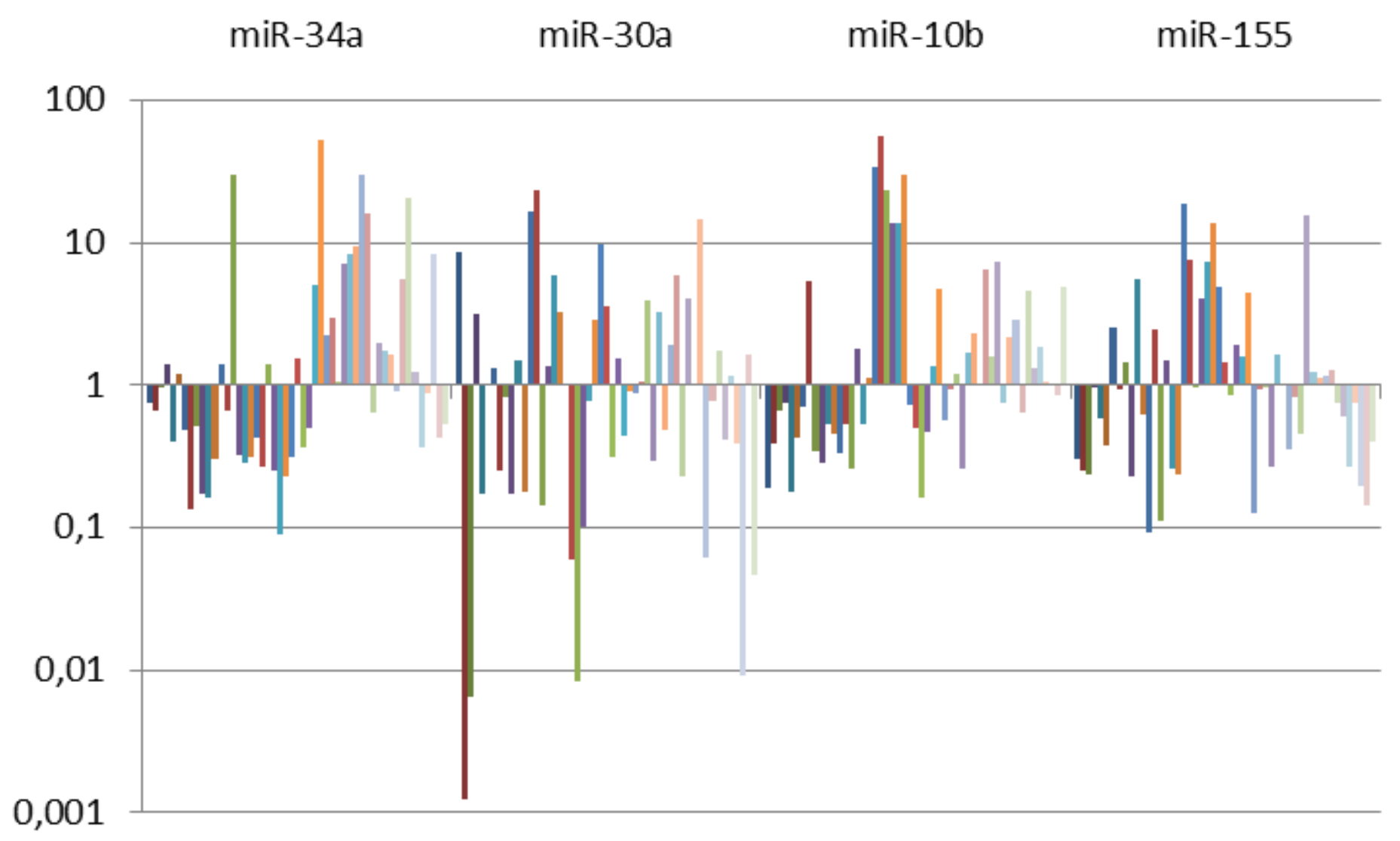

Figura 8. Perfil de expressão dos miRNAs que exibiram padrão variável em 51 pacientes com câncer de próstata 


\subsection{Perfil de expressão geral dos genes no câncer de próstata localizado}

O resultado da expressão dos 10 genes estudados está ilustrado nas Figuras 9 e 10 e na Tabela 7. A E-caderina e o Twist1 estão superexpressos em 98\% e 73\% dos casos, respectivamente (Figura 9). A N-caderina, TGF- $\beta 1$, Vimentina, ZEB1 e o Slug encontram-se subexpressos (Figura 10). O ZEB2, o Snail e o PDGF-D apresentaram expressão variável (Figura 11).

Tabela 7. Média de expressão dos genes estudados nos 51 pacientes com câncer de próstata, comparada com o grupo controle

\begin{tabular}{lcccc}
\multicolumn{1}{c}{ Gene } & Média & Mediana & Superexpressão & Subexpressão \\
E-caderina & 5,46 & 4,11 & $98 \%$ & $2 \%$ \\
Twist1 & 7,50 & 2,60 & $73 \%$ & $27 \%$ \\
Snail & 2,60 & 1,32 & $55 \%$ & $45 \%$ \\
ZEB2 & 1,35 & 1,07 & $53 \%$ & $47 \%$ \\
N-caderina & 1,29 & 0,52 & $29 \%$ & $71 \%$ \\
Vimentina & 0,78 & 0,40 & $20 \%$ & $80 \%$ \\
TGF-ß1 & 0,89 & 0,79 & $29 \%$ & $71 \%$ \\
ZEB1 & 1,12 & 0,63 & $29 \%$ & $71 \%$ \\
Slug & 0,85 & 0,37 & $18 \%$ & $82 \%$ \\
PDGF-D & 1,56 & 0,84 & $41 \%$ & $59 \%$ \\
\hline
\end{tabular}




\section{E-caderina}

Twist1

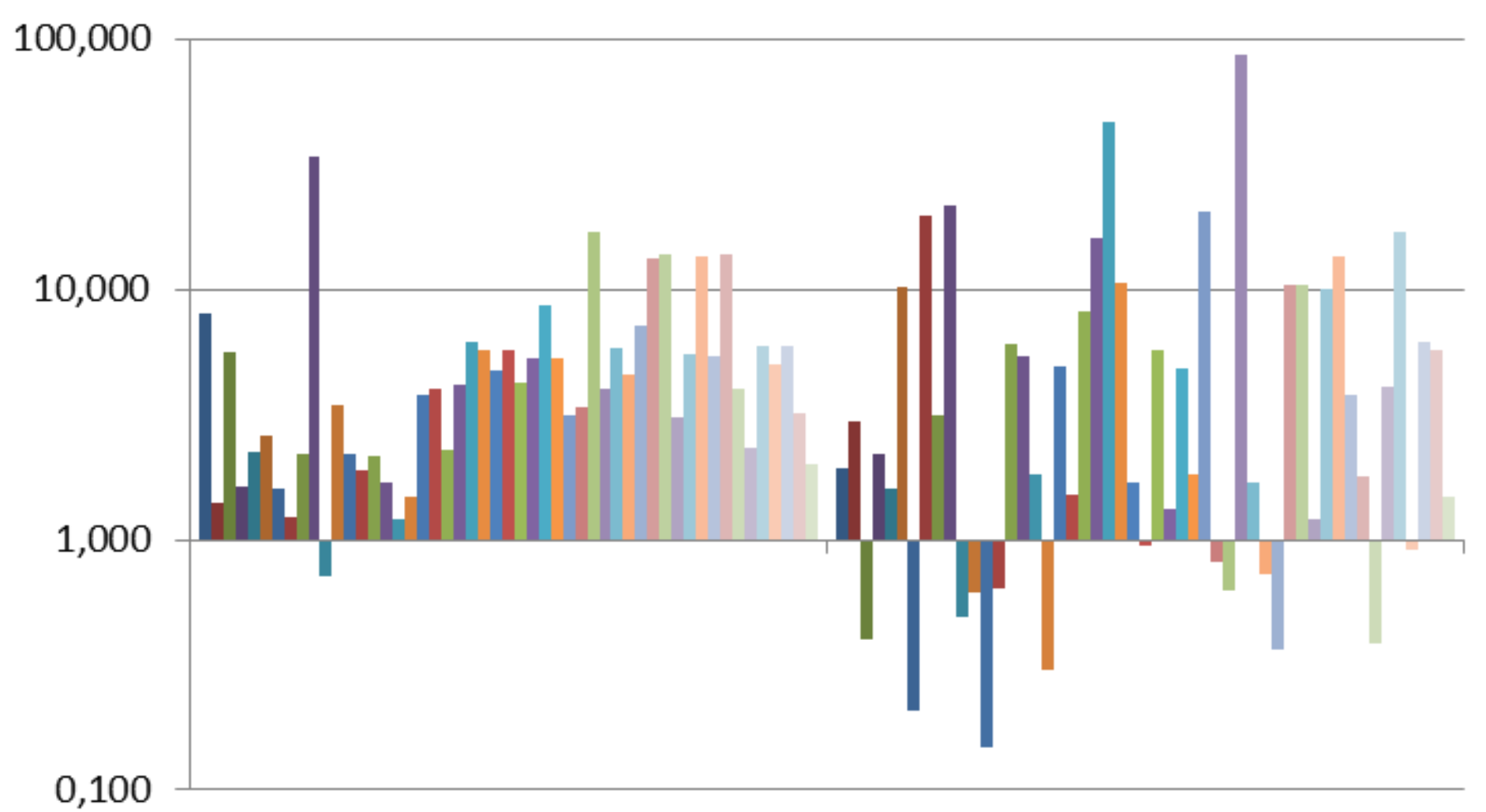

Figura 9. Perfil de expressão dos genes com predomínio de superexpressão em 51 pacientes com câncer de próstata 


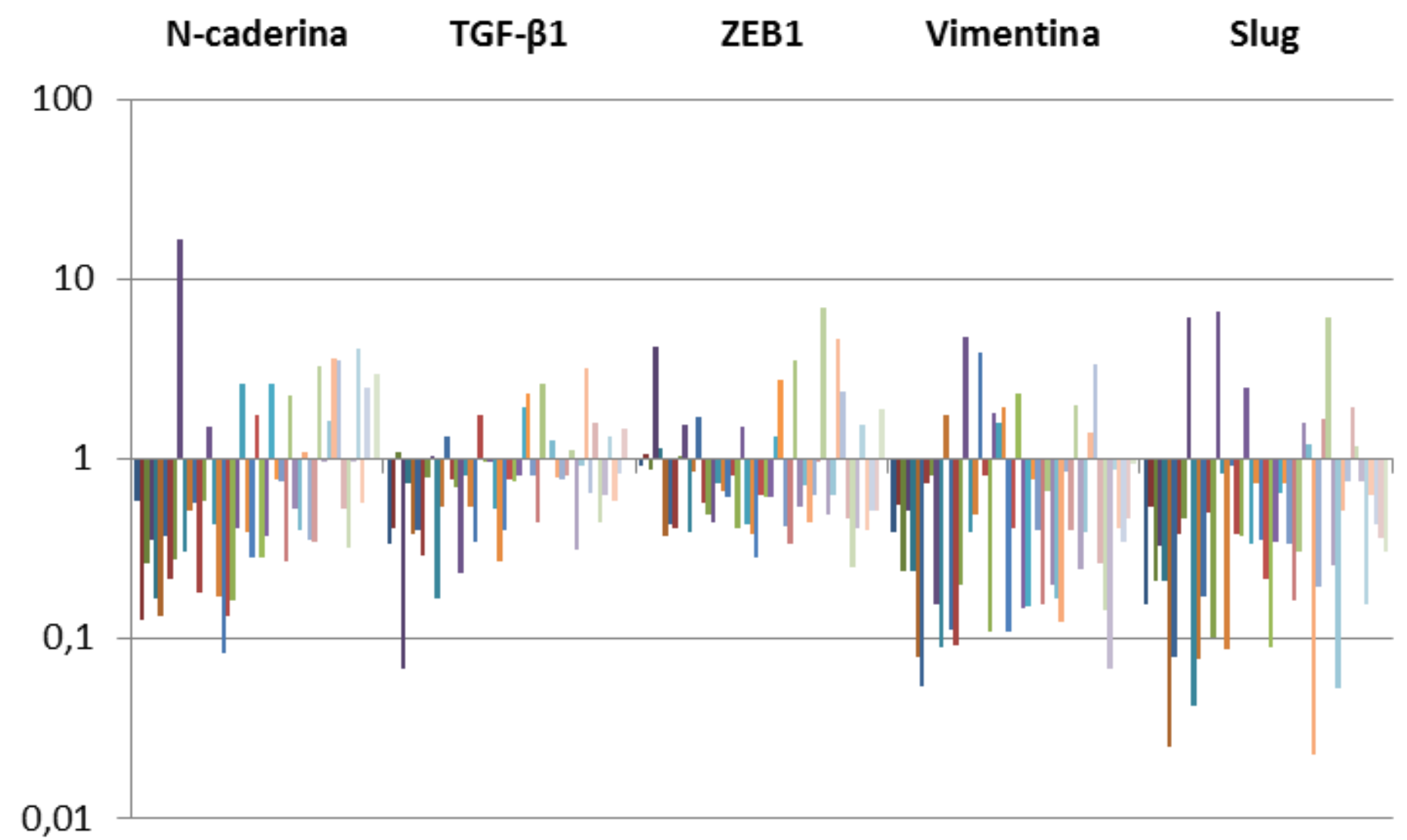

Figura 10. Perfil de expressão dos genes com predomínio de subexpressão em 51 pacientes com câncer de próstata 


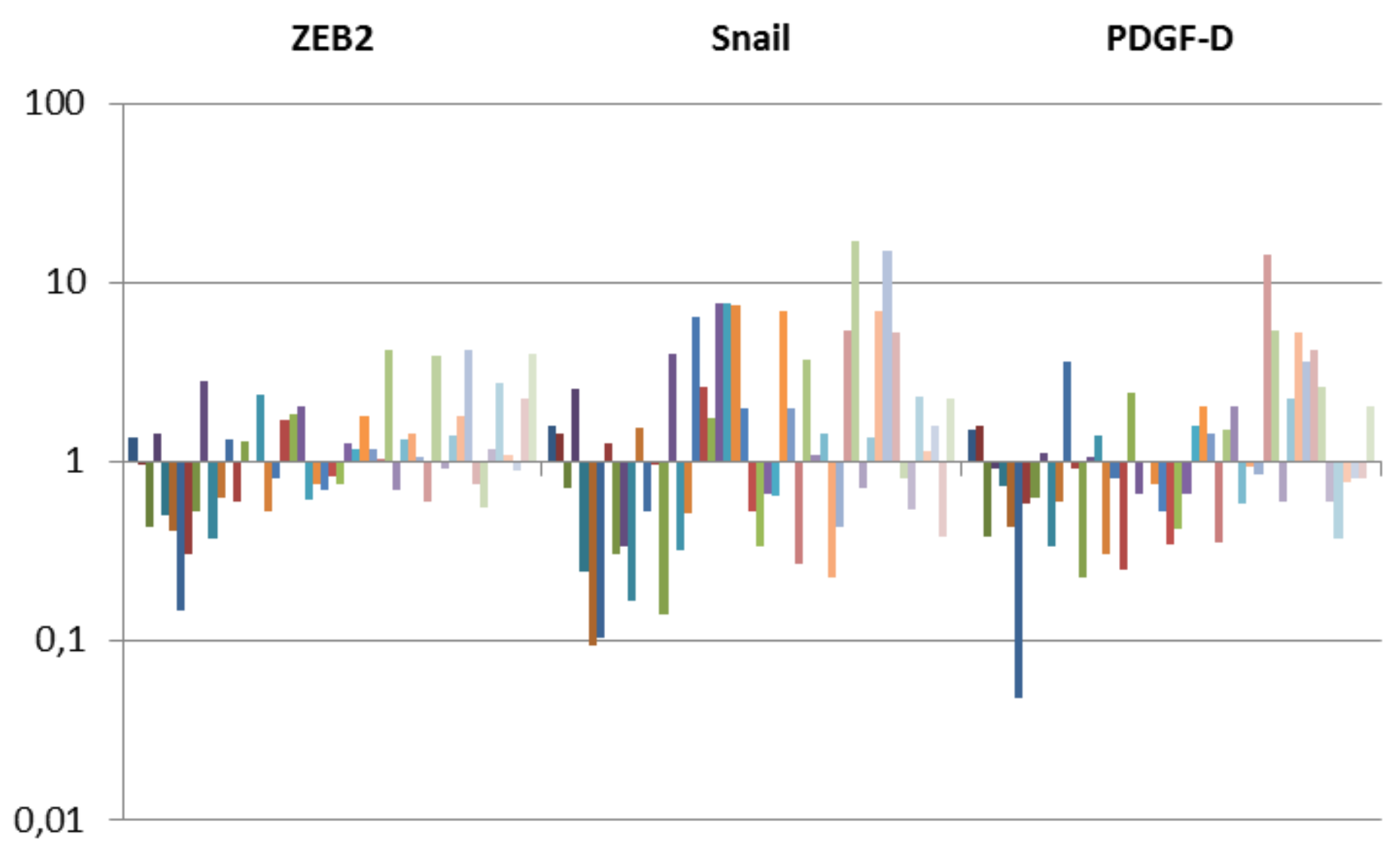

Figura 11. Perfil de expressão dos genes que exibiram padrão variável em 51 pacientes com câncer de próstata 


\subsection{Expressão dos miRNAs e a graduação histológica de Gleason}

A análise da expressão dos 18 miRNAs de acordo com o escore de Gleason está demonstrada na Tabela 8. Os grupos foram divididos primeiramente em pacientes com escore de Gleason $\leq 6 \mathrm{e} \geq 7$. Não encontramos diferença estatisticamente significativa na expressão dos miRNAs em relação à graduação de Gleason.

Devido à grande importância desse parâmetro como fator prognóstico no $\mathrm{CaP}$, decidimos avaliar apenas os pacientes com tumores bem diferenciados (escore de Gleason $\leq 6$ ) e com tumores pouco diferenciados (escore de Gleason $\geq 8$ ). Para tal, excluímos os pacientes com tumores de grau intermediário (escore de Gleason 7), cujo comportamento é incerto, que correspondiam a 13 casos. Quinze pacientes apresentavam escore de Gleason $\leq 6$, e vinte e três, $\geq 8$. Observamos que pacientes com tumores com escore de Gleason $\geq 8$ possuíam níveis de expressão do miR-200b significativamente menores que os pacientes com tumores com escore de Gleason $\leq$ 6 (6,94 vs. 18,$67 ; \mathrm{P}=0,035)$.

\subsection{Expressão dos miRNAs e o estadiamento patológico}

Em relação ao estadiamento patológico, encontramos diferença estatística significante na expressão dos miRNAs 200b, 1 e 30a comparando os pacientes com doença pT2 e pT3 (Tabela 8). Os três miRNAs apresentaram níveis de expressão menores em tumores pT3 em relação a tumores pT2.

O miR-200b mostrou-se superexpresso em ambos os grupos, porém a média de expressão em pacientes com doença pT3, de 7,73, foi significativamente inferior à média de expressão dos pacientes com doença pT2, esta de 23,86 ( $\mathrm{P}=0,02)$.

Em relação ao miR-1, embora esteja subexpresso na grande maioria dos casos, o grupo pT2 apresentou uma média de expressão de 1,97, valor este significativamente mais elevado que o do grupo pT3, o qual foi de $0,72(\mathrm{P}=0,04)$. 
Já o miR-30a apresentou-se superexpresso em $68 \%$ dos casos de pT2, enquanto que estava subexpresso em $62 \%$ dos tumores pT3. A média de expressão foi significativamente mais baixa nos pacientes com tumores pT3 em relação aos tumores pT2 (1,73 vs. 3,$79 ; \mathrm{P}=0,048)$.

Tabela 8. Expressão dos miRNAs de acordo com o escore de Gleason e estadiamento patológico

\begin{tabular}{|c|c|c|c|c|c|c|c|c|c|}
\hline \multirow[b]{2}{*}{ miRNA } & \multicolumn{3}{|c|}{ Escore de Gleason } & \multicolumn{3}{|c|}{$\begin{array}{c}\text { Escore de Gleason, } \\
\text { excluindo padrão } 7 \\
\text { Média } \\
\text { (DP) }\end{array}$} & \multicolumn{3}{|c|}{$\begin{array}{l}\text { Estadiamento } \\
\text { patológico } \\
\text { Média } \\
\text { (DP) }\end{array}$} \\
\hline & $\leq 6$ & $\geq 7$ & $\mathbf{P}$ & $\leq 6$ & $\geq 8$ & $\mathbf{P}$ & pT2 & pT3 & $\mathbf{P}$ \\
\hline 200a & $\begin{array}{c}2,41 \\
(2,47)\end{array}$ & $\begin{array}{c}10,50 \\
(34,48)\end{array}$ & 0,371 & $\begin{array}{c}2,41 \\
(2,47)\end{array}$ & $\begin{array}{c}11,77 \\
(42,35)\end{array}$ & 0,401 & $\begin{array}{c}4,03 \\
(6,51)\end{array}$ & $\begin{array}{c}11,22 \\
(38,20)\end{array}$ & 0,388 \\
\hline $200 b$ & $\begin{array}{c}18,67 \\
(18,05)\end{array}$ & $\begin{array}{c}13,03 \\
(33,00)\end{array}$ & 0,537 & $\begin{array}{l}18,67 * \\
(18,05)\end{array}$ & $\begin{array}{c}6,94 \\
(6,36)\end{array}$ & 0,035 & $\begin{array}{l}23,86 * \\
(42,40)\end{array}$ & $\begin{array}{c}7,74 \\
(8,47)\end{array}$ & 0,02 \\
\hline 200c & $\begin{array}{c}3,52 \\
(3,88)\end{array}$ & $\begin{array}{c}3,73 \\
(6,11)\end{array}$ & 0,902 & $\begin{array}{c}3,52 \\
(3,88)\end{array}$ & $\begin{array}{l}(3,17) \\
(5,05)\end{array}$ & 0,821 & $\begin{array}{c}4,10 \\
(6,31)\end{array}$ & $\begin{array}{c}3,35 \\
(4,91)\end{array}$ & 0,636 \\
\hline 429 & $\begin{array}{c}5,99 \\
(6,59)\end{array}$ & $\begin{array}{c}8,48 \\
(18,22)\end{array}$ & 0,610 & $\begin{array}{c}5,99 \\
(6,59)\end{array}$ & $\begin{array}{c}8,10 \\
(15,61)\end{array}$ & 0,625 & $\begin{array}{c}9,45 \\
(17,82)\end{array}$ & $\begin{array}{c}6,46 \\
(14,02)\end{array}$ & 0,505 \\
\hline 141 & $\begin{array}{c}18,64 \\
(17,32)\end{array}$ & $\begin{array}{c}17,62 \\
(36,95)\end{array}$ & 0,919 & $\begin{array}{c}18,64 \\
(17,32)\end{array}$ & $\begin{array}{c}13,88 \\
(17,57)\end{array}$ & 0,416 & $\begin{array}{c}21,98 \\
(44,95)\end{array}$ & $\begin{array}{c}14,85 \\
(17,85)\end{array}$ & 0,440 \\
\hline 205 & $\begin{array}{l}29,41 * \\
(51,68)\end{array}$ & $\begin{array}{c}13,51 \\
(26,11)\end{array}$ & 0,397 & $\begin{array}{l}29,41 * \\
(51,68)\end{array}$ & $\begin{array}{c}10,75 \\
(12,15)\end{array}$ & 0,555 & $\begin{array}{l}31,09 * \\
(50,98)\end{array}$ & $\begin{array}{c}8,39 \\
(10,19)\end{array}$ & 0,159 \\
\hline 203 & $\begin{array}{c}2,40 \\
(2,48)\end{array}$ & $\begin{array}{c}8,26 \\
(29,97)\end{array}$ & 0,456 & $\begin{array}{c}2,40 \\
(2,48)\end{array}$ & $\begin{array}{c}3,23 \\
(3,25)\end{array}$ & 0,405 & $\begin{array}{l}11,47 * \\
(38,21)\end{array}$ & $\begin{array}{c}2,79 \\
(3,13)\end{array}$ & 0,193 \\
\hline 183 & $\begin{array}{c}7,79 \\
(11,37)\end{array}$ & $\begin{array}{c}9,39 \\
(15,03)\end{array}$ & 0,713 & $\begin{array}{c}7,79 \\
(11,37)\end{array}$ & $\begin{array}{c}7,72 \\
(14,20)\end{array}$ & 0,989 & $\begin{array}{c}10,53 \\
(15,60)\end{array}$ & $\begin{array}{c}7,70 \\
(12,72)\end{array}$ & 0,479 \\
\hline 21 & $\begin{array}{c}60,48 \\
(106,85)\end{array}$ & $\begin{array}{c}95,64 \\
(209,68)\end{array}$ & 0,542 & $\begin{array}{c}60,48 \\
(106,85)\end{array}$ & $\begin{array}{c}105,61 \\
(193,84)\end{array}$ & 0,417 & $\begin{array}{c}108,96 \\
(213,46)\end{array}$ & $\begin{array}{c}67,34 \\
(161,82)\end{array}$ & 0,432 \\
\hline 373 & $\begin{array}{l}0,34^{*} \\
(0,39)\end{array}$ & $\begin{array}{c}0,25 \\
(0,30)\end{array}$ & 0,116 & $\begin{array}{l}0,34 * \\
(0,39)\end{array}$ & $\begin{array}{c}0,28 \\
(0,28)\end{array}$ & 0,108 & $\begin{array}{c}0,29 \\
(0,37)\end{array}$ & $\begin{array}{c}0,28 \\
(0,31)\end{array}$ & 0,231 \\
\hline 1 & $\begin{array}{l}2,47 * \\
(3,91)\end{array}$ & $\begin{array}{c}0,75 \\
(1,30)\end{array}$ & 0,200 & $\begin{array}{l}2,47 * \\
(3,91)\end{array}$ & $\begin{array}{c}0,68 \\
(1,48)\end{array}$ & 0,101 & $\begin{array}{l}1,97 * \\
(3,32)\end{array}$ & $\begin{array}{c}0,72 \\
(1,39)\end{array}$ & 0,040 \\
\hline 29b & $\begin{array}{l}0,76^{*} \\
(0,96)\end{array}$ & $\begin{array}{c}0,47 \\
(0,63)\end{array}$ & 0,264 & $\begin{array}{l}0,76^{*} \\
(0,96)\end{array}$ & $\begin{array}{c}0,31 \\
(0,32)\end{array}$ & 0,224 & $\begin{array}{c}0,74 \\
(0,77)\end{array}$ & $\begin{array}{c}0,42 \\
(0,70)\end{array}$ & 0,123 \\
\hline 9 & $\begin{array}{l}0,83^{*} \\
(0,84)\end{array}$ & $\begin{array}{c}1,44 \\
(2,61)\end{array}$ & 0,469 & $\begin{array}{l}0,83 * \\
(0,84)\end{array}$ & $\begin{array}{c}1,75 \\
(3,03)\end{array}$ & 0,930 & $\begin{array}{c}1,44 \\
(2,86)\end{array}$ & $\begin{array}{c}1,13 \\
(1,69)\end{array}$ & 0,622 \\
\hline 495 & $\begin{array}{l}0,66^{*} \\
(0,41)\end{array}$ & $\begin{array}{c}0,99 \\
(0,32)\end{array}$ & 0,491 & $\begin{array}{c}0,66 \\
(0,41)\end{array}$ & $\begin{array}{c}0,92 \\
(0,33)\end{array}$ & 0,536 & $\begin{array}{c}1,03 \\
(0,35)\end{array}$ & $\begin{array}{c}0,81 \\
(0,33)\end{array}$ & 0,623 \\
\hline $34 \mathbf{a}$ & $\begin{array}{c}2,79 \\
(7,69)\end{array}$ & $\begin{array}{c}5,12 \\
(10,41)\end{array}$ & 0,438 & $\begin{array}{c}2,79 \\
(7,69)\end{array}$ & $\begin{array}{c}5,44 \\
(11,31)\end{array}$ & 0,433 & $\begin{array}{c}3,81 \\
(7,93)\end{array}$ & $\begin{array}{c}4,92 \\
(10,92)\end{array}$ & 0,690 \\
\hline 155 & $\begin{array}{l}3,90 * \\
(5,84)\end{array}$ & $\begin{array}{c}1,62 \\
(2,62)\end{array}$ & 0,264 & $\begin{array}{l}3,90 * \\
(5,84)\end{array}$ & $\begin{array}{c}1,65 \\
(2,95)\end{array}$ & 0,260 & $\begin{array}{c}2,83 \\
(4,22)\end{array}$ & $\begin{array}{c}1,89 \\
(3,73)\end{array}$ & 0,405 \\
\hline $30 a$ & $\begin{array}{l}4,73^{*} \\
(6,92)\end{array}$ & $\begin{array}{c}1,74 \\
(2,84)\end{array}$ & 0,264 & $\begin{array}{l}4,73 * \\
(6,92)\end{array}$ & $\begin{array}{c}2,13 \\
(3,32)\end{array}$ & 0,425 & $\begin{array}{l}3,79 * \\
(5,85)\end{array}$ & $\begin{array}{c}1,73 \\
(3,14)\end{array}$ & 0,048 \\
\hline $10 b$ & $\begin{array}{c}8,75^{*} \\
(16,51)\end{array}$ & $\begin{array}{c}3,03 \\
(5,68)\end{array}$ & 0,679 & $\begin{array}{c}8,75^{*} \\
(16,51)\end{array}$ & $\begin{array}{c}2,69 \\
(6,14)\end{array}$ & 0,680 & $\begin{array}{c}5,22 \\
(8,13)\end{array}$ & $\begin{array}{c}4,32 \\
(11,79)\end{array}$ & 0,760 \\
\hline
\end{tabular}

* Valores obtidos através do teste de Mann-Whitney; demais obtidos através do teste T de Student 


\subsection{Expressão dos genes e a graduação histológica de Gleason}

Não encontramos diferença estatisticamente significativa na expressão dos genes em relação à graduação de Gleason, mesmo quando excluímos os pacientes com escore de Gleason 7. Os dados estão expostos na Tabela 9.

\subsection{Expressão dos genes e o estadiamento patológico}

Em relação ao estadiamento patológico, não houve diferença estatisticamente significativa na expressão dos genes quando comparamos os pacientes com doença pT2 com aqueles com doença pT3 (Tabela 9).

Tabela 9. Expressão dos genes de acordo com o escore de Gleason e estadiamento patológico

\begin{tabular}{|c|c|c|c|c|c|c|c|c|c|}
\hline & \multicolumn{3}{|c|}{$\begin{array}{l}\text { Escore de Gleason } \\
\text { Média } \\
\text { (DP) }\end{array}$} & \multicolumn{3}{|c|}{$\begin{array}{l}\text { Escore de Gleason, } \\
\text { excluindo padrão } \\
7 \\
\text { Média } \\
\text { (DP) }\end{array}$} & \multicolumn{3}{|c|}{$\begin{array}{l}\text { Estadiamento } \\
\text { patológico } \\
\text { Média } \\
\text { (DP) }\end{array}$} \\
\hline Gene & $\leq 6$ & $\geq 7$ & $\mathbf{P}$ & $\leq 6$ & $\geq 8$ & $\mathbf{P}$ & pT2 & pT3 & $\mathbf{P}$ \\
\hline E-caderina & $\begin{array}{c}5,07 \\
(8,19)\end{array}$ & $\begin{array}{c}5,62 \\
(4,06)\end{array}$ & 0,746 & $\begin{array}{c}5,07 \\
(8,19)\end{array}$ & $\begin{array}{c}5,75 \\
(4,12)\end{array}$ & 0,736 & $\begin{array}{c}4,61 \\
(3,39)\end{array}$ & $\begin{array}{c}6,10 \\
(6,68)\end{array}$ & 0,343 \\
\hline Twist & $\begin{array}{c}3,62 \\
(5,54)\end{array}$ & $\begin{array}{c}9,12 \\
(16,04)\end{array}$ & 0,203 & $\begin{array}{c}3,62 \\
(5,54)\end{array}$ & $\begin{array}{c}4,78 \\
(5,78)\end{array}$ & 0,543 & $\begin{array}{c}6,51 \\
(10,14)\end{array}$ & $\begin{array}{c}8,25 \\
(16,43)\end{array}$ & 0,665 \\
\hline Snail & $\begin{array}{l}1,47^{*} \\
(1,65)\end{array}$ & $\begin{array}{c}3,07 \\
(4,07)\end{array}$ & 0,342 & $\begin{array}{l}1,47^{*} \\
(1,65)\end{array}$ & $\begin{array}{c}2,66 \\
(3,64)\end{array}$ & 0,637 & $\begin{array}{c}2,80 \\
(4,07)\end{array}$ & $\begin{array}{c}2,44 \\
(3,25)\end{array}$ & 0,728 \\
\hline ZEB2 & $\begin{array}{c}1,48 \\
(0,99)\end{array}$ & $\begin{array}{c}1,29 \\
(1,03)\end{array}$ & 0,560 & $\begin{array}{c}1,48 \\
(0,99)\end{array}$ & $\begin{array}{c}1,38 \\
(1,08)\end{array}$ & 0,764 & $\begin{array}{c}1,23 \\
(1,01)\end{array}$ & $\begin{array}{c}1,45 \\
(1,02)\end{array}$ & 0,459 \\
\hline $\mathrm{N}$-caderina & $\begin{array}{l}1,74 * \\
(4,22)\end{array}$ & $\begin{array}{c}1,09 \\
(1,16)\end{array}$ & 0,420 & $\begin{array}{c}1,74 \\
(4,22)\end{array}$ & $\begin{array}{c}1,19 \\
(1,25)\end{array}$ & 0,561 & $\begin{array}{c}0,86 \\
(0,96)\end{array}$ & $\begin{array}{c}1,61 \\
(3,13)\end{array}$ & 0,288 \\
\hline Vimentina & $\begin{array}{c}0,55 \\
(0,96)\end{array}$ & $\begin{array}{c}0,88 \\
(1,02)\end{array}$ & 0,293 & $\begin{array}{c}0,55 \\
(0,96)\end{array}$ & $\begin{array}{c}0,63 \\
(0,79)\end{array}$ & 0,760 & $\begin{array}{c}0,67 \\
(0,75)\end{array}$ & $\begin{array}{c}2,80 \\
(1,17)\end{array}$ & 0,533 \\
\hline TGFß1 & $\begin{array}{c}0,77 \\
(0,43)\end{array}$ & $\begin{array}{c}0,94 \\
(0,69)\end{array}$ & 0,389 & $\begin{array}{l}0,77^{*} \\
(0,43)\end{array}$ & $\begin{array}{c}1,06 \\
(0,81)\end{array}$ & 0,497 & $\begin{array}{l}0,68 * \\
(0,31)\end{array}$ & $\begin{array}{c}1,04 \\
(0,75)\end{array}$ & 0,123 \\
\hline ZEB1 & $\begin{array}{c}1,03 \\
(1,02)\end{array}$ & $\begin{array}{c}1,16 \\
(1,38)\end{array}$ & 0,759 & $\begin{array}{c}1,03 \\
(1,02)\end{array}$ & $\begin{array}{c}1,13 \\
(1,14)\end{array}$ & 0,803 & $\begin{array}{c}1,15 \\
(1,58)\end{array}$ & $\begin{array}{c}1,10 \\
(1,02)\end{array}$ & 0,903 \\
\hline Slug & $\begin{array}{c}0,75 \\
(1,50)\end{array}$ & $\begin{array}{c}0,89 \\
(1,47)\end{array}$ & 0,751 & $\begin{array}{c}0,75 \\
(1,50)\end{array}$ & $\begin{array}{c}0,48 \\
(0,47)\end{array}$ & 0,422 & $\begin{array}{c}0,76 \\
(1,33)\end{array}$ & $\begin{array}{c}0,93 \\
(1,58)\end{array}$ & 0,684 \\
\hline PDGF-D & $\begin{array}{c}1,06 \\
(0,97)\end{array}$ & $\begin{array}{c}1,77 \\
(2,55)\end{array}$ & 0,303 & $\begin{array}{c}1,06 \\
(0,97)\end{array}$ & $\begin{array}{c}1,39 \\
(1,37)\end{array}$ & 0,423 & $\begin{array}{l}1,91 * \\
(3,09)\end{array}$ & $\begin{array}{c}1,30 \\
(1,21)\end{array}$ & 0,985 \\
\hline
\end{tabular}

\footnotetext{
* Valores obtidos através do teste de Mann-Whitney; demais obtidos através do teste T de Student
} 


\subsection{Expressão dos miRNAs e os níveis de PSA pré-operatório}

De acordo com o valor pré-operatório do PSA, não encontramos nenhuma diferença estatística significante quando comparamos os miRNAs estudados dos pacientes que apresentavam PSA pré-operatório $<10 \mathrm{ng} / \mathrm{mL}$ com os daqueles com PSA pré-operatório $\geq 10 \mathrm{ng} / \mathrm{mL}$. Os resultados estão demonstrados nas Tabelas 10 .

\subsection{Expressão dos miRNAs e a recidiva bioquímica}

Não encontramos nenhuma diferença estatística significante entre pacientes que apresentavam ou não recidiva bioquímica quanto à expressão dos miRNAs estudados por um tempo médio de 63,06 meses de seguimento (Tabela 10).

\subsection{Expressão dos miRNAs e grupos de baixo e alto risco}

Em relação aos grupos de risco, dentre os miRNAs, apenas o miR-30a apresentou diferença estatística significante (Tabela 10). Pacientes pertencentes ao grupo de alto risco apresentaram níveis de expressão menores do que aqueles do grupo de baixo risco (1,70 vs. 6,37; $\mathrm{P}=0.039)$. Ainda, observamos que o miR-30a estava superexpresso em $80 \%$ dos casos do grupo de baixo risco, enquanto que, no de alto risco, estava subexpresso na maioria dos casos (56\%). 
Tabela 10. Expressão dos miRNAs de acordo com o valor do PSA pré-operatório, presença ou não de recorrência bioquímica, e grupos de risco

\begin{tabular}{|c|c|c|c|c|c|c|c|c|c|}
\hline \multirow{3}{*}{$\begin{array}{c}\text { miRNA } \\
\text { 200a }\end{array}$} & \multicolumn{3}{|c|}{$\begin{array}{c}\text { PSA pré-operatório } \\
\text { Média } \\
\text { (DP) }\end{array}$} & \multicolumn{3}{|c|}{$\begin{array}{c}\text { Recidiva bioquímica } \\
\text { Média } \\
\text { (DP) }\end{array}$} & \multicolumn{3}{|c|}{$\begin{array}{l}\text { Grupo de risco } \\
\text { Média } \\
\text { (DP) }\end{array}$} \\
\hline & $<10$ & $\geq 10$ & $\mathbf{P}$ & Não & Sim & $\mathbf{P}$ & Baixo & Alto & $\mathbf{P}$ \\
\hline & $\begin{array}{l}4,61^{*} \\
(8,17)\end{array}$ & $\begin{array}{c}18,67 \\
(56,29)\end{array}$ & 0,938 & $\begin{array}{c}10,31 \\
(35,50)\end{array}$ & $\begin{array}{c}3,74 \\
(4,38)\end{array}$ & 0,453 & $\begin{array}{c}2,72 \\
(2,82)\end{array}$ & $\begin{array}{c}9,43 \\
(32,39)\end{array}$ & 0,519 \\
\hline $200 b$ & $\begin{array}{c}16,85 \\
(33,99)\end{array}$ & $\begin{array}{c}8,98 \\
(8,03)\end{array}$ & 0,412 & $\begin{array}{c}18,65 \\
(35,16)\end{array}$ & $\begin{array}{c}6,78 \\
(6,19)\end{array}$ & 0,139 & $\begin{array}{c}21,44 \\
(19,54)\end{array}$ & $\begin{array}{c}13,04 \\
(31,23)\end{array}$ & 0,422 \\
\hline 200c & $\begin{array}{c}3,59 \\
(5,41)\end{array}$ & $\begin{array}{c}4,18 \\
(6,10)\end{array}$ & 0,743 & $\begin{array}{c}4,06 \\
(6,29)\end{array}$ & $\begin{array}{c}2,90 \\
(3,49)\end{array}$ & 0,483 & $\begin{array}{c}3,18 \\
(3,34)\end{array}$ & $\begin{array}{c}3,79 \\
(5,94)\end{array}$ & 0,757 \\
\hline 429 & $\begin{array}{c}8,68 \\
(18,16)\end{array}$ & $\begin{array}{c}5,29 \\
(4,34)\end{array}$ & 0,436 & $\begin{array}{c}8,57^{*} \\
(19,03)\end{array}$ & $\begin{array}{c}6,10 \\
(4,11)\end{array}$ & 093 & $\begin{array}{c}7,74 \\
(7,34)\end{array}$ & $\begin{array}{c}7,75 \\
(17,18)\end{array}$ & 0,998 \\
\hline 141 & $\begin{array}{c}20,23 \\
(36,79)\end{array}$ & $\begin{array}{c}11,82 \\
(12,05)\end{array}$ & 0,321 & $\begin{array}{c}17,74 \\
(37,07)\end{array}$ & $\begin{array}{c}18,28 \\
(20,38)\end{array}$ & 0,956 & $\begin{array}{c}13,53 \\
(13,96)\end{array}$ & $\begin{array}{c}18,99 \\
(35,35)\end{array}$ & 0,635 \\
\hline 205 & $\begin{array}{c}19,85 \\
(40,96)\end{array}$ & $\begin{array}{c}13,78 \\
(15,85)\end{array}$ & 0,561 & $\begin{array}{c}16,63 \\
(30,50)\end{array}$ & $\begin{array}{c}21,30 \\
(45,39)\end{array}$ & 0,665 & $\begin{array}{l}39,61^{*} \\
(61,38)\end{array}$ & $\begin{array}{c}12,96 \\
(24,64)\end{array}$ & 0,200 \\
\hline 203 & $\begin{array}{c}7,72 \\
(29,63)\end{array}$ & $\begin{array}{c}3,42 \\
(2,68)\end{array}$ & 0,587 & $\begin{array}{c}8,28 \\
(30,83)\end{array}$ & $\begin{array}{c}3,05 \\
(3,66)\end{array}$ & 0,491 & $\begin{array}{c}2,04 \\
(1,62)\end{array}$ & $\begin{array}{c}7,63 \\
(28,11)\end{array}$ & 0,535 \\
\hline 183 & $\begin{array}{c}9,03 \\
(13,86)\end{array}$ & $\begin{array}{c}8,64 \\
(15,15)\end{array}$ & 0,958 & $\begin{array}{l}11,21^{*} \\
(16,22)\end{array}$ & $\begin{array}{c}4,33 \\
(5,74)\end{array}$ & 0,299 & $\begin{array}{c}10,13 \\
(13,21)\end{array}$ & $\begin{array}{c}8,63 \\
(14,28)\end{array}$ & 0,763 \\
\hline 21 & $\begin{array}{c}85,29 \\
(169,55)\end{array}$ & $\begin{array}{c}85,30 \\
(237,02)\end{array}$ & 0,950 & $\begin{array}{c}96,75 \\
(214,95)\end{array}$ & $\begin{array}{c}62,38 \\
(104,17)\end{array}$ & 0,537 & $\begin{array}{c}68,24 \\
(126,44)\end{array}$ & $\begin{array}{c}89,46 \\
(197,75)\end{array}$ & 0,749 \\
\hline 373 & $\begin{array}{c}0,28 \\
(0,34)\end{array}$ & $\begin{array}{c}0,30 \\
(0,31)\end{array}$ & 0,927 & $\begin{array}{l}6,16^{*} \\
(8,29)\end{array}$ & $\begin{array}{c}2,79 \\
(4,32)\end{array}$ & 0,169 & $\begin{array}{c}0,26 \\
(0,37)\end{array}$ & $\begin{array}{c}0,29 \\
(0,32)\end{array}$ & 0,186 \\
\hline 1 & $\begin{array}{c}1,42 \\
(2,70)\end{array}$ & $\begin{array}{c}0,82 \\
(1,79)\end{array}$ & 0,504 & $\begin{array}{l}1,52^{*} \\
(2,79)\end{array}$ & $\begin{array}{c}0,73 \\
(1,59)\end{array}$ & 0,119 & $\begin{array}{l}2,59^{*} \\
(4,43)\end{array}$ & $\begin{array}{c}0,93 \\
(1,63)\end{array}$ & 0,112 \\
\hline 29b & $\begin{array}{c}0,51 \\
(0,66)\end{array}$ & $\begin{array}{c}0,68 \\
(0,98)\end{array}$ & 0,546 & $\begin{array}{l}0,57^{*} \\
(0,72)\end{array}$ & $\begin{array}{c}0,53 \\
(0,81)\end{array}$ & 0,780 & $\begin{array}{c}0,51 \\
(0,64)\end{array}$ & $\begin{array}{c}0,56 \\
(0,77)\end{array}$ & 0,852 \\
\hline 9 & $\begin{array}{c}0,92 \\
(1,39)\end{array}$ & $\begin{array}{c}2,17 \\
(1,59)\end{array}$ & 0,415 & $\begin{array}{l}0,89^{*} \\
(1,27)\end{array}$ & $\begin{array}{c}2,01 \\
(3,41)\end{array}$ & 0,281 & $\begin{array}{c}0,96 \\
(0,89)\end{array}$ & $\begin{array}{c}1,34 \\
(2,47)\end{array}$ & 0,637 \\
\hline 495 & $\begin{array}{c}0,81 \\
(0,37)\end{array}$ & $\begin{array}{c}1,13 \\
(0,31)\end{array}$ & 0,479 & $\begin{array}{c}0,95 \\
(1,73)\end{array}$ & $\begin{array}{c}0,80 \\
(1,18)\end{array}$ & 0,752 & $\begin{array}{c}0,77 \\
(0,39)\end{array}$ & $\begin{array}{c}0,93 \\
(0,32)\end{array}$ & 0,780 \\
\hline $34 a$ & $\begin{array}{c}4,53 \\
(10,31)\end{array}$ & $\begin{array}{c}4,20 \\
(8,35)\end{array}$ & 0,976 & $\begin{array}{c}4,03 \\
(8,11)\end{array}$ & $\begin{array}{c}5,25 \\
(12,47)\end{array}$ & 0,675 & $\begin{array}{l}1,02^{*} \\
(0,58)\end{array}$ & $\begin{array}{c}5,27 \\
(10,64)\end{array}$ & 0,924 \\
\hline 155 & $\begin{array}{c}1,97 \\
(3,41)\end{array}$ & $\begin{array}{c}3,16 \\
(5,28)\end{array}$ & 0,281 & $\begin{array}{c}2,40 \\
(3,69)\end{array}$ & $\begin{array}{c}2,08 \\
(4,49)\end{array}$ & 0,788 & $\begin{array}{c}3,12 \\
(4,56)\end{array}$ & $\begin{array}{c}2,09 \\
(3,80)\end{array}$ & 0,463 \\
\hline 30a & $\begin{array}{c}2,72 \\
(4,72)\end{array}$ & $\begin{array}{c}2,34 \\
(4,46)\end{array}$ & 0,877 & $\begin{array}{l}3,43^{*} \\
(5,39)\end{array}$ & $\begin{array}{c}0,99 \\
(1,13)\end{array}$ & 0,145 & $\begin{array}{l}6,37^{*} \\
(7,91)\end{array}$ & $\begin{array}{c}1,70 \\
(2,77)\end{array}$ & $\mathbf{0 , 0 3 9}$ \\
\hline $10 \mathrm{~b}$ & $\begin{array}{c}4,74 \\
(10,75)\end{array}$ & $\begin{array}{c}4,63 \\
(9,67)\end{array}$ & 0,967 & $\begin{array}{c}5,52 \\
(11,22)\end{array}$ & $\begin{array}{c}3,10 \\
(8,18)\end{array}$ & 0,434 & $\begin{array}{c}3,95 \\
(7,16)\end{array}$ & $\begin{array}{c}4,89 \\
(10,98)\end{array}$ & 0,798 \\
\hline
\end{tabular}

* Valores obtidos através do teste de Mann-Whitney; demais obtidos através do teste T de Student 


\subsection{Expressão dos genes e os níveis de PSA pré-operatório}

De acordo com o valor pré-operatório do PSA, não encontramos nenhuma diferença estatística significativa quando comparamos os genes estudados dos pacientes que apresentavam PSA pré-operatório $<10 \mathrm{ng} / \mathrm{mL}$ com os daqueles com PSA pré-operatório $\geq 10 \mathrm{ng} / \mathrm{mL}$. Os resultados estão demonstrados nas Tabelas 11 .

\subsection{Expressão dos genes e a recidiva bioquímica}

Não encontramos nenhuma diferença estatística significante entre pacientes que apresentavam ou não recidiva bioquímica quanto à expressão dos genes estudados por um tempo médio de 63,06 meses de seguimento (Tabela 11).

\subsection{Expressão dos genes e grupos de baixo e alto risco}

Dos genes estudados, tanto a Vimentina como o Twist1 apresentaram associação estatisticamente significativa com os grupos de risco (Tabela 11). Os pacientes de baixo risco têm níveis de expressão de Vimentina inferiores aos pacientes do grupo de alto risco $(0,27$ vs. 0,$90 ; \mathrm{P}=0,017)$. Igualmente, o grupo de baixo risco tem níveis de expressão menor do Twist1 quando comparado ao grupo de alto risco $(1,81$ vs. 8,$89 ; \mathrm{P}=0,018)$. 
Tabela 11. Expressão dos genes de acordo com o valor do PSA pré-operatório, presença ou não de recorrência bioquímica, e grupos de risco

\begin{tabular}{|c|c|c|c|c|c|c|c|c|c|}
\hline \multirow[b]{2}{*}{ Gene } & \multicolumn{3}{|c|}{$\begin{array}{l}\text { PSA pré-operatório } \\
\text { Média } \\
\text { (DP) }\end{array}$} & \multicolumn{3}{|c|}{$\begin{array}{c}\text { Recidiva bioquímica } \\
\text { Média } \\
\text { (DP) }\end{array}$} & \multicolumn{3}{|c|}{$\begin{array}{l}\text { Grupo de risco } \\
\text { Média } \\
\text { (DP) }\end{array}$} \\
\hline & $<10$ & $\geq 10$ & $\mathbf{P}$ & Não & Sim & $\mathbf{P}$ & Baixo & Alto & $\mathbf{P}$ \\
\hline E-caderina & $\begin{array}{c}5,74 \\
(6,14)\end{array}$ & $\begin{array}{c}4,72 \\
(3,45)\end{array}$ & 0,644 & $\begin{array}{c}5,70 \\
(6,29)\end{array}$ & $\begin{array}{c}4,98 \\
(3,60)\end{array}$ & 0667 & $\begin{array}{c}3,06 \\
(1,61)\end{array}$ & $\begin{array}{c}6,04 \\
(5,96)\end{array}$ & 12 \\
\hline Twist & $\begin{array}{l}4,76^{*} \\
(5,33)\end{array}$ & $\begin{array}{c}14,75 \\
(25,16)\end{array}$ & 0,445 & $\begin{array}{c}9,48 \\
(16,69)\end{array}$ & $\begin{array}{c}3,53 \\
(3,14)\end{array}$ & 0,153 & $81^{*}$ & $\begin{array}{c}8,89 \\
(15,25)\end{array}$ & $\mathbf{0 , 0 1 8}$ \\
\hline Snail & $\begin{array}{c}2,73 \\
(3,90)\end{array}$ & $\begin{array}{c}2,24 \\
(2,76)\end{array}$ & 1 & $\begin{array}{l}3,11^{*} \\
(4,06)\end{array}$ & $\begin{array}{c}1,58 \\
(2,15)\end{array}$ & 0,072 & $\begin{array}{l}21^{*} \\
, 85)\end{array}$ & $\begin{array}{c}2,94 \\
(3,92)\end{array}$ & 0,602 \\
\hline $\mathbf{Z}$ & $\begin{array}{l}1,53^{*} \\
(1,12)\end{array}$ & $\begin{array}{c}0,89 \\
(0,44)\end{array}$ & 0,50 & $\begin{array}{c}1,41 \\
(1,07)\end{array}$ & $\begin{array}{c}1,24 \\
(0,91)\end{array}$ & 0,577 & $\begin{array}{c}1,32 \\
(1,08)\end{array}$ & $\begin{array}{c}1,36 \\
(1,01)\end{array}$ & 0,904 \\
\hline N-cac & $\begin{array}{c}1,39 \\
(2,81)\end{array}$ & $\begin{array}{c}1,01 \\
(1,16)\end{array}$ & 0,641 & $\begin{array}{c}1,44 \\
(2,94)\end{array}$ & $\begin{array}{c}0,97 \\
(0,88)\end{array}$ & 0,525 & $\begin{array}{c}0,81 \\
(0,91)\end{array}$ & $\begin{array}{c}1,40 \\
(2,69)\end{array}$ & 0,496 \\
\hline Vime & $\begin{array}{c}0,76 \\
(0,99)\end{array}$ & $\begin{array}{c}0,83 \\
(1,08)\end{array}$ & 0,692 & $\begin{array}{c}0,88 \\
(1,06)\end{array}$ & $\begin{array}{c}0,58 \\
(0,89)\end{array}$ & 0,315 & $\begin{array}{l}0,27 * \\
(0,28)\end{array}$ & $\begin{array}{c}0,90 \\
(1,08)\end{array}$ & 0,017 \\
\hline TGF- $\beta 1$ & $\begin{array}{c}0,89 \\
(0,55)\end{array}$ & $\begin{array}{c}0,87 \\
(0,83)\end{array}$ & 0,994 & $\begin{array}{c}0,83 \\
(0,59)\end{array}$ & $\begin{array}{c}1,01 \\
(0,69)\end{array}$ & 0,335 & $\begin{array}{c}0,69 \\
(0,38)\end{array}$ & $\begin{array}{c}0,94 \\
(0,66)\end{array}$ & 0,263 \\
\hline ZEB1 & $\begin{array}{c}1,21 \\
(1,34)\end{array}$ & $\begin{array}{c}0,90 \\
(1,15)\end{array}$ & 0,520 & $\begin{array}{c}1,19 \\
(1,44)\end{array}$ & $\begin{array}{c}0,98 \\
(0,88)\end{array}$ & 0,580 & $\begin{array}{c}1,13 \\
(1,23)\end{array}$ & $\begin{array}{c}1,12 \\
(1,31)\end{array}$ & 0,980 \\
\hline Slug & $\begin{array}{l}1,01^{*} \\
(1,68)\end{array}$ & $\begin{array}{c}0,46 \\
(0,43)\end{array}$ & 0,382 & $\begin{array}{l}1,08^{*} \\
(1,74)\end{array}$ & $\begin{array}{c}0,39 \\
(0,27)\end{array}$ & 0,369 & $\begin{array}{l}0,29 * \\
(2,34)\end{array}$ & $\begin{array}{c}0,99 \\
(1,60)\end{array}$ & 0,176 \\
\hline PDGF-D & $\begin{array}{c}1,68 \\
(2,49)\end{array}$ & $\begin{array}{c}1,25 \\
(1,31)\end{array}$ & 0,596 & $\begin{array}{l}1,85^{*} \\
(2,65)\end{array}$ & $\begin{array}{c}0,98 \\
(0,60)\end{array}$ & 0,562 & $\begin{array}{c}1,21 \\
(1,13)\end{array}$ & $\begin{array}{c}1,65 \\
(2,42)\end{array}$ & 0,582 \\
\hline
\end{tabular}

* Valores obtidos através do teste de Mann-Whitney; demais obtidos através do teste T de Student

\subsection{Análise de sobrevida livre de recorrência bioquímica dos microRNAs 200b, 30a e 1}

Embora não tenhamos encontrado associação dos genes e miRNAs estudados com recidiva bioquímica, realizamos análise de sobrevida livre de recorrência bioquímica dos miRNAs que apresentaram associação com fatores prognósticos: miR-200b, miR-30a e miR-1. Comparamos altos níveis de expressão com baixos níveis de expressão de cada um dos três miRNAs, utilizando a média para definir esses dois grupos.

Observamos associação significativa entre baixos níveis de expressão de miR200b e recidiva bioquímica mais precoce. Pacientes com níveis de expressão de miR200b abaixo da média recidivavam em um tempo médio de 95 meses, enquanto que pacientes com expressão de miR-200b maior que a média possuíam um tempo médio de sobrevida livre de recidiva de 133 meses (Figura 12) $(\mathrm{P}=0,049)$. 
Em relação aos miRNAs 30a e 1, os pacientes com níveis de expressão abaixo da média recidivavam em 97 e 102 meses, enquanto que aqueles com expressão maior que a média tinham um tempo médio de sobrevida livre de recidiva de 122 e 112 meses, respectivamente (Figura 13). No entanto, os resultados não apresentaram diferença estatística significativa.

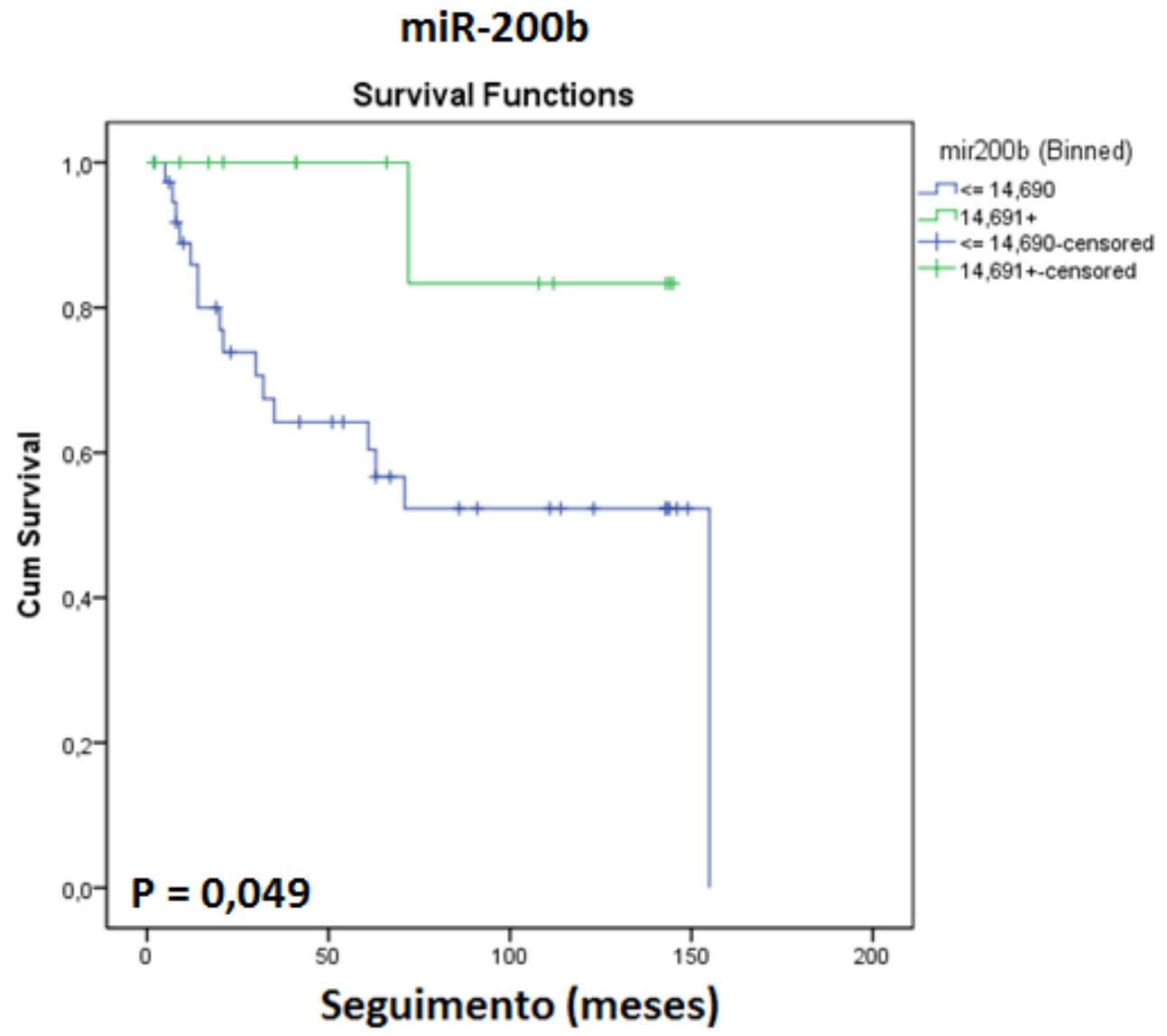

Figura 12. Curva de sobrevida livre de recorrência bioquímica de acordo com a expressão do miR-200b 

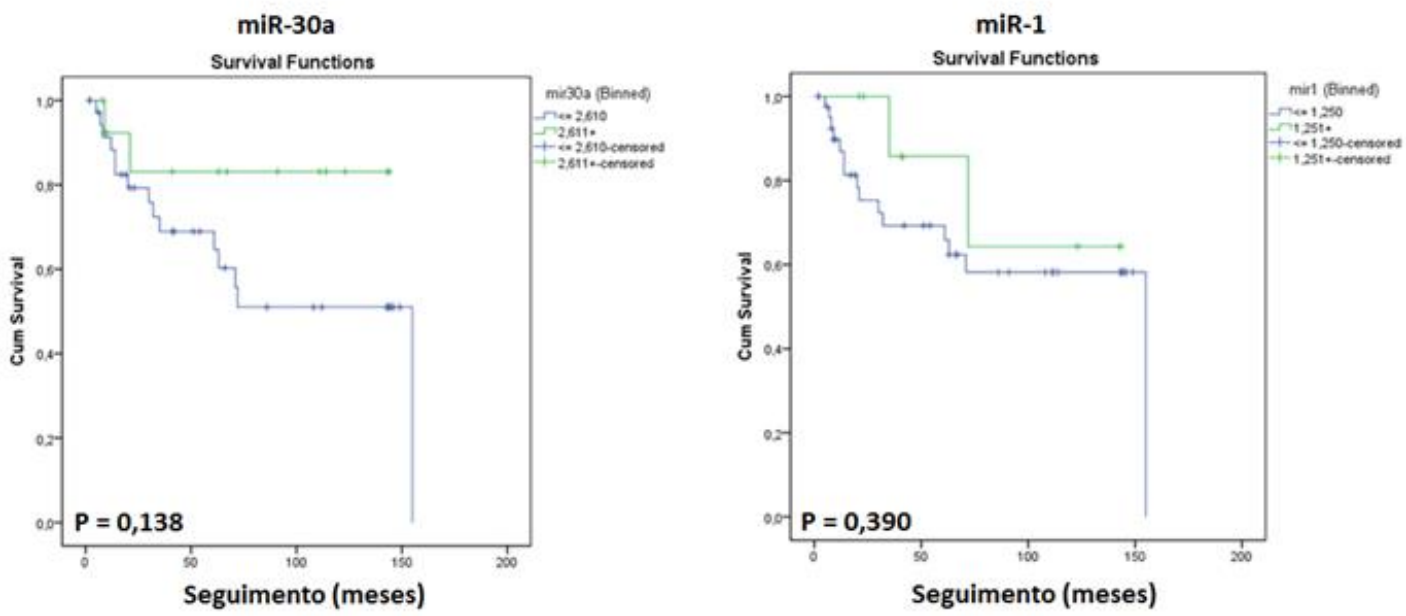

Figura 13. Curvas de sobrevida livre de recorrência bioquímica de acordo com a expressão do miR-30a e do miR-1

\subsection{Comparação entre o câncer de próstata localizado e as linhagens celulares metastáticas}

Quando comparamos as amostras a fresco dos tumores primários com as três linhagens celulares metastáticas, observamos que o miR-183 e o gene Twist1 apresentavam níveis de expressão significativamente aumentados nas linhagens metastáticas em relação ao estadiamento patológico. Os dados estão expostos na Tabela 12 e nas Figuras 14 e 15.

Em relação aos tumores pT2, houve um aumento nos níveis de expressão do miR-183 de 2,64 nos tumores pT3 para 40,41 nas linhagens metastáticas $(\mathrm{P}=0,009)$. Já em relação ao Twist1, esse aumento foi de 3,54 para 14,44 $(\mathrm{P}=0,049)$. 
Tabela 12. Expressão dos miRNAs e genes nos tumores pT3 e nas linhagens celulares metastáticas

\begin{tabular}{|c|c|c|c|c|c|c|c|c|c|c|c|}
\hline \multirow[b]{3}{*}{ miRNA } & \multicolumn{3}{|c|}{$\begin{array}{c}\text { Linhagens celulares de CaP } \\
\text { metastático }\end{array}$} & \multicolumn{5}{|c|}{$\begin{array}{c}\text { Linhagens celulares de CaP } \\
\text { metastático }\end{array}$} & \multicolumn{3}{|c|}{$\begin{array}{c}\text { Linhagens celulares de CaP } \\
\text { metastático }\end{array}$} \\
\hline & \multicolumn{3}{|c|}{$\begin{array}{l}\text { Média } \\
\text { (DP) }\end{array}$} & \multicolumn{4}{|c|}{$\begin{array}{l}\text { Média } \\
\text { (DP) }\end{array}$} & & \multicolumn{3}{|c|}{$\begin{array}{l}\text { Média } \\
\text { (DP) }\end{array}$} \\
\hline & pT3 & Célula & $\mathbf{P}$ & miRNA & pT3 & Célula & $\mathbf{P}$ & Gene & pT3 & Célula & $\mathbf{P}$ \\
\hline $200 a$ & $\begin{array}{c}8,18 \\
(27,83)\end{array}$ & $\begin{array}{c}0,51 \\
(0,73)\end{array}$ & 0,642 & 1 & $\begin{array}{c}1,09 \\
(2,09)\end{array}$ & $\begin{array}{l}0,0007 \\
(0,001)\end{array}$ & 0,382 & E-caderina & $\begin{array}{c}1,63 \\
(1,79)\end{array}$ & $\begin{array}{c}0,81 \\
(1,10)\end{array}$ & 0,446 \\
\hline $200 \mathrm{~b}$ & $\begin{array}{c}0,77 \\
(0,84)\end{array}$ & $\begin{array}{c}1,31 \\
(0,96)\end{array}$ & 0,310 & $29 b$ & $\begin{array}{l}1,11^{*} \\
(1,87)\end{array}$ & $\begin{array}{c}6,21 \\
(9,58)\end{array}$ & 0,317 & TGFß1 & $\begin{array}{l}1,76^{*} \\
(1,27)\end{array}$ & $\begin{array}{c}3,98 \\
(3,47)\end{array}$ & 0,383 \\
\hline $200 c$ & $\begin{array}{c}1,73 \\
(2,53)\end{array}$ & $\begin{array}{c}0,06 \\
(0,10)\end{array}$ & 0,271 & 9 & $\begin{array}{l}1,98^{*} \\
(2,97)\end{array}$ & $\begin{array}{c}37,10 \\
(59,33)\end{array}$ & 0,258 & ZEB1 & $\begin{array}{c}1,52 \\
(1,41)\end{array}$ & $\begin{array}{c}0,27 \\
(0,31)\end{array}$ & 0,140 \\
\hline 429 & $\begin{array}{c}1,83 \\
(3,98)\end{array}$ & $\begin{array}{c}0,65 \\
(0,65)\end{array}$ & 0,615 & 495 & $\begin{array}{c}1,96 \\
(3,05)\end{array}$ & $\begin{array}{c}0,02 \\
(0,008)\end{array}$ & 0,287 & ZEB2 & $\begin{array}{c}1,49 \\
(1,02)\end{array}$ & $\begin{array}{c}0,03 \\
(0,02)\end{array}$ & 0,057 \\
\hline 141 & $\begin{array}{c}3,43 \\
(6,71)\end{array}$ & $\begin{array}{c}3,50 \\
(3,31)\end{array}$ & 0,985 & $34 a$ & $\begin{array}{c}4,72 \\
(10,50)\end{array}$ & $\begin{array}{c}0,81 \\
(0,57)\end{array}$ & 0,530 & Twist1 & $\begin{array}{c}3,54 \\
(7,05)\end{array}$ & $\begin{array}{c}14,44 \\
(11,37)\end{array}$ & 0,049 \\
\hline 205 & $\begin{array}{c}0,96 \\
(1,16)\end{array}$ & $\begin{array}{c}0,001 \\
(0,002)\end{array}$ & 0,171 & 155 & $\begin{array}{c}1,52 \\
(3,01)\end{array}$ & $\begin{array}{c}0,02 \\
(0,04)\end{array}$ & 0,400 & Snail & $\begin{array}{c}2,05 \\
(2,72)\end{array}$ & $\begin{array}{c}3,09 \\
(2,78)\end{array}$ & 0,533 \\
\hline 203 & $\begin{array}{l}0,98^{*} \\
(1,10)\end{array}$ & $\begin{array}{c}2,50 \\
(4,22)\end{array}$ & 0,497 & $30 a$ & $\begin{array}{c}1,43 \\
(2,59)\end{array}$ & $\begin{array}{c}0,73 \\
(0,55)\end{array}$ & 0,651 & N-caderina & $\begin{array}{c}3,05 \\
(5,94)\end{array}$ & $\begin{array}{c}0,99 \\
-\end{array}$ & 0,737 \\
\hline 183 & $\begin{array}{l}2,64^{*} \\
(4,36)\end{array}$ & $\begin{array}{c}40,41 \\
(51,87)\end{array}$ & 0,009 & $10 \mathrm{~b}$ & $\begin{array}{c}2,43 \\
(6,64)\end{array}$ & $\begin{array}{c}0,07 \\
(0,06)\end{array}$ & 0,548 & Vimentina & $\begin{array}{c}2,48 \\
(3,38)\end{array}$ & $\begin{array}{c}4,78 \\
(3,87)\end{array}$ & 0,275 \\
\hline 21 & $\begin{array}{c}2,79 \\
(6,71)\end{array}$ & $\begin{array}{c}8,57 \\
(8,96)\end{array}$ & 0,177 & & & & & Slug & $\begin{array}{c}2,83 \\
(4,81)\end{array}$ & $\begin{array}{c}2,11 \\
(1,51)\end{array}$ & 0,799 \\
\hline 373 & $\begin{array}{c}1,11 \\
(1,47)\end{array}$ & $\begin{array}{c}1,08 \\
(1,03)\end{array}$ & 0,975 & & & & & PDGF-D & $\begin{array}{c}1,36 \\
(1,27)\end{array}$ & $\begin{array}{c}0,53 \\
(0,48)\end{array}$ & 0,273 \\
\hline
\end{tabular}

* Valores obtidos através do teste de Mann-Whitney; demais obtidos através do teste T de Student 


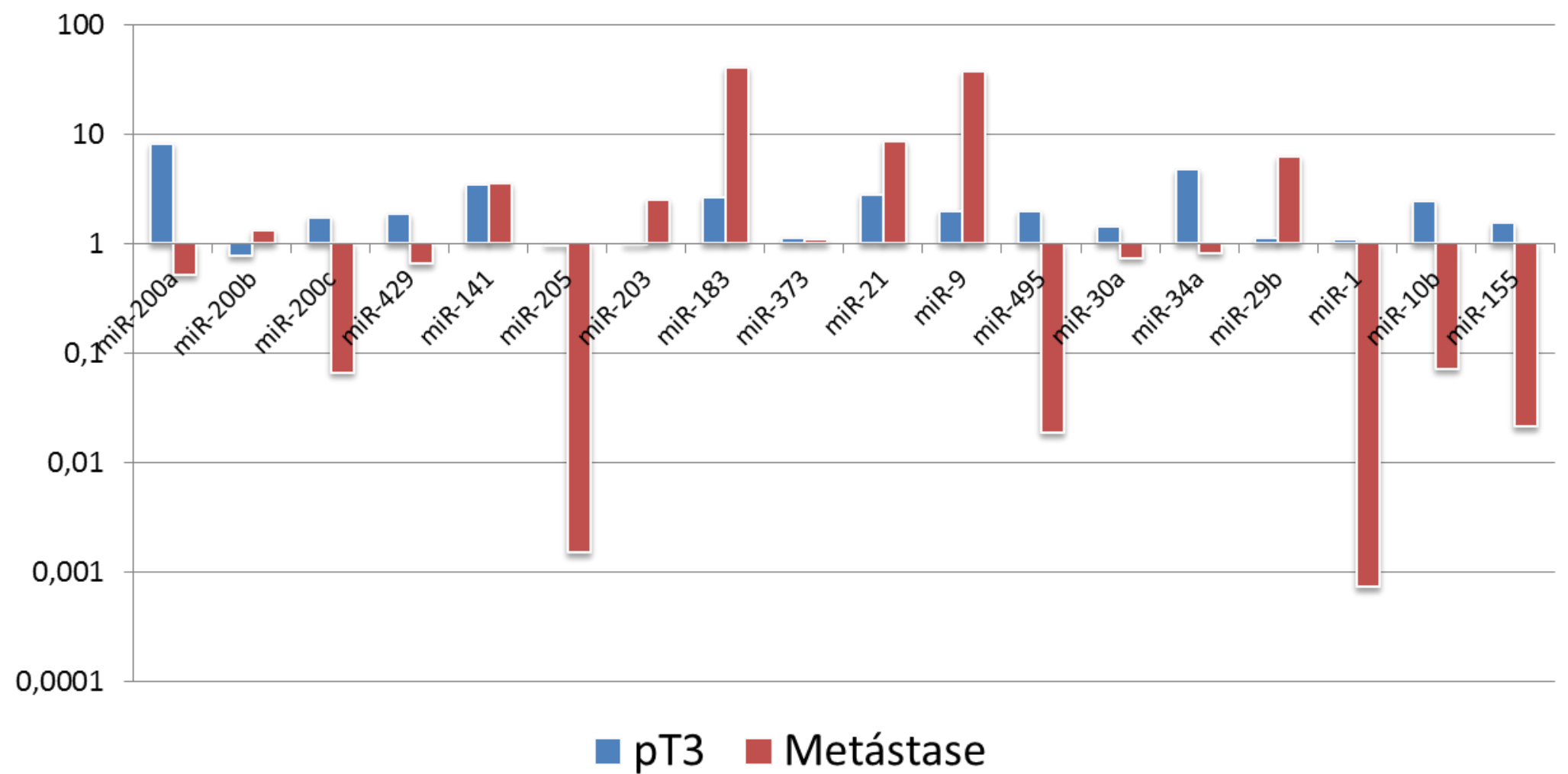

Figura 14. Perfil de expressão dos miRNAs nos tumores pT3 e nas linhagens celulares metastáticas 


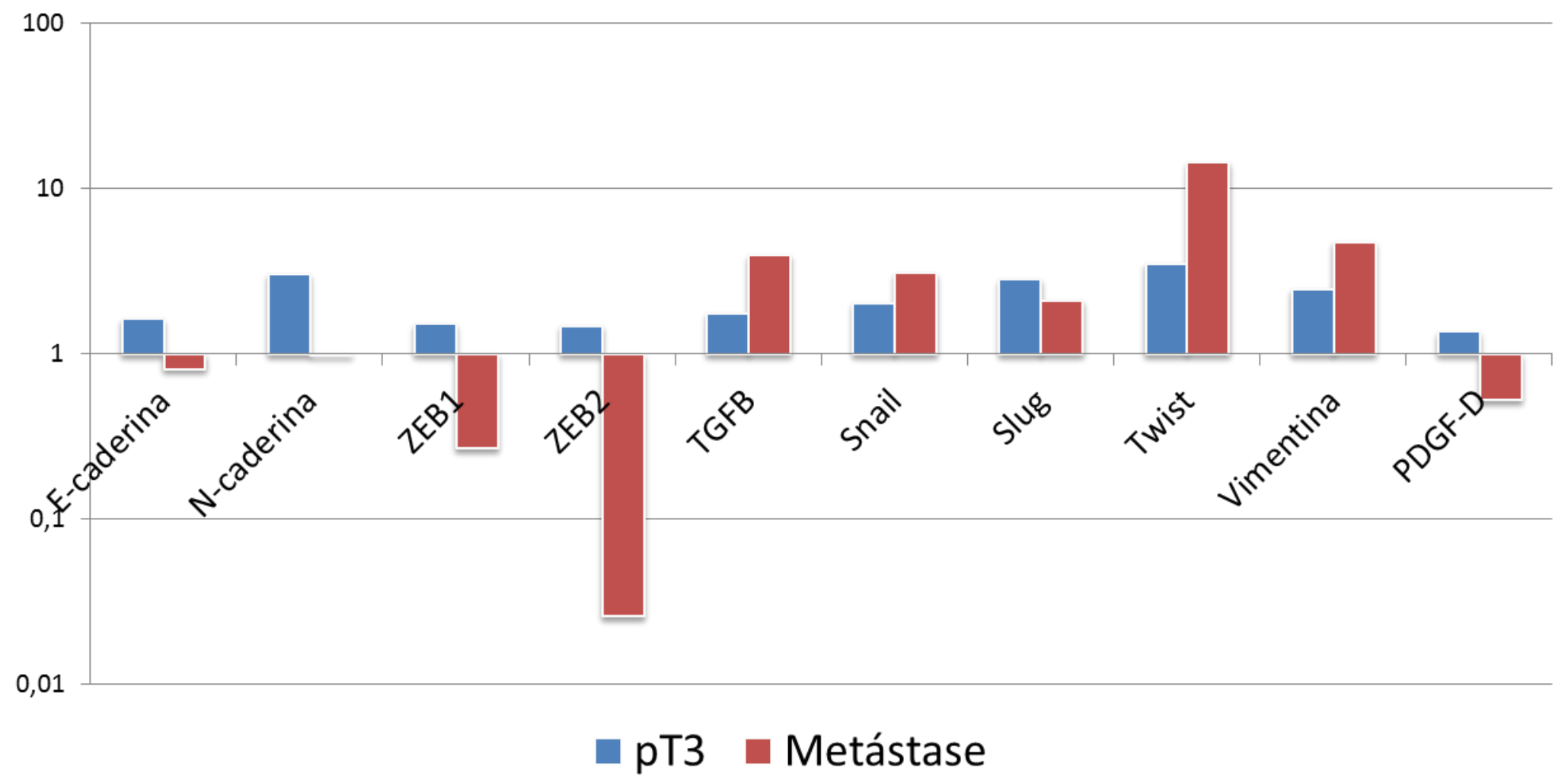

Figura 15. Perfil de expressão dos genes nos tumores pT3 e nas linhagens celulares metastáticas 


\subsection{Correlação entre os genes e miRNAs}

Para avaliar a relação entre os genes e miRNAs estudados, realizamos análise de correlação. Não encontramos correlação significativa entre os miRNAs e os genes, nem entre os miRNAs em si. No entanto, observamos uma correlação positiva forte entre os genes ZEB1 e ZEB2 (rho = 0,55; $\mathrm{P}=0,03$ ). 
5. DISCUSSÃO 


\section{DISCUSSÃO}

\subsection{0 câncer de próstata localizado mantém o fenótipo epitelial}

O papel da transição epitélio-mesenquimal no câncer tem sido muito estudado nos últimos anos, pois acredita-se que seja um dos principais mecanismos responsáveis pela progressão tumoral e pela disseminação metastática. Por se tratar de um evento dinâmico e parcial, algumas das alterações da TEM provavelmente já estão presentes no tumor localizado, enquanto que outras ocorrem mais tardiamente. O nosso objetivo, portanto, foi avaliar a TEM em duas etapas do processo de carcinogênese - no CaP localizado e em linhagens celulares metastáticas -, através da expressão dos miRNAs e dos genes notoriamente envolvidos nesse processo. Ainda, na tentativa de identificar marcadores prognósticos, também avaliamos a relação dos miRNAs e genes com os principais parâmetros clínico-patológicos.

Nossos resultados demonstram que o CaP localizado mantém um fenótipo epitelial. Em nosso trabalho, 98\% dos casos apresentam superexpressão de Ecaderina, enquanto que os genes N-caderina, Vimentina, ZEB1, TGF- $\beta 1$ e Slug estão subexpressos na grande maioria dos casos. Assim sendo, o princípio fundamental da TEM - a repressão da E-caderina, com concomitante superexpressão de marcadores mesenquimais, como a Vimentina e a $\mathrm{N}$-caderina - ainda não ocorreu. Ademais, um dos principais indutores do processo responsável pela regulação dos genes envolvidos, o fator de crescimento TGF- $\beta 1$, encontra-se subexpresso.

Entre os miRNAs estudados que contribuem para o fenótipo epitelial estão a família do miR-200, o miR-205 e o miR-203. Todos eles apresentaram-se superexpressos. A Figura 16 expõe o perfil do CaP localizado recém descrito.

Em relação à família miR-200, nossos resultados estão de acordo com o perfil de expressão encontrado em estudos em $\mathrm{CaP}^{64}$ e em outras neoplasias, como pâncreas, colangiocarcinoma, ovário e endométrio ${ }^{75,90-94}$. Alguns trabalhos, no entanto, encontraram subexpressão do miR-200 em carcinomas gástricos e renais ${ }^{95}$, 96. 
A família do miR-200 é um potente indutor do fenótipo epitelial, tendo como principal gene alvo a família do ZEB - o ZEB1 e o ZEB2. Conforme esperado nos tumores com fenótipo epitelial, observamos uma subexpressão do ZEB1, porém não encontramos correlação significativa entre este e os membros da família do miR-200.

De forma inesperada, o ZEB2 mostrou um padrão de expressão variável, estando superexpresso em pouco mais da metade dos pacientes. Apesar da discrepância de expressão em relação ao ZEB1, na análise de correlação encontramos uma correlação positiva significativa entre ambos.

Uma possível explicação para esse padrão de expressão de ZEB2 pode ser atribuída à sua regulação pelo Snail, que também se encontra superexpresso numa proporção semelhante de casos. O Snail aumenta a expressão de ZEB2 através de um mecanismo complexo que envolve a regulação de um transcrito antissenso natural do ZEB2. O Snail impede o splicing de um íntron na 5'UTR do ZEB2, aumentando seus níveis de transcrição ${ }^{97}$.

Ainda, os dados acerca da família ZEB, particularmente do ZEB2, são conflitantes. Chen e col mostraram que, após transfecção do miR-200b em linhagens celulares de tumor de ovário, houve uma significativa diminuição na expressão do ZEB1 e ZEB2 quando analisada através de RT-PCR. No entanto, quando realizada análise em microarray para comparação, o ZEB2 não sofreu uma mudança significativa em sua expressão ${ }^{98}$. Um resultado muito contrastante foi evidenciado por Kurashige e col, os quais identificaram uma correlação significativa do miR200b com ZEB2 no câncer gástrico, porém não com ZEB1 ${ }^{99}$. Postigo demonstrou que, apesar de as proteínas ZEB1 e ZEB2 serem estruturalmente similares e ambas reprimirem a transcrição de vários genes envolvidos na diferenciação $\mathrm{e}$ desenvolvimento celular, elas possuem efeitos opostos na via de sinalização do TGF$\beta /$ BMP, onde o papel de ambas é crucial ${ }^{100}$. Enquanto que o ZEB1 sinergiza com a proteína SMAD para regular a transcrição, diferenciação e parada do crescimento celular, o ZEB2 reprime a função desta. Além disso, a correlação inversa entre ZEB2 e E-caderina nas linhagens celulares tumorais não é tão evidente como no caso de ZEB $1^{101}$. 
Outros dois genes que também são regulados pelo miR-200 são o Slug, que será discutido posteriormente, e o PDGF-D. Encontramos uma expressão variável do PDGF-D, um fator de crescimento que regula a invasão tumoral e participa da indução da TEM através da repressão de miR-200 ${ }^{51}$. Kong e col observaram que o miR-200 encontrava-se diminuído em células que expressavam PDGF-D, resultando numa superexpressão de ZEB1, ZEB2 e Slug, enquanto que a reexpressão de miR200 b induzia um fenótipo epitelial ${ }^{102}$.

O miR-200 impede que a transição epitélio-mesenquimal ocorra, o que nos levaria a crer que, em tecidos tumorais, sua expressão estaria diminuída. No entanto, alguns estudos mostram que a mudança para o fenótipo epitelial induzida pelo miR200 está associada a maior atividade proliferativa ${ }^{34,103}$. Como já mencionado previamente, no processo da TEM há uma redução da atividade proliferativa celular, e, para que ocorra proliferação, as células com fenótipo mesenquimal devem reverter a alça em direção ao miR-200. Conclui-se, portanto, que o estado epitelial é crucial para o crescimento do tumor, o que poderia justificar a superexpressão do miR-200 em tecidos neoplásicos quando comparados a tecidos não tumorais.

Um estudo realizado em linhagens celulares de câncer de mama ilustra claramente esse processo e justifica nossos achados ${ }^{104,105}$. Os autores estudaram três linhagens não aptas a colonizar locais distantes - 67NR, 168FARN e 4 TO7 - e uma linhagem altamente metastática (4T1). Os resultados foram surpreendentes. Nas células 4T1, a família do miR-200 estava superexpressa, enquanto que nas demais linhagens seus níveis de expressão eram muito baixos ou até mesmo indetectáveis. $\mathrm{O}$ mesmo ocorreu em relação à E-caderina e ao ZEB2, que apresentavam superexpressão e subexpressão na linhagem 4T1, respectivamente. Ensaios in vitro com transfecção de miR-200 nas células 4TO7 reduziram os níveis de expressão de ZEB2 e Snai1 e aumentaram os de E-caderina. Após aquisição do fenótipo epitelial, observaram-se um aumento na motilidade celular e um maior potencial metastático. Contudo, não houve diferença em relação à formação do número ou tamanho de colônias, nem em relação à atividade proliferativa. Nos experimentos in vivo, a introdução de células 4T1 e de células 4TO7 transfectadas com miR-200 levou à detecção de tumores palpáveis em um menor tempo em relação às células 4TO7 
parentais. No entanto, uma vez estabelecido o tumor, não se observou diferença na taxa de crescimento. O que sugerem os autores é que as propriedades epiteliais podem aumentar a capacidade das células tumorais de colonizar e de se estabelecer tanto no sítio primário quanto no local da metástase, mas não oferecem vantagem no crescimento quando o tumor já está estabelecido ${ }^{105}$.

Utilizando as mesmas linhagens, Korpal e col ratificaram que a reexpressão do miR-200 é absolutamente necessária no processo de colonização ${ }^{106}$. O miR-200 promove o crescimento de macrometástase através da inibição direta do SEC23A, que medeia a secreção de proteínas supressoras de metástase. No CaP, o SEC23A reduz a indução e o crescimento do $\mathrm{CaP}$ em linhagens celulares ${ }^{107}$. Os autores sugerem que o miR-200 exerce funções diferentes dependendo do estágio da metástase: enquanto que no início do processo baixos níveis de expressão de miR200 e a TEM promovem invasão tumoral e intravasamento, numa etapa mais tardia altos níveis de expressão de miR-200 e a TME são necessários para a colonização eficiente de órgãos secundários.

Acreditamos que, uma vez estabelecido o tumor, não há mais vantagem na manutenção do fenótipo epitelial. À medida que a neoplasia progride, observam-se diminuição da expressão do miR-200 e aquisição de um fenótipo mesenquimal, que será responsável pela invasão tumoral e migração celular. No entanto, quando chegam ao local secundário, as células neoplásicas têm de readquirir o estado epitelial para se estabelecer e iniciar o crescimento tumoral.

A identificação de um alvo novo do miR-200b, o supressor de metástase TIMP2, identificado em linhagens celulares de câncer de endométrio por Dai e col 108, também confirma nossos achados. A subexpressão de TIMP2 pelo miR-200b resulta num aumento da atividade da MMP2. A MMP2 é uma enzima que degrada o colágeno tipo IV, o principal componente estrutural da membrana basal. Os autores observaram que sua expressão estava anormalmente elevada nos tecidos tumorais quando comparada ao tecido normal adjacente, sugerindo um possível papel do miR200b na iniciação do carcinoma de endométrio. Em um estudo realizado pelo nosso grupo, encontramos que TIMP2 está subexpresso na maioria dos tumores de próstata ${ }^{109}$, o que poderia ser decorrente da ação do miR-200b sobre ele. 
A superexpressão do miR-205 e do miR-203 suporta o estado epitelial dos tumores localizados, e estes também têm como alvos o ZEB1 e o ZEB2 ${ }^{74,110,111 .}$ Contudo, os estudos que avaliaram a expressão desses dois microRNAs no $\mathrm{CaP}$ encontraram subexpressão dos mesmos ${ }^{62,112-114}$.

O miR-205 foi recentemente identificado como presente em níveis mais elevados no estroma prostático em relação ao tumor ${ }^{115}$. De forma curiosa, no entanto, em tumores de alto grau o miR-205 apresentou superexpressão em relação ao tecido epitelial adjacente, demonstrando uma diferenciação para o fenótipo epitelial. O miR-205 já foi descrito como supressor tumoral no $\mathrm{CaP}$ ao inibir a propriedade migratória e invasiva de linhagens celulares de $\mathrm{CaP}^{116,117}$. Gandellini e col mostraram que a restauração da expressão do miR-205 nas células tumorais prostáticas resultou na TME, com consequente superexpressão da E-caderina e redução da motilidade e da invasão ${ }^{112}$. Os autores atribuem parte do efeito supressivo tumoral do miR-205 à subexpressão de $\mathrm{PKC} \varepsilon$, o qual tem papel na migração e invasão do CaP e relação com agressividade tumoral ${ }^{118}$.

O miR-203 é um dos miRNAs com maior diversidade no padrão de expressão em linhagens tumorais epiteliais ${ }^{119}$. Além do ZEB1, o miR-203 regula vários efetores metastáticos em linhagens celulares do CaP, incluindo ZEB2, BMI1 e survinina ${ }^{111}$. O gene Slug também foi descrito como alvo do miR-203, assim como do miR-182, membro da família do miR-183 ${ }^{120}$. O UTR' do Slug contém sítios de ligação conservados para esses miRNAs, e a superexpressão dos dois miRNAs leva à diminuição nos níveis de transcrição do Slug em linhagens celulares. Ainda, o Slug também é regulado pelo miR-200b e pelo miR-1, o que será discutido posteriormente.

O Slug está subexpresso em $82 \%$ dos casos, enquanto que seus miRNAs reguladores, com exceção do miR-1, estão superexpressos, apresentando uma relação inversa de expressão. Nossos resultados em relação ao gene Slug estão de acordo com a literatura, uma vez que este é encontrado fortemente subexpresso no $\mathrm{CaP}$ quando comparado ao tecido benigno ${ }^{121,122}$. 
O miR-183 mostrou-se superexpresso no CaP localizado em relação ao grupo controle de HPB, estando de acordo com os demais estudos em CaP que mostram superexpressão do mesmo ${ }^{114,123-126}$. Esse dado poderia reforçar o fenótipo epitelial, pois alguns estudos sugerem sua participação na TEM através da ação inibitória sobre o ZEB1 ${ }^{110,127}$. No entanto, como será descrito posteriormente, nossos achados sugerem que o miR-183 age como oncomiR no CaP.

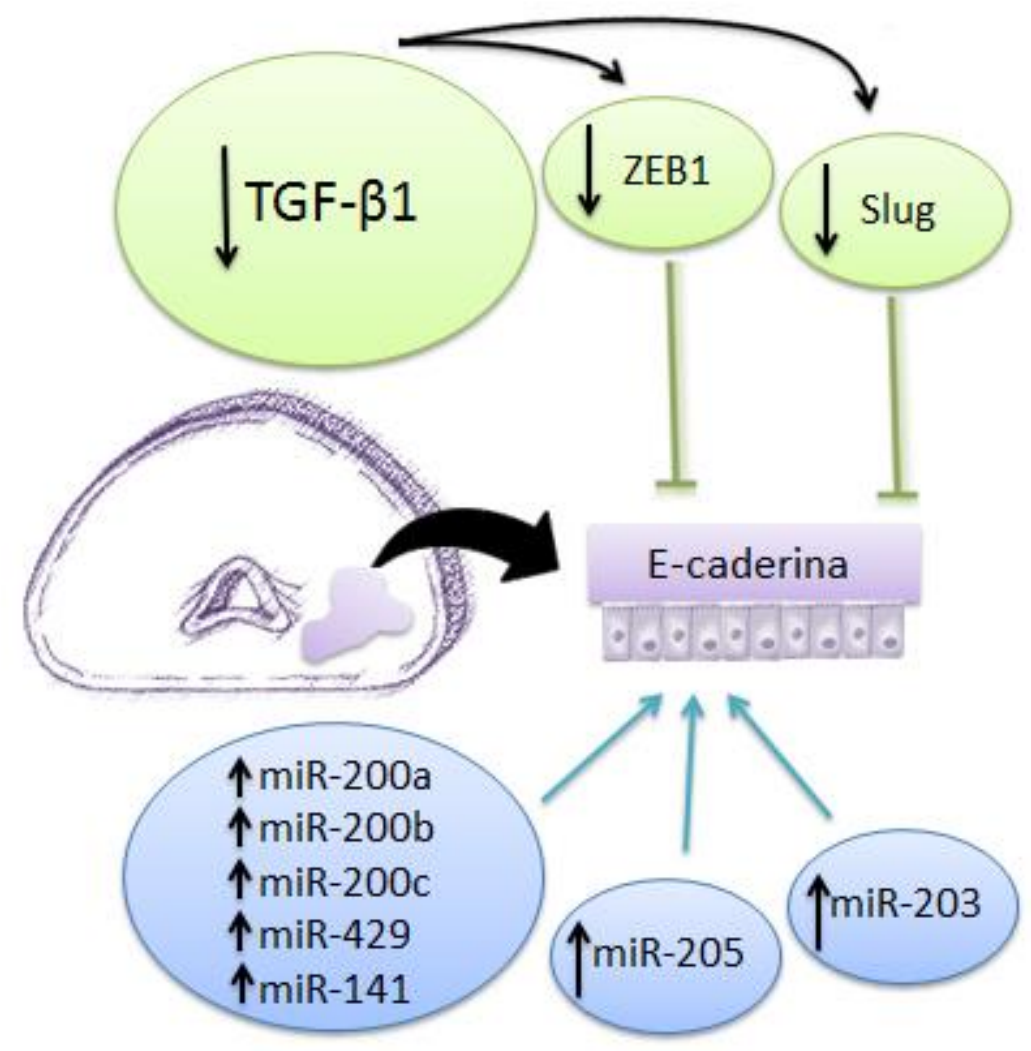

Figura 16. Fenótipo molecular do câncer de próstata localizado. Na quase totalidade dos casos, há superexpressão de E-caderina, demonstrando a manutenção do fenótipo epitelial. As setas para cima indicam superexpressão dos miRNAs em questão, enquanto que as setas para baixo indicam subexpressão dos genes.

\subsection{0 início da transição epitélio-mesenquimal}

Sabemos que a TEM completa não é necessária para nenhuma das etapas do processo de invasão e metástase, e que, na realidade, ela é raramente observada nessa forma ${ }^{128}$. Embora nossos resultados mostrem que o tumor localizado tenha um 
fenótipo predominantemente epitelial, algumas alterações do processo podem estar presentes já nesse estágio da doença. Entre os miRNAs estudados que agem como supressores tumorais e que se encontram subexpressos no nosso trabalho estão o miR-29b e o miR-1. Nossos achados estão de acordo com a literatura em que ambos os miRNAs estão subexpressos no $\mathrm{CaP}^{62,84,129}$.

Podemos aventar a hipótese de que estes sejam os primeiros miRNAs a sofrer diminuição no processo da TEM e da carcinogênese. O miR-1 está subexpresso em diversos tumores sólidos ${ }^{130,131}$, inclusive no $\mathrm{CaP}^{64}$. Acredita-se que o miR-1 participe da TEM de várias formas nessa neoplasia: através de efeitos epigenéticos, como a metilação e a acetilação de histonas ${ }^{132}$; através de uma alça de regulação inibitória mútua com o Slug, juntamente com o miR-200 ${ }^{87}$; e através de outros alvos independentes que agem na proliferação, migração e invasão, como KIF2A, FOXP1, HDAC4 e PNP ${ }^{87,133}$.

Em nosso estudo, a subexpressão precoce do miR-1 poderia ser explicada pelos efeitos epigenéticos que este sofre, os quais são eventos iniciais no processo de carcinogênese do tumor de próstata ${ }^{134,}{ }^{135}$. A subexpressão do miR-1 não foi suficiente para aumentar a expressão do Slug, pois este encontra-se também subexpresso. Como já discutido previamente, a subexpressão do Slug pode ser decorrente da ação dos seus outros miRNAs reguladores, o miR-200b e o miR-203, que estão superexpressos.

O fato de o Slug parecer depender de vários miRNAs para que sua superexpressão ocorra pode ser um mecanismo protetor contra a TEM. Dentre os genes reguladores, o principal responsável pela iniciação do processo parece ser o Slug, sendo este o mais limitante de todos os genes no processo da TEM. Casas e col demonstraram que a indução do Slug é necessária para a ocorrência da TEM, e que toda a morfogênese é bloqueada na ausência desse ${ }^{120}$. Em estudo posterior, Liu e col mostraram que a depleção de Slug inibe a TEM, enquanto que a depleção de Snail é significativamente menos limitante ${ }^{136}$. Ainda, observaram que a ausência de Slug inibe também a expressão de outros reguladores da TEM, como o ZEB2 e o Snail. 
O miR-29b tem um possível papel na modulação da metástase ao inibir a expressão de MMP2 ${ }^{129}$, além de possuir um sítio alvo na terminação 3'UTR do Snail 84. O Snail, em nosso estudo, exibe um perfil de expressão variável, estando superexpresso em $55 \%$ dos casos e subexpresso em $45 \%$. O Snail parece ser regulado por numerosos miRNAs, apresentando mais sítios alvo que o próprio Slug. Entre os miRNAs envolvidos e estudados no nosso trabalho estão os miRNAs 29b, 30a, 34a e 21 (Figura 17). Os três primeiros inibem o Snail, enquanto que o último o estimula. Embora o inibidor miR-29b e o estimulador miR-21 estejam subexpresso e superexpresso, respectivamente, os outros dois inibidores, os miRNAs 30a e 34a, apresentam um perfil de expressão variável. Essa grande variação entre seus miRNAs reguladores nos impossibilita qualquer conclusão acerca do Snail. Contudo, ao contrário do Slug, o Snail não é capaz de iniciar a TEM, apenas de manter o fenótipo mesenquimal.

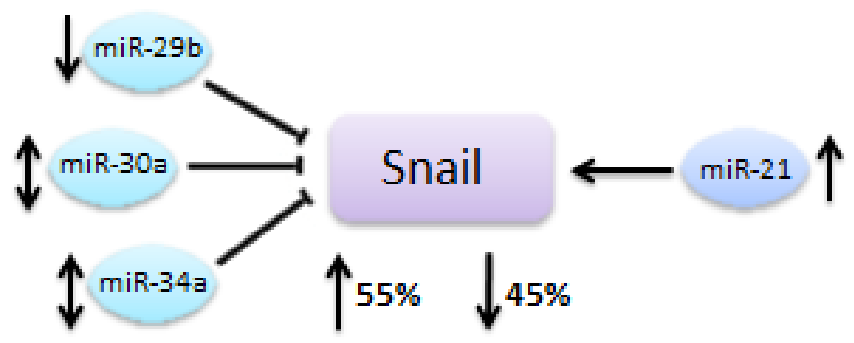

Figura 17. Gene Snail e seus miRNAs reguladores. O gene Snail é regulado por diversos miRNAs. Aqueles avaliados em nosso estudo exibiram perfis de expressão muito variáveis, resultando na superexpressão do Snail em pouco mais da metade dos casos.

\subsection{A superexpressão de Twist1 nos tumores localizados}

Dentre os genes estudados que participam da transição para o fenótipo mesenquimal, o Twist1 foi o único gene que se mostrou superexpresso na grande maioria dos casos, correspondendo a 73\%. O gene Twist1 é um fator de transcrição hélice-alça-hélice que estimula a TEM através da inibição indireta da E-caderina ${ }^{137}$. 
Os nossos achados estão de acordo com a literatura, que mostra superexpressão de Twist1 no CaP e correlação positiva com o escore de Gleason ${ }^{138,139}$.

Chama a atenção que um gene com tamanha importância na TEM e com potencial valor prognóstico no $\mathrm{CaP}$ já se apresente superexpresso nos tumores ainda localizados. Uma das possíveis explicações para a superexpressão precoce do Twist1 pode ser a regulação pelo gene NKX3.1 ${ }^{140}$. Eide e col demonstraram que o Twist1 é alvo do gene NKX3.1, um supressor tumoral que se encontra subexpresso em estágios iniciais do $\mathrm{CaP}^{141}$. Em um estudo de $\mathrm{CaP}$ em modelo animal, observou-se que, na neoplasia prostática intraepitelial (PIN) de alto grau, a expressão de NKX3.1 já se encontra diminuída ${ }^{142}$. De forma interessante, Yuen e col demonstraram um possível papel do Twist1 na progressão do $\mathrm{CaP}$ ao observarem que os níveis de expressão imuno-histoquímica deste aumentavam significativamente com a progressão do HPB para PIN de alto grau, seguido pelo CaP de baixo grau e depois pelo $\mathrm{CaP}$ de alto grau ${ }^{139}$.

Contudo, a estimulação precoce do Twist1 parece ser insuficiente para iniciar o processo de transição epitélio-mesenquimal. De acordo com Casas e col, o Twist1 é dependente da ativação do Slug, tendo papel na TEM apenas quando da indução do Slug ${ }^{120}$. Este possui uma caixa $\mathrm{E}$ conservada na região proximal à área promotora à qual o Twist1 se liga, promovendo sua transcrição. Os autores demonstraram que a depleção de Slug bloqueia completamente a capacidade do Twist1 de suprimir a Ecaderina e de induzir alterações morfológicas associadas a TEM.

Ainda, o Twist1 parece estar envolvido não só na etapa inicial da progressão do $\mathrm{CaP}$, mas também na disseminação metastática. Isso será discutido no item a seguir.

\subsection{0 miR-183 e o gene Twist1 estão envolvidos no processo de disseminação da doença}

Durante o processo de disseminação tumoral, observamos que dois marcadores têm seus níveis de expressão significativamente alterados em relação ao 
tumor primário. Os níveis de expressão do miR-183 e do gene Twist1 aumentam significativamente quando o tumor evolui para a metástase em relação ao estadiamento patológico.

O miR-183 pertence ao cluster miR-183, constituído ainda pelos membros miR-182 e miR-96, estando localizados na mesma região cromossômica (7q32.2) ${ }^{143}$. O papel do cluster miR-183 ainda é incerto, e alguns estudos mostram que o miR183 promove migração e invasão tumoral ${ }^{125,144,145}$, enquanto outros indicam que esse miRNA age como supressor tumoral ${ }^{110,127,146 .}$

Tsuchiyama e col demonstraram que níveis de expressão elevada de miR182-5p estavam associados com escore de Gleason alto ${ }^{124}$. Ueno e col observaram que níveis de expressão elevada de miR-183 estavam significativamente associados com alto PSA pré-operatório, estadiamento patológico mais avançado e menor sobrevida geral após prostatectomia radical ${ }^{125}$. Ainda, a diminuição dos níveis de miR-183 inibiu a proliferação e a motilidade celular in vitro e reduziu o crescimento tumoral in vivo.

Dois alvos do miR-183 no CaP, os supressores tumorais DKK3 e SMAD4, foram descritos pelos mesmos autores, demonstrando seu papel como oncomiR, uma vez que ambos são inibidores do crescimento celular em linhagens de $\mathrm{CaP}^{147,148}$. O miR-183 também apresenta potencial oncogênico através da regulação de dois supressores tumorais, EGR1 e PTEN, identificado em linhagens celulares de câncer de cólon e de sarcoma sinovial ${ }^{144}$.

Por outro lado, Qu e col mostraram que a reexpressão de um dos membros do cluster miR-183, o miR-182, induzia TME em células mesenquimais de $\mathrm{CaP}$ e aquisição de características oncogências através da repressão do Slug ${ }^{146}$. A ação do miR-183 sobre esse gene também foi descrita em linhagens celulares de câncer colorretal, onde inibiam uma série de genes controladores da migração celular, invasão e TEM, incluindo o Slug, ZEB1, ITGB1 e KLF4 ${ }^{127}$.

De acordo com nossos resultados e baseado em dados prévios, acreditamos que o miR-183 age como oncogene no $\mathrm{CaP}$ através de um mecanismo que pode envolver o SMAD4 e o PTEN. A perda do PTEN se correlaciona com a progressão 
do CaP e metástase, com cerca de 70\% de amostras de câncer avançado mostrando perda de PTEN ou ativação de PI3K ${ }^{149}$. A via de sinalização TGF- $\beta$ /BMP-SMAD4, que estimula a TEM, é conhecida por impedir a progressão do $\mathrm{CaP}$ induzida pela deleção do PTEN. Ding e col demonstraram que o SMAD4 é um regulador chave na progressão do $\mathrm{CaP}$ em camundongos e humanos, e que a proliferação celular e a invasão são duas características biológicas fundamentais no modelo metastático de CaP SMAD4/PTEN-null ${ }^{150}$. A inativação concomitante de PTEN e SMAD4 no epitélio prostático é capaz de produzir um fenótipo totalmente penetrante e metastático no camundongo.

Observamos que os níveis de expressão de Twist1 aumentam significativamente do tumor pT3 para o tumor metastático. Kwok e col também demonstraram que os níveis de expressão imuno-histoquímicos de Twist1 eram significativamente mais elevados nas lesões metastáticas de osso e linfonodo em comparação com o tumor primário ${ }^{138}$. Yuen e col também mostraram valor preditor metastático em estudo imuno-histoquímico ${ }^{139}$.

O papel do Twist1 no estágio mais avançado da TEM pode ser devido à sua ativação de seu alvo miR-10b ${ }^{151}$, que por sua vez reprime a E-caderina ${ }^{152}$. O miR10b também inibe a tradução da proteína HOXD10, resultando num aumento da expressão do gene pró-metastático RHOC. Embora o miR-10b tenha tido um padrão de expressão variável e não tenhamos encontrado uma correlação significativa entre o Twist1 e o miR-10b, em 29 pacientes (57\%) eles apresentaram o mesmo perfil de expressão.

O miR-10b está superexpresso no $\mathrm{CaP}$ em relação ao epitélio normal e em níveis mais elevados em pacientes com pT3 ${ }^{115}$ e naqueles que apresentaram recorrência bioquímica ${ }^{153}$. O miR-10b também já foi descrito como fator prognóstico de sobrevida em câncer gástrico ${ }^{154}$ e na progressão tumoral do câncer de mama ${ }^{151}$. 


\subsection{Aplicação prática: associação com parâmetros clínico-patológicos}

Embora já existam na literatura alguns estudos sobre o perfil dos miRNAs no $\mathrm{CaP}$, são poucos os que investigaram a relação da expressão em tecido com parâmetros clínico-patológicos. Em nosso estudo, encontramos associação entre os níveis de expressão do miR-200b, miR-30a e miR-1 e o estadiamento patológico. Pacientes com doença extraprostática (pT3) apresentaram níveis de expressão significativamente mais baixos dos três miRNAs em relação aos pacientes com doença órgão-confinada (pT2). Os nossos resultados estão de acordo com a função dos mesmos, pois eles induzem o fenótipo epitelial. À medida que o tumor progride localmente, os níveis de expressão dos miRNAs 200b, 30a e 1 diminuem significativamente. $\mathrm{Na}$ prática, esses três miRNAs poderiam ser utilizados como marcadores do comportamento biológico da doença, auxiliando na decisão terapêutica, quando necessário.

Ao contrário dos nossos achados em relação ao miR-200b, Ambs e col encontraram níveis significativamente mais elevados dos miRNAs 200a e 200b em pacientes com doença extraprostática ${ }^{64}$. No entanto, estudos realizados em câncer de bexiga e estômago encontraram resultados semelhantes aos nossos. Nos tumores vesicais, observou-se maior expressão do miR-200c em tumores pT1, enquanto que a diminuição da sua expressão apresentava associação significativa com progressão da doença (pT2) e prognóstico desfavorável ${ }^{155}$. Kurashige e col demonstraram que algumas características patológicas adversas do carcinoma gástrico, incluindo estadiamento avançado, estavam associadas com uma menor expressão do miR-200b 99

Em relação ao miR-30a e ao miR-1, não há estudos que demonstrem sua associação com estadiamento no CaP. Cheng e col, por outro lado, observaram que níveis reduzidos do miR-30a foram preditores de estadiamento avançado e metástase linfonodal no câncer de mama invasivo ${ }^{156}$.

Nossos resultados demonstraram que pacientes com baixos níveis de expressão do miR-200b apresentam tempo de sobrevida livre de recorrência bioquímica significativamente menor que pacientes com altos níveis. Barron e col 
mostraram resultados semelhantes em relação ao miR-200a, cujos níveis de expressão estavam reduzidos em pacientes que apresentaram recorrência da doença 157. Níveis reduzidos de miR-200a também estão significativamente associados com recorrência precoce e menor sobrevida no câncer de ovário ${ }^{158,159}$. Ainda, baixos níveis de expressão de miR-200c também mostraram relação significativa com menor sobrevida no câncer de ovário ${ }^{160}$ e pâncreas ${ }^{161}$.

Em relação aos miRNAs 30a e 1, embora os pacientes com baixos níveis de expressão desses miRNAs tenham apresentado um menor tempo livre de recidiva bioquímica, não encontramos diferença estatisticamente significativa. No $\mathrm{CaP}$, o miR-1 já foi descrito como potencial marcador prognóstico, sendo que a redução de seus níveis de expressão está associada com recorrência mais precoce ${ }^{132}$.

A importância dos miRNAS 200b e 1 já foi descrita em experimento comum no CaP. Liu e col estudaram a interação dos miRNAs 1 e 200 com o gene Slug em linhagens celulares do $\mathrm{CaP}$ a fim de determinar um modelo de progressão tumoral através da TEM ${ }^{87}$. Esse foi o primeiro estudo a observar que o miR-1 e o miR-200b podem regular diretamente o Slug, assim como o Slug também é capaz de inibir a transcrição de ambos miRNAs. Os autores observaram que a supressão de Slug pelos miR-1 e miR-200 parece ser o principal determinante para inibir a diferenciação mesenquimal no $\mathrm{CaP}$.

Já o papel do miR-30a no processo de carcinogênese é pouco conhecido no $\mathrm{CaP}$ e foi inicialmente descrito como subexpresso no estudo de Porkka e col ${ }^{62}$, enquanto que Carlsson e col, posteriormente, observaram sua superexpressão ${ }^{162}$. Em nosso estudo, o miR-30a apresentou superexpressão em 51\% dos casos. Entretanto, sua associação com o estadiamento patológico sugere uma função de supressor tumoral. Um estudo recente em CaP demonstrou que o gene ERG, um dos oncogenes mais frequentemente superexpresso nesse tumor, é alvo direto do miR-30a, e que este inibe a TEM, migração celular e invasão em linhagens celulares de $\mathrm{CaP}^{163}$. O papel da família do miR-30 na TEM foi estudado em linhagens celulares de carcinoma pulmonar ${ }^{164}$, mamário ${ }^{156}$ e hepatocelular ${ }^{85,165}$, onde parece inibir a migração celular, invasão e metástase. O miR-30a parece se ligar à região 3'UTR do gene Snail $^{85,164}$, além de inibir também o gene Vimentina ${ }^{156,165}$. 
Os miRNAs 200b e 30a também apresentaram associação estatisticamente significativa com escore de Gleason e grupo de risco, respectivamente. Tumores de alto grau, com escore de Gleason $\geq 8$, apresentaram níveis de expressão do miR-200b significativamente menores que tumores de baixo grau (escore de Gleason $\leq 6$ ). Os pacientes classificados como de alto risco apresentaram níveis de expressão significativamente menores do miR-30a que os do grupo de baixo risco. De forma análoga, Wang e col observaram que baixos níveis de miR-30a estavam significativamente associados com uma maior incidência de trombo tumoral de veia porta em pacientes com carcinoma hepatocelular ${ }^{165}$.

Observamos, também, que níveis de expressão elevados de Twist1, assim como de Vimentina, estavam significativamente associados com pacientes do grupo de alto risco. Ainda, a Vimentina é alvo do miR-30a, e ambos apresentaram associação com o grupo de risco de maneira inversa. Num estudo recente por Behnsawy e col, a expressão imuno-histoquímica de marcadores da TEM foi avaliada em tumores de próstata localizados ${ }^{166}$. Os autores demonstraram que a alta expressão destes exatos dois genes, Twist1 e Vimentina, é fator independente relacionado a menor sobrevida livre de recorrência bioquímica, podendo eles servir como marcadores para a predição de recorrência bioquímica após prostatectomia radical.

\subsection{Considerações finais}

Pela primeira vez na literatura, caracterizamos o perfil de expressão dos miRNAS e genes envolvidos na transição epitélio-mesenquimal no CaP localizado. Com base em nossos achados, a Figura 18 ilustra a TEM no CaP de maneira mais sistemática.

A busca dos fenômenos moleculares envolvidos na promoção e progressão da doença nos fez analisar as linhagens de $\mathrm{CaP}$ metastático além do carcinoma localizado órgão-confinado e não órgão-confinado. Com isso pretendemos estudar os passos envolvidos no processo de carcinogênese que estejam relacionados à invasão e disseminação da doença, na tentativa de identificar marcadores prognósticos e 
prováveis alvos para tratamento de alvo molecular. Na Figura 19 estão expostas as principais alterações envolvidas no processo de TEM no CaP encontradas no nosso estudo.

Ainda, a identificação de miRNAs cujos genes alvo têm papel bem estabelecido na TEM e que estão associados com parâmetros clínico-patológicos é um dado promissor. Dessa forma, poderemos especular sobre seus papéis como potenciais marcadores prognósticos. A possibilidade de expandirmos nosso conhecimento sobre a doença através da avaliação desses miRNAs permitirá não só prever o comportamento biológico do $\mathrm{CaP}$, mas também oferecer uma conduta mais precisa e eficaz para casos de evolução incerta. 


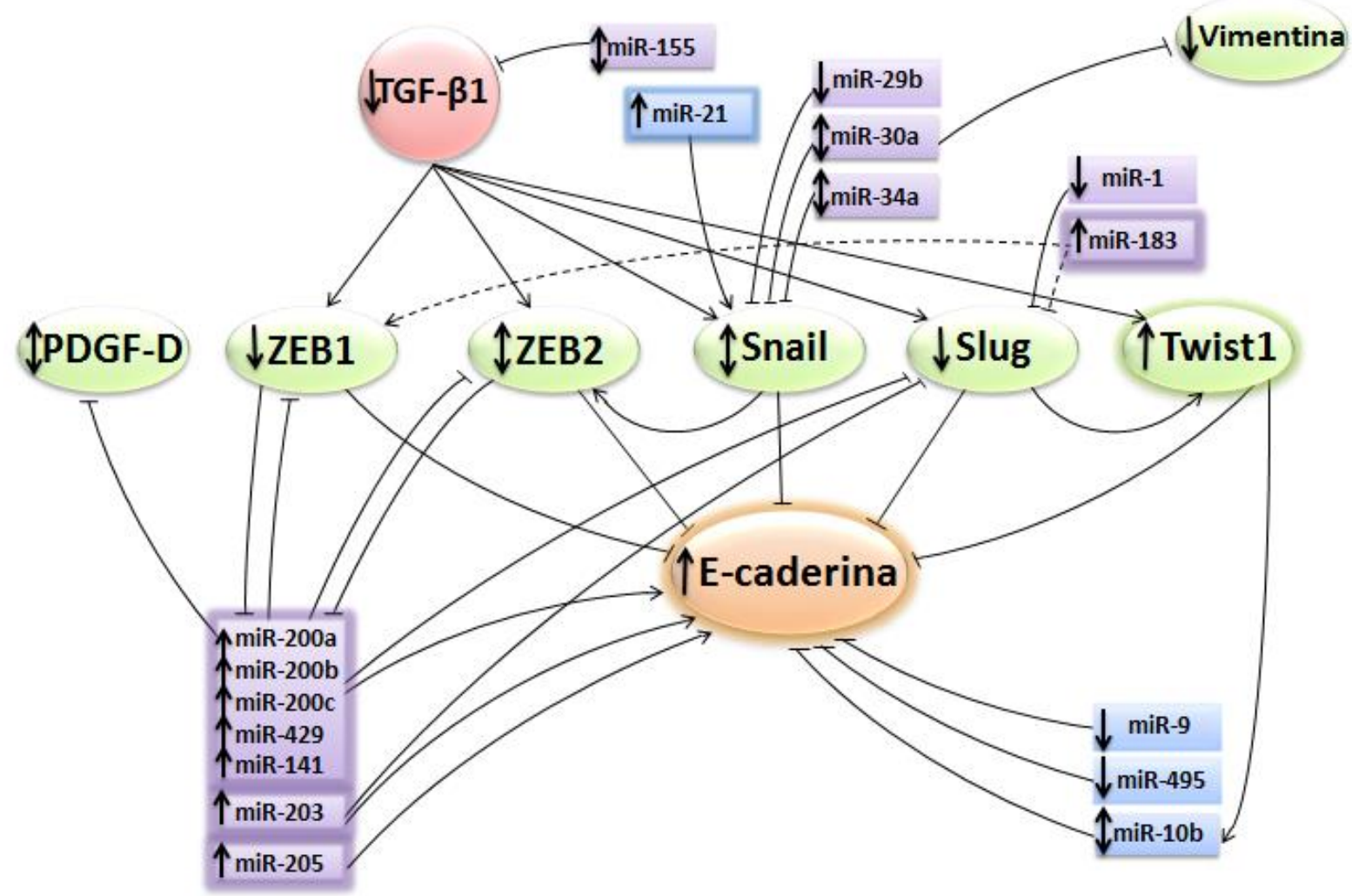

Figura 18. Interpretação dos resultados da expressão dos miRNAs e genes reguladores da transição epitélio-mesenquimal no câncer de próstata localizado. A família do miR-200 e os miRNAs 203 e 205 encontram-se superexpressos e participam da regulação da E-caderina, que também demonstra superexpressão. Em contrapartida, os miRNAs 9 e 495, inibidores da E-caderina, estão subexpressos. Os genes TGF- $\beta 1$ e ZEB1 estão subexpressos, contribuindo para a manutenção do fenótipo epitelial. O gene Twist1 apresenta superexpressão, porém sua ação na transição epitélio-mesenquimal é dependente do Slug, este subexpresso. O Slug é regulado pelo miR-200b, pelo miR-203, pela família do miR-183 e pelo miR-1, estando este, no entanto, subexpresso. Contudo, de acordo com os nossos achados, o miR-183 age como oncogene no câncer de próstata, tornando questionável sua ação sobre o Slug e o ZEB1 nessa neoplasia. Os miRNAs 30a, 34a e 10b têm um perfil de expressão variável. Os demais reguladores do Snail, o miR-21 e o miR-29b, apresentam superexpressão e subexpressão, respectivamente. As setas para cima indicam superexpressão dos miRNAs e genes em questão, enquanto que as setas para baixo indicam subexpressão. As setas de dupla ponta indicam perfil de expressão variável. 


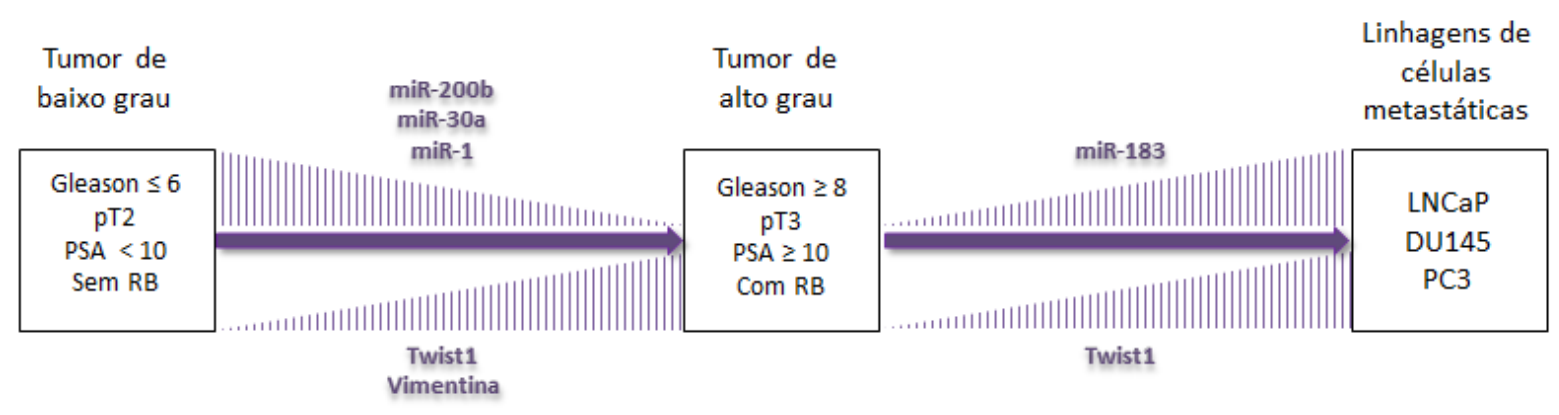

Legenda: $\mathrm{RB}$ = recorrência bioquímica

Figura 19. Principais miRNAs e genes envolvidos na transição epitéliomesenquimal no câncer de próstata. Os miRNAs 200b, 30a e 1 têm seus níveis de expressão diminuídos quando o $\mathrm{CaP}$ evolui para um tumor de alto grau, enquanto os genes Twist1 e Vimentina têm seus níveis aumentados. Na transição para o tumor metastático, observa-se um aumento nos níveis de expressão do miR-183 e do Twist1. 
6. CONCLUSÃO 


\section{CONCLUSÃO}

O CaP localizado mantém o fenótipo epitelial caracterizado pela superexpressão dos miRNAs 200a, 200b, 200c, 429, 141, 205 e 203 e do gene Ecaderina, e pela subexpressão de Vimentina, N-caderina, TGF- $\beta 1$, ZEB1 e Slug. Entre os marcadores mesenquimais, o Twist 1 mostrou-se superexpresso em dois terços dos casos.

O miR-183 e o gene Twist1 têm seus níveis de expressão significativamente aumentados nas linhagens celulares metastáticas quando comparados ao tumor primário em relação ao estadiamento patológico.

Em relação aos parâmetros clínico-patológicos, os miRNAs 200b, 1 e 30a apresentaram associação com estadiamento patológico, e menores níveis se relacionaram com estadiamento mais avançado (pT3). Baixos níveis do miR-200b também apresentaram associação significativa com tumores de alto grau (escore de Gleason $\geq 8$ ) e com menor sobrevida livre de recorrência bioquímica.

Ainda, o miR-30a e os genes Vimentina e Twist1 estão associados com os grupos de risco. Os pacientes pertencentes ao grupo de alto risco apresentaram menores níveis de expressão do miRNA em questão e maiores níveis de expressão de Vimentina e Twist1. 
7. ANEXOS 
Anexo 1. Nível de expressão dos miRNAs e genes nos casos, individualmente em relação às amostras de HPB

\begin{tabular}{|c|c|c|c|c|c|c|c|c|c|c|c|c|c|c|c|c|c|c|c|c|c|c|c|c|c|c|c|c|}
\hline Casos & E-caderina & \begin{tabular}{|l|l|}
$\mathrm{N}$-caderina \\
\end{tabular} & TGFB1 & ZEB1 & ZEB2 & & ail & Slug & Twist & PDGFD & & & & ir29b & mir205 & & & & & & & & & & & & & \\
\hline & & 0,585 & & & & & & & & & & & & & & & & & & & & & & & & & & \\
\hline 432 & & & & & & & & & & & & & & $\overline{88}$ & & & & & & & & & & & & & & \\
\hline 433 & & & & & & & & & & & 2,101 & & & & & & & & & & & & & & & & & \\
\hline 436 & & & & & & & & & & & & & & & & & & & & & & & & & & & & \\
\hline 442 & & & 0,726483 & 1,160704 & & & & & & & & & & & & & & & & & & & & & & & & \\
\hline 443 & & & & 0,37 & & & & 0,025348 & & & & & & & & 599907] & $0,112111]$ & & & 0,474013 & & & & & $|0,780786|$ & & & \\
\hline 444 & & & \begin{tabular}{|l|l|l|l}
0,405564 \\
\end{tabular} & & & & 0,104458 & 0,078672 & \begin{tabular}{|l|l|l|}
0,208194 \\
\end{tabular} & \begin{tabular}{|c|}
0,048496 \\
\end{tabular} & 00 & 0 & 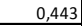 & 0,00 & 1,30 & & & & & $\begin{array}{l}0,050942 \\
\end{array}$ & 0,49107 & & & & 078618 & & & \\
\hline 445 & 4056 & 0,213602 & 0,29078 & 0,412367 & 0,305872 & 0,727995 & 1,282537 & 0,38716 & \begin{tabular}{|l|l|}
19,657739 \\
\end{tabular} & 0,58927 & 3,123 & 3,609 & 0,77 & 0,04 & 3,17 & $5,223439]$ & 1,132884 & 5,441483 & 0,95 & {$[0,074687$} & |0,132862 & 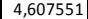 & 0,253139 & 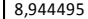 & 336109 & 2533 & |13414 & 7088 \\
\hline 446 & $2, x$ & & & 1,049717 & 332554 & 21311 & & 22374 & 3,140512 & 0,63905 & 4,284 & 15,774 & 3,87 & 0,757 & 11,816 & 5,723906 & 0,514413 & 034772 & 1,465101 & 0,283025 & \begin{tabular}{|l|l|l|l|l|l|} 
\\
\end{tabular} & \begin{tabular}{|l|l|}
6,892369 \\
\end{tabular} & 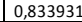 & \begin{tabular}{|l|l}
5,007186 \\
\end{tabular} & 0,414947 & 0,326013 & 13557 & 6,027668 \\
\hline 447 & & 16,73736 & & 1,574616 & 2,869899 & & 0,342933 & 6,096579 & 21,82637 & 1,1111109 & 34,723 & 56,906 & 9 & 1,91 & 20,163 & 0,369335 & $0,029421]$ & 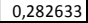 & 0,23229 & 0,163913 & 7567 & \begin{tabular}{|l|l|l|l|l|} 
\\
\end{tabular} & 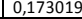 & \begin{tabular}{|l|l|l|l|l|l|} 
\\
\end{tabular} & 0,019038 & & 51227 & 98988 \\
\hline 448 & 0 & & 0,167589 & 0,390664 & \begin{tabular}{|l|l}
0,372936 \\
\end{tabular} & 39003 & 0,166894 & 0,042837 & $0,0,494485 \mid$ & 0,342221 & 0,981 & 1,995 & 0 & 104 & 4,063 & 0,931095 & 0,07505 & & 5,594464 & $0,063372]$ & 0,161209 & & 4204 & & 143687] & 20006 & 5755. & \\
\hline 449 & 3,46054 & $\begin{array}{l}0,51691 \\
\end{array}$ & 5095 & 0,84792 & 0,63905 & & 1,554015 & $0,077267 \mid$ & $0,0,61386$ & $0,603322 \mid$ & 6,524 & 9,63 & 3,90 & 0,47 & 0,327 & 1,880348 & 0,146808 & 0,452817 & $0,629379 \mid$ & 0,522318 & 0,301034 & 5,37774 & \begin{tabular}{|l|l|}
0,176287 \\
\end{tabular} & 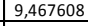 & 0,454074 & 46955 & $0,36500 \varepsilon$ & 370309 \\
\hline 450 & 2,19618 & & 2960 & 1,704088 & 1,344435 & 3047] & & 0,172062 & 0,14772 & 3,617518 & 19,519 & 7,993 & 0,5 & 0,42 & 5,77 & 023706 & 0,51907 & 0,332402 & 0,093428 & 0,481297 & & & 67945 & 0916 & 192 & & & 7539 \\
\hline 480 & & & 7378. & & & 1887 & 11261 & & 0,639493 & 15734 & 3,668 & 16,49 & & 21 & & .097276 & 0,95 & 32923 & 75981. &, 130531 & 65747 & & 49041 & 1,28283 & 23687 & 10644 & 02028 & 96676 \\
\hline 488 & & 0,594192 & 99793 & & 292353 & & 2595 & 02238 & $\frac{6,117745}{6}$ & 0,2283 & 2,642 & 28,492 & 0,55 & 16 & (2) &, 664804 & 136693 & 598955 & 112734 & 99995 & & & 5592 & 432129 & 770953 & 9471 & 0399 & 6733 \\
\hline & & & 35696 & 0,441658 & & & & 6488367] & 5,42 & 1,058484 & 22,956 & 18,772 & 1,201 & 0,036 & 1,302 & .572663 &, 478304 & 782621 & 1,489677 & 0,00065 & 107 & 07708 & 0783 & & 65167] & & 608 & 6696 \\
\hline 490 & 1,2184 & 7089 & 15637 & 31536 & $44^{43}$ & & , 3184419 & 0,838568 & & 1,394744 & 4,31 & 0,551 & & 0 & 0,261 & & 79244 & 29976 &, 259355 & & 8717 & 22274 & & & & 196455 & 401 & 3069 \\
\hline & & & & & 24858 & & 7 7688 & 0,08675 & 0 & & 2,31 & 0,234 & 2,578 & & 10 & & & & & & & & & & 07333 & & & \\
\hline & & & S13535 & 13868 & 10365 & & & 3831 & & 0,820742 & 1,103 & 23,352 & & & & & & & & & & & & & & & & \\
\hline $\begin{array}{ll}4.88 \\
502\end{array}$ & & & & & 18898 & & & 5 & . & & 22,892 & $\frac{35,17}{18,4}$ & & & $\begin{array}{r}5,83 \\
33,65\end{array}$ & & & & 63 & & & & & & & & & \\
\hline & & & 0,0176099 & & 1, 1,35901 & & & 0,51500 & & & & & & & & & & 01 & & & & & & & 33966 & & (242405) & \\
\hline & & & & $\frac{1,5104 / 3}{1,472}$ & 2509 & & & & & & $\frac{2,418}{2,289}$ & $\frac{20,628}{265}$ & & & & & & & & & & & & & & & & \\
\hline & & & 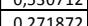 & 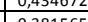 & & & & & & & 26,3 & & & & & & & & & & & & & & & & & \\
\hline 508 & 4,770035 & 3614 [ & \begin{tabular}{|l|l|l|l|l|l|}
0,39998 \\
\end{tabular} & 0,28146 & $\frac{0}{0,700125}$ & & & 0,35 & & & & $\begin{array}{r}4,4 \\
5,38\end{array}$ & 2,64 & & & & & & & & & & & & & & & \\
\hline 509 & & & \begin{tabular}{|l|l|l|l}
0,773 \\
\end{tabular} & & & & & & & 25 & & 44,67 & 0 & & 192,44 & & 0,142497 & & & & & & & & & $\frac{167}{67}$ & 808 [ & \\
\hline & & & & 516426 & 46907 & & & & & & 15,6 & & & & & & & & & & & & & & & & & \\
\hline 514 & & 76834 & 0,814508 & 0,618566 & 1,28076 & & & & & 383 & 31 & & 4 & & & & $0,344601]$ & & & & & & & & & 33968 & & \\
\hline 515 & & & 1, & & 169588 & & & 0 & & 1,604362 & 12,0 & 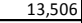 & 3,63 & & & & & & & 207 & & 64467 & & & & 7545 & & \\
\hline 518 & & & 882 & 52991 & 252 & & & & & & 23 & so & 14,24 & & 42,5 & & & & 4,5 & 68 & & \begin{tabular}{|l|}
97,14043 \\
\end{tabular} & & & & & 0846 & 432 \\
\hline 519 & 3,14 & 6389 & 0, & 26022 & 383 & & & & & & $6, x$ & & 1,32 & & & & & & & \begin{tabular}{|l|l}
4,733804 \\
\end{tabular} & 2,236124 & 215 & & & & 1,456999 & & 96753 \\
\hline & & 0,267 & 0,441964 & 0,337 & 262 & & & & & & & 0,04 & 0 & & & & & & & & & & & & & & & \\
\hline & & & & 3,531 & 184 & & & & & & & 11 & & & & & & & & & & & & & & & & \\
\hline (2) & & & & 49427 & 466 & & & & & & & & 年 & & & & & & & & & & & & & & & \\
\hline 524 & & & $1,28=$ & & & & & & & & & & 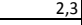 & & & & & & & & & & & & & & & \\
\hline & & & & & & & & & & & & & 7,30 & & & & & & & & & & & & & & & \\
\hline 526 & & & & & & & & & & & & 14,6 & 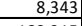 & & & & & & & & & & & & & & & \\
\hline 527 & & & & & & & & & & & & 215, & 18 & & 151 & & & $6,4, \quad-1$ & & & & & & & & & & \\
\hline$\frac{528}{523}$ & & & & & & & & & & & & & & & & & & & & & & & & & & & & \\
\hline$\frac{532}{523}$ & & 0.3434 & 439 & & & & & & & & & & & & & & & & & & & & & & & & & \\
\hline 533 & & $1 \frac{16}{32}$ & & & 10115 & & & & & & & & & & & & & & & & & & & & & & & \\
\hline$\frac{344}{525}$ & & , & 3,224 & $\begin{array}{l}4,030 \\
1507212\end{array}$ & 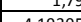 & & & & & & & & & & & & & & & & & & & & & & & \\
\hline \begin{tabular}{|l|l|}
538 \\
\end{tabular} & & 05 & 势, & 174013 & & & & & & & & & & & & & & & & & & & & & & & & \\
\hline \begin{tabular}{|l|}
543 \\
\end{tabular} & & 0.32466 & 44421 & $\frac{124879}{0.2879}$ & 62529 & 8 & & & 203 & 20 & 22 & & & & & & & & & & & & & & & & 82225 & \\
\hline 544 & 2344045 & 92404 & 254 & & 80177 & & 1054 & 0,74 & 110 & 0,595 & 9, & & & 1,0 & 24, & & & 1,3 & 0,60 & & & & & 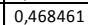 & & & & \\
\hline 549 & 997 & & 24089 & 57461 & & & & 0,15 & & & & 7,6 & & 0 & 7.5 & & & & & & & & & & & & & \\
\hline 554 & 36 & & & 69 & & & & & & & & 0 & 0.6 & & 3,7 & & & & & & & & & & & & & \\
\hline 556 & & 31 & 225305 & 015 & 04379 & $0,343647]$ & 1,615 & 8303| & 6,151763 & 3851 & 0,41 & 0,18 & 0,0 & 0 & 4,95 & 0,035378 & 74842 & 1,001387 & 312 & 4977 & 8,282119 & 1,59992 & $23=$ & 1,958 & 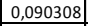 & 2044 & 418 | & \\
\hline 568 & \begin{tabular}{|r|}
3,231043 \\
201813
\end{tabular} & $\begin{array}{c}3 \\
3 \\
3\end{array}$ & \begin{tabular}{|l|l|}
1,468151 \\
10233137
\end{tabular} & $\begin{array}{l}0,51907 \\
102119\end{array}$ & $\begin{array}{l}2,294214 \\
4050210\end{array}$ & $\begin{array}{l}0,468136 \\
0392827\end{array}$ & $\begin{array}{l}0,386355 \\
262659\end{array}$ & 68057| & $\begin{array}{l}5,696201 \\
1,1971744\end{array}$ & $\frac{0,812252}{2025614}$ & $\begin{array}{l}2,737 \\
7599 \\
\end{array}$ & 4342 & $\begin{array}{l}1,188 \\
1284\end{array}$ & & $\begin{array}{l}3,407 \\
3,484\end{array}$ & $\begin{array}{l}3,887924 \\
0,707597\end{array}$ & $\begin{array}{l}0,092142 \\
0325561\end{array}$ & \begin{tabular}{|c|}
0,859161 \\
404053
\end{tabular} & $\begin{array}{l}0,142102 \\
0,005352\end{array}$ & $\begin{array}{l}0,021285 \\
0\end{array}$ & \begin{tabular}{|l|l}
0,43077 \\
\end{tabular} & $\frac{196,7}{25512}$ & 629019 & \begin{tabular}{|l|l|}
, 306765 \\
0104205
\end{tabular} & 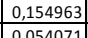 & & 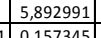 & $\begin{array}{l}0,035 \\
0,05\end{array}$ \\
\hline
\end{tabular}


Anexo 2. Nível de expressão dos miRNAs nos tumores pT3 e nas células em relação aos tumores pT2

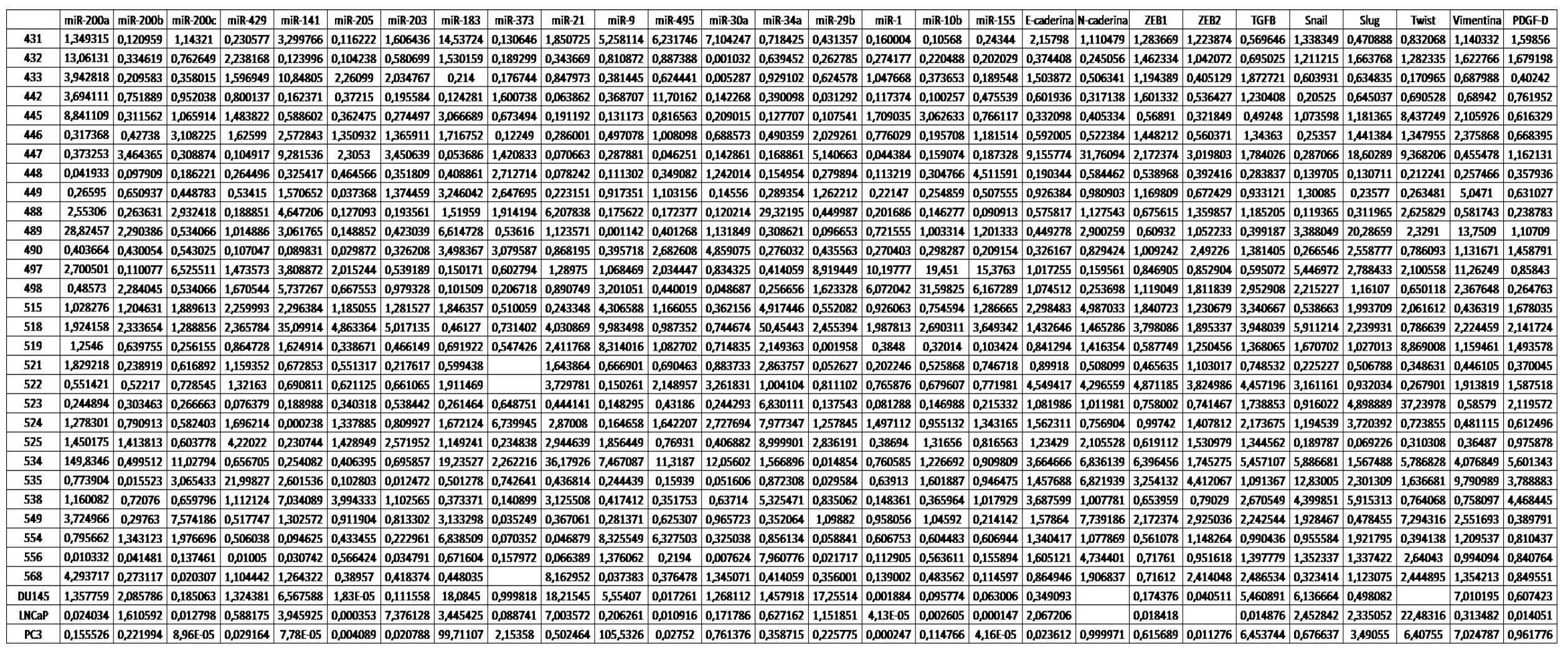


8. REFER $\hat{E} N C I A S$ 
1. Siegel R, Naishadham D, Jemal A. Cancer statistics, 2013. CA: a cancer journal for clinicians. 2013 Jan;63(1):11-30.

2. Reddy S, Shapiro M, Morton R, Jr., Brawley OW. Prostate cancer in black and white Americans. Cancer metastasis reviews. 2003 Mar;22(1):83-6.

3. Quinn M, Babb P. Patterns and trends in prostate cancer incidence, survival, prevalence and mortality. Part I: international comparisons. BJU international. 2002 Jul;90(2):162-73.

4. Candas B, Cusan L, Gomez JL, Diamond P, Suburu RE, Levesque J, et al. Evaluation of prostatic specific antigen and digital rectal examination as screening tests for prostate cancer. The Prostate. 2000 Sep 15;45(1):19-35.

5. Ross KS, Carter HB, Pearson JD, Guess HA. Comparative efficiency of prostatespecific antigen screening strategies for prostate cancer detection. JAMA : the journal of the American Medical Association. 2000 Sep 20;284(11):1399-405.

6. Siegel R, Naishadham D, Jemal A. Cancer statistics, 2012. CA: a cancer journal for clinicians. 2012 Jan-Feb;62(1):10-29.

7. Gleason DF. Histologic grading of prostate cancer: a perspective. Human pathology. 1992 Mar;23(3):273-9.

8. Epstein JI, Allsbrook WC, Jr., Amin MB, Egevad LL, Committee IG. The 2005 International Society of Urological Pathology (ISUP) Consensus Conference on Gleason Grading of Prostatic Carcinoma. The American journal of surgical pathology. 2005 Sep;29(9):1228-42.

9. D'Amico AV, Whittington R, Malkowicz SB, Schultz D, Blank K, Broderick GA, et al. Biochemical outcome after radical prostatectomy, external beam radiation therapy, or interstitial radiation therapy for clinically localized prostate cancer. JAMA : the journal of the American Medical Association. 1998 Sep 16;280(11):969-74.

10. Bastian PJ, Mangold LA, Epstein JI, Partin AW. Characteristics of insignificant clinical T1c prostate tumors. A contemporary analysis. Cancer. 2004 Nov 1;101(9):2001-5.

11. Brawer MK, Stamey TA, Fowler J, Droller M, Messing E, Fair WR. Perspectives on prostate cancer diagnosis and treatment: a roundtable. Urology. 2001 Aug;58(2):135-40.

12. Sharifi N, Gulley JL, Dahut WL. Androgen deprivation therapy for prostate cancer. JAMA : the journal of the American Medical Association. 2005 Jul 13;294(2):238-44.

13. Huggins C, Hodges CV. Studies on prostatic cancer: I. The effect of castration, of estrogen and of androgen injection on serum phosphatases in metastatic carcinoma of the prostate. 1941. The Journal of urology. 2002 Jul;168(1):9-12.

14. Beltran H, Beer TM, Carducci MA, de Bono J, Gleave M, Hussain M, et al. New therapies for castration-resistant prostate cancer: efficacy and safety. European urology. 2011 Aug;60(2):279-90.

15. Chi KN, Bjartell A, Dearnaley D, Saad F, Schroder FH, Sternberg C, et al. Castration-resistant prostate cancer: from new pathophysiology to new treatment targets. European urology. 2009 Oct;56(4):594-605.

16. Saylor PJ, Smith MR. Metabolic complications of androgen deprivation therapy for prostate cancer. The Journal of urology. 2009 May;181(5):1998-2006; discussion 7-8.

17. Keating NL, O'Malley AJ, Freedland SJ, Smith MR. Diabetes and cardiovascular disease during androgen deprivation therapy: observational study of veterans with prostate cancer. Journal of the National Cancer Institute. 2010 Jan 6;102(1):39-46.

18. Alibhai SM, Duong-Hua M, Sutradhar R, Fleshner NE, Warde P, Cheung AM, et al. Impact of androgen deprivation therapy on cardiovascular disease and diabetes. Journal of clinical oncology : official journal of the American Society of Clinical Oncology. 2009 Jul 20;27(21):3452-8.

19. Schubert M, Joniau S, Gontero P, Kneitz S, Scholz CJ, Kneitz B, et al. The role of adjuvant hormonal treatment after surgery for localized high-risk prostate cancer: results of a matched multiinstitutional analysis. Advances in urology. 2012;2012:612707. 
20. Dorff TB, Flaig TW, Tangen CM, Hussain MH, Swanson GP, Wood DP, Jr., et al. Adjuvant androgen deprivation for high-risk prostate cancer after radical prostatectomy: SWOG S9921 study. Journal of clinical oncology : official journal of the American Society of Clinical Oncology. 2011 May 20;29(15):2040-5.

21. McVey GP, McPhail S, Fowler S, McIntosh G, Gillatt D, Parker CC. Initial management of low-risk localized prostate cancer in the UK: analysis of the British Association of Urological Surgeons Cancer Registry. BJU international. 2010 Oct;106(8):1161-4.

22. Klotz L, Zhang L, Lam A, Nam R, Mamedov A, Loblaw A. Clinical results of longterm follow-up of a large, active surveillance cohort with localized prostate cancer. Journal of clinical oncology : official journal of the American Society of Clinical Oncology. 2010 Jan 1;28(1):126-31.

23. Porten SP, Whitson JM, Cowan JE, Cooperberg MR, Shinohara K, Perez N, et al. Changes in prostate cancer grade on serial biopsy in men undergoing active surveillance. Journal of clinical oncology : official journal of the American Society of Clinical Oncology. 2011 Jul 10;29(20):2795-800.

24. Xu J, Neale AV, Dailey RK, Eggly S, Schwartz KL. Patient perspective on watchful waiting/active surveillance for localized prostate cancer. Journal of the American Board of Family Medicine : JABFM. 2012 Nov-Dec;25(6):763-70.

25. Loeb S, Bjurlin MA, Nicholson J, Tammela TL, Penson DF, Carter HB, et al. Overdiagnosis and Overtreatment of Prostate Cancer. European urology. 2014 Jan 9.

26. Kalluri R, Weinberg RA. The basics of epithelial-mesenchymal transition. The Journal of clinical investigation. 2009 Jun;119(6):1420-8.

27. Greenburg G, Hay ED. Epithelia suspended in collagen gels can lose polarity and express characteristics of migrating mesenchymal cells. The Journal of cell biology. 1982 Oct;95(1):333-9.

28. Lee JM, Dedhar S, Kalluri R, Thompson EW. The epithelial-mesenchymal transition: new insights in signaling, development, and disease. The Journal of cell biology. 2006 Mar 27;172(7):973-81.

29. Zeisberg M, Neilson EG. Biomarkers for epithelial-mesenchymal transitions. The Journal of clinical investigation. 2009 Jun;119(6):1429-37.

30. Bracken CP, Gregory PA, Khew-Goodall Y, Goodall GJ. The role of microRNAs in metastasis and epithelial-mesenchymal transition. Cellular and molecular life sciences : CMLS. 2009 May;66(10):1682-99.

31. Zeisberg EM, Potenta SE, Sugimoto H, Zeisberg M, Kalluri R. Fibroblasts in kidney fibrosis emerge via endothelial-to-mesenchymal transition. Journal of the American Society of Nephrology : JASN. 2008 Dec;19(12):2282-7.

32. Sarrio D, Rodriguez-Pinilla SM, Hardisson D, Cano A, Moreno-Bueno G, Palacios J. Epithelial-mesenchymal transition in breast cancer relates to the basal-like phenotype. Cancer research. 2008 Feb 15;68(4):989-97.

33. Chaffer CL, Weinberg RA. A perspective on cancer cell metastasis. Science. 2011 Mar 25;331(6024):1559-64.

34. Brabletz S, Brabletz T. The ZEB/miR-200 feedback loop--a motor of cellular plasticity in development and cancer? EMBO reports. 2010 Sep;11(9):670-7.

35. Jung A, Brabletz $\mathrm{T}$, Kirchner $\mathrm{T}$. The migrating cancer stem cells model--a conceptual explanation of malignant tumour progression. Ernst Schering Foundation symposium proceedings. 2006 (5):109-24.

36. Friedl P, Alexander S. Cancer invasion and the microenvironment: plasticity and reciprocity. Cell. 2011 Nov 23;147(5):992-1009.

37. Moreno-Bueno G, Portillo F, Cano A. Transcriptional regulation of cell polarity in EMT and cancer. Oncogene. 2008 Nov 24;27(55):6958-69.

38. Huber MA, Kraut N, Beug H. Molecular requirements for epithelial-mesenchymal transition during tumor progression. Current opinion in cell biology. 2005 Oct;17(5):548-58. 
39. Halbleib JM, Nelson WJ. Cadherins in development: cell adhesion, sorting, and tissue morphogenesis. Genes \& development. 2006 Dec 1;20(23):3199-214.

40. Wiemer EA. The role of microRNAs in cancer: no small matter. Eur J Cancer. 2007 Jul;43(10):1529-44.

41. Nauseef JT, Henry MD. Epithelial-to-mesenchymal transition in prostate cancer: paradigm or puzzle? Nature reviews Urology. 2011 Aug;8(8):428-39.

42. Siegel PM, Massague J. Cytostatic and apoptotic actions of TGF-beta in homeostasis and cancer. Nature reviews Cancer. 2003 Nov;3(11):807-21.

43. Cano A, Perez-Moreno MA, Rodrigo I, Locascio A, Blanco MJ, del Barrio MG, et al. The transcription factor snail controls epithelial-mesenchymal transitions by repressing Ecadherin expression. Nature cell biology. 2000 Feb;2(2):76-83.

44. Batlle E, Sancho E, Franci C, Dominguez D, Monfar M, Baulida J, et al. The transcription factor snail is a repressor of E-cadherin gene expression in epithelial tumour cells. Nature cell biology. 2000 Feb;2(2):84-9.

45. Moreno-Bueno G, Cubillo E, Sarrio D, Peinado H, Rodriguez-Pinilla SM, Villa S, et al. Genetic profiling of epithelial cells expressing E-cadherin repressors reveals a distinct role for Snail, Slug, and E47 factors in epithelial-mesenchymal transition. Cancer research. 2006 Oct 1;66(19):9543-56.

46. Tomita K, van Bokhoven A, van Leenders GJ, Ruijter ET, Jansen CF, Bussemakers $\mathrm{MJ}$, et al. Cadherin switching in human prostate cancer progression. Cancer research. 2000 Jul 1;60(13):3650-4.

47. Alexander NR, Tran NL, Rekapally H, Summers CE, Glackin C, Heimark RL. Ncadherin gene expression in prostate carcinoma is modulated by integrin-dependent nuclear translocation of Twist1. Cancer research. 2006 Apr 1;66(7):3365-9.

48. Putzke AP, Ventura AP, Bailey AM, Akture C, Opoku-Ansah J, Celiktas M, et al. Metastatic progression of prostate cancer and e-cadherin regulation by zeb1 and SRC family kinases. The American journal of pathology. 2011 Jul;179(1):400-10.

49. Pontes J, Jr., Srougi M, Borra PM, Dall' Oglio MF, Ribeiro-Filho LA, Leite KR. Ecadherin and beta-catenin loss of expression related to bone metastasis in prostate cancer. Applied immunohistochemistry \& molecular morphology : AIMM / official publication of the Society for Applied Immunohistochemistry. 2010 Mar;18(2):179-84.

50. Graham TR, Zhau HE, Odero-Marah VA, Osunkoya AO, Kimbro KS, Tighiouart M, et al. Insulin-like growth factor-I-dependent up-regulation of ZEB1 drives epithelial-tomesenchymal transition in human prostate cancer cells. Cancer research. 2008 Apr 1;68(7):2479-88.

51. Kong D, Wang Z, Sarkar SH, Li Y, Banerjee S, Saliganan A, et al. Platelet-derived growth factor-D overexpression contributes to epithelial-mesenchymal transition of PC3 prostate cancer cells. Stem Cells. 2008 Jun;26(6):1425-35.

52. Zhang Q, Helfand BT, Jang TL, Zhu LJ, Chen L, Yang XJ, et al. Nuclear factorkappaB-mediated transforming growth factor-beta-induced expression of vimentin is an independent predictor of biochemical recurrence after radical prostatectomy. Clinical cancer research : an official journal of the American Association for Cancer Research. 2009 May 15;15(10):3557-67.

53. Vandewalle C, Van Roy F, Berx G. The role of the ZEB family of transcription factors in development and disease. Cellular and molecular life sciences : CMLS. 2009 Mar;66(5):773-87.

54. Comijn J, Berx G, Vermassen P, Verschueren K, van Grunsven L, Bruyneel E, et al. The two-handed E box binding zinc finger protein SIP1 downregulates E-cadherin and induces invasion. Molecular cell. 2001 Jun;7(6):1267-78.

55. Beach S, Tang H, Park S, Dhillon AS, Keller ET, Kolch W, et al. Snail is a repressor of RKIP transcription in metastatic prostate cancer cells. Oncogene. 2008 Apr 3;27(15):2243-8. 
56. Bartel DP. MicroRNAs: genomics, biogenesis, mechanism, and function. Cell. 2004 Jan 23;116(2):281-97.

57. Kim VN. MicroRNA biogenesis: coordinated cropping and dicing. Nature reviews Molecular cell biology. 2005 May;6(5):376-85.

58. Calin GA, Dumitru CD, Shimizu M, Bichi R, Zupo S, Noch E, et al. Frequent deletions and down-regulation of micro- RNA genes miR15 and miR16 at 13q14 in chronic lymphocytic leukemia. Proceedings of the National Academy of Sciences of the United States of America. 2002 Nov 26;99(24):15524-9.

59. Lu J, Getz G, Miska EA, Alvarez-Saavedra E, Lamb J, Peck D, et al. MicroRNA expression profiles classify human cancers. Nature. 2005 Jun 9;435(7043):834-8.

60. Volinia S, Calin GA, Liu CG, Ambs S, Cimmino A, Petrocca F, et al. A microRNA expression signature of human solid tumors defines cancer gene targets. Proceedings of the National Academy of Sciences of the United States of America. 2006 Feb 14;103(7):225761.

61. Mattie MD, Benz CC, Bowers J, Sensinger K, Wong L, Scott GK, et al. Optimized high-throughput microRNA expression profiling provides novel biomarker assessment of clinical prostate and breast cancer biopsies. Molecular cancer. 2006;5:24.

62. Porkka KP, Pfeiffer MJ, Waltering KK, Vessella RL, Tammela TL, Visakorpi T. MicroRNA expression profiling in prostate cancer. Cancer research. 2007 Jul 1;67(13):61305.

63. Shi XB, Xue L, Ma AH, Tepper CG, Kung HJ, White RW. miR-125b promotes growth of prostate cancer xenograft tumor through targeting pro-apoptotic genes. The Prostate. 2011 Apr;71(5):538-49.

64. Ambs S, Prueitt RL, Yi M, Hudson RS, Howe TM, Petrocca F, et al. Genomic profiling of microRNA and messenger RNA reveals deregulated microRNA expression in prostate cancer. Cancer research. 2008 Aug 1;68(15):6162-70.

65. Bonci D, Coppola V, Musumeci M, Addario A, Giuffrida R, Memeo L, et al. The miR-15a-miR-16-1 cluster controls prostate cancer by targeting multiple oncogenic activities. Nature medicine. 2008 Nov;14(11):1271-7.

66. Peng X, Guo W, Liu T, Wang X, Tu X, Xiong D, et al. Identification of miRs-143 and -145 that is associated with bone metastasis of prostate cancer and involved in the regulation of EMT. PloS one. 2011;6(5):e20341.

67. Sun T, Wang Q, Balk S, Brown M, Lee GS, Kantoff P. The role of microRNA-221 and microRNA-222 in androgen-independent prostate cancer cell lines. Cancer research. 2009 Apr 15;69(8):3356-63.

68. Li T, Li D, Sha J, Sun P, Huang Y. MicroRNA-21 directly targets MARCKS and promotes apoptosis resistance and invasion in prostate cancer cells. Biochemical and biophysical research communications. 2009 Jun 5;383(3):280-5.

69. Ribas J, Ni X, Haffner M, Wentzel EA, Salmasi AH, Chowdhury WH, et al. miR-21: an androgen receptor-regulated microRNA that promotes hormone-dependent and hormoneindependent prostate cancer growth. Cancer research. 2009 Sep 15;69(18):7165-9.

70. Reis ST, Pontes-Junior J, Antunes AA, Dall'Oglio MF, Dip N, Passerotti CC, et al. miR-21 may acts as an oncomir by targeting RECK, a matrix metalloproteinase regulator, in prostate cancer. BMC urology. 2012;12:14.

71. Leite KR, Sousa-Canavez JM, Reis ST, Tomiyama AH, Camara-Lopes LH, Sanudo A, et al. Change in expression of miR-let7c, miR-100, and miR-218 from high grade localized prostate cancer to metastasis. Urologic oncology. 2011 May-Jun;29(3):265-9.

72. Korpal M, Kang Y. The emerging role of miR-200 family of microRNAs in epithelial-mesenchymal transition and cancer metastasis. RNA biology. 2008 JulSep;5(3):115-9.

73. Korpal M, Lee ES, Hu G, Kang Y. The miR-200 family inhibits epithelialmesenchymal transition and cancer cell migration by direct targeting of E-cadherin 
transcriptional repressors ZEB1 and ZEB2. The Journal of biological chemistry. 2008 May 30;283(22):14910-4.

74. Gregory PA, Bert AG, Paterson EL, Barry SC, Tsykin A, Farshid G, et al. The miR200 family and miR-205 regulate epithelial to mesenchymal transition by targeting ZEB1 and SIP1. Nature cell biology. 2008 May;10(5):593-601.

75. Bendoraite A, Knouf EC, Garg KS, Parkin RK, Kroh EM, O'Briant KC, et al. Regulation of miR-200 family microRNAs and ZEB transcription factors in ovarian cancer: evidence supporting a mesothelial-to-epithelial transition. Gynecologic oncology. 2010 Jan;116(1):117-25.

76. Chang CJ, Chao $\mathrm{CH}$, Xia W, Yang JY, Xiong Y, Li CW, et al. p53 regulates epithelial-mesenchymal transition and stem cell properties through modulating miRNAs. Nature cell biology. 2011 Mar;13(3):317-23.

77. Bracken CP, Gregory PA, Kolesnikoff N, Bert AG, Wang J, Shannon MF, et al. A double-negative feedback loop between ZEB1-SIP1 and the microRNA-200 family regulates epithelial-mesenchymal transition. Cancer research. 2008 Oct 1;68(19):7846-54.

78. Vega S, Morales AV, Ocana OH, Valdes F, Fabregat I, Nieto MA. Snail blocks the cell cycle and confers resistance to cell death. Genes \& development. 2004 May 15;18(10):1131-43.

79. Mejlvang J, Kriajevska M, Vandewalle C, Chernova T, Sayan AE, Berx G, et al. Direct repression of cyclin D1 by SIP1 attenuates cell cycle progression in cells undergoing an epithelial mesenchymal transition. Molecular biology of the cell. 2007 Nov;18(11):461524.

80. Jung A, Schrauder M, Oswald U, Knoll C, Sellberg P, Palmqvist R, et al. The invasion front of human colorectal adenocarcinomas shows co-localization of nuclear betacatenin, cyclin D1, and p16INK4A and is a region of low proliferation. The American journal of pathology. $2001 \mathrm{Nov} ; 159(5): 1613-7$.

81. Burstyn-Cohen T, Kalcheim C. Association between the cell cycle and neural crest delamination through specific regulation of G1/S transition. Developmental cell. 2002 Sep;3(3):383-95.

82. Gregory PA, Bracken CP, Bert AG, Goodall GJ. MicroRNAs as regulators of epithelial-mesenchymal transition. Cell Cycle. 2008 Oct;7(20):3112-8.

83. Ustach CV, Kim HR. Platelet-derived growth factor D is activated by urokinase plasminogen activator in prostate carcinoma cells. Molecular and cellular biology. 2005 Jul;25(14):6279-88.

84. Ru P, Steele R, Newhall P, Phillips NJ, Toth K, Ray RB. miRNA-29b suppresses prostate cancer metastasis by regulating epithelial-mesenchymal transition signaling. Molecular cancer therapeutics. 2012 May;11(5):1166-73.

85. Zhang J, Zhang H, Liu J, Tu X, Zang Y, Zhu J, et al. miR-30 inhibits TGF-beta1induced epithelial-to-mesenchymal transition in hepatocyte by targeting Snaill. Biochemical and biophysical research communications. 2012 Jan 20;417(3):1100-5.

86. Siemens H, Jackstadt R, Hunten S, Kaller M, Menssen A, Gotz U, et al. miR-34 and SNAIL form a double-negative feedback loop to regulate epithelial-mesenchymal transitions. Cell cycle. 2011 Dec 15;10(24):4256-71.

87. Liu YN, Yin JJ, Abou-Kheir W, Hynes PG, Casey OM, Fang L, et al. MiR-1 and miR-200 inhibit EMT via Slug-dependent and tumorigenesis via Slug-independent mechanisms. Oncogene. 2013 Jan 17;32(3):296-306.

88. Ma L, Young J, Prabhala H, Pan E, Mestdagh P, Muth D, et al. miR-9, a MYC/MYCN-activated microRNA, regulates E-cadherin and cancer metastasis. Nature cell biology. 2010 Mar;12(3):247-56.

89. Livak KJ, Schmittgen TD. Analysis of relative gene expression data using real-time quantitative PCR and the 2(-Delta Delta C(T)) Method. Methods. 2001 Dec;25(4):402-8.

90. Li A, Omura N, Hong SM, Vincent A, Walter K, Griffith M, et al. Pancreatic cancers epigenetically silence SIP1 and hypomethylate and overexpress miR-200a/200b in 
association with elevated circulating miR-200a and miR-200b levels. Cancer research. 2010 Jul 1;70(13):5226-37.

91. Yang H, Kong W, He L, Zhao JJ, O'Donnell JD, Wang J, et al. MicroRNA expression profiling in human ovarian cancer: miR-214 induces cell survival and cisplatin resistance by targeting PTEN. Cancer research. 2008 Jan 15;68(2):425-33.

92. Hiroki E, Akahira J, Suzuki F, Nagase S, Ito K, Suzuki T, et al. Changes in microRNA expression levels correlate with clinicopathological features and prognoses in endometrial serous adenocarcinomas. Cancer science. 2010 Jan;101(1):241-9.

93. Meng F, Henson R, Lang M, Wehbe H, Maheshwari S, Mendell JT, et al. Involvement of human micro-RNA in growth and response to chemotherapy in human cholangiocarcinoma cell lines. Gastroenterology. 2006 Jun;130(7):2113-29.

94. Ladeiro Y, Couchy G, Balabaud C, Bioulac-Sage P, Pelletier L, Rebouissou S, et al. MicroRNA profiling in hepatocellular tumors is associated with clinical features and oncogene/tumor suppressor gene mutations. Hepatology. 2008 Jun;47(6):1955-63.

95. Du Y, Xu Y, Ding L, Yao H, Yu H, Zhou T, et al. Down-regulation of miR-141 in gastric cancer and its involvement in cell growth. Journal of gastroenterology. 2009;44(6):556-61.

96. Nakada C, Matsuura K, Tsukamoto Y, Tanigawa M, Yoshimoto T, Narimatsu T, et al. Genome-wide microRNA expression profiling in renal cell carcinoma: significant downregulation of miR-141 and miR-200c. The Journal of pathology. 2008 Dec;216(4):418-27.

97. Beltran M, Puig I, Pena C, Garcia JM, Alvarez AB, Pena R, et al. A natural antisense transcript regulates Zeb2/Sip1 gene expression during Snail1-induced epithelialmesenchymal transition. Genes \& development. 2008 Mar 15;22(6):756-69.

98. Chen J, Wang L, Matyunina LV, Hill CG, McDonald JF. Overexpression of miR429 induces mesenchymal-to-epithelial transition (MET) in metastatic ovarian cancer cells. Gynecologic oncology. 2011 Apr;121(1):200-5.

99. Kurashige J, Kamohara H, Watanabe M, Hiyoshi Y, Iwatsuki M, Tanaka Y, et al. MicroRNA-200b regulates cell proliferation, invasion, and migration by directly targeting ZEB2 in gastric carcinoma. Ann Surg Oncol. 2012 Jul;19 Suppl 3:S656-64.

100. Postigo AA. Opposing functions of ZEB proteins in the regulation of the TGFbeta/BMP signaling pathway. The EMBO journal. 2003 May 15;22(10):2443-52.

101. Reinhold WC, Reimers MA, Lorenzi P, Ho J, Shankavaram UT, Ziegler MS, et al. Multifactorial regulation of E-cadherin expression: an integrative study. Molecular cancer therapeutics. 2010 Jan;9(1):1-16.

102. Kong D, Li Y, Wang Z, Banerjee S, Ahmad A, Kim HR, et al. miR-200 regulates PDGF-D-mediated epithelial-mesenchymal transition, adhesion, and invasion of prostate cancer cells. Stem Cells. 2009 Aug;27(8):1712-21.

103. Kent OA, Mullendore M, Wentzel EA, Lopez-Romero P, Tan AC, Alvarez H, et al. A resource for analysis of microRNA expression and function in pancreatic ductal adenocarcinoma cells. Cancer biology \& therapy. 2009 Nov;8(21):2013-24.

104. Gravgaard KH, Lyng MB, Laenkholm AV, Sokilde R, Nielsen BS, Litman T, et al. The miRNA-200 family and miRNA-9 exhibit differential expression in primary versus corresponding metastatic tissue in breast cancer. Breast cancer research and treatment. 2012 Jul;134(1):207-17.

105. Dykxhoorn DM, Wu Y, Xie H, Yu F, Lal A, Petrocca F, et al. miR-200 enhances mouse breast cancer cell colonization to form distant metastases. PloS one. 2009;4(9):e7181.

106. Korpal M, Ell BJ, Buffa FM, Ibrahim T, Blanco MA, Celia-Terrassa T, et al. Direct targeting of Sec23a by miR-200s influences cancer cell secretome and promotes metastatic colonization. Nature medicine. $2011 \mathrm{Sep} ; 17(9): 1101-8$.

107. Szczyrba J, Nolte E, Wach S, Kremmer E, Stohr R, Hartmann A, et al. Downregulation of Sec23A protein by miRNA-375 in prostate carcinoma. Molecular cancer research : MCR. 2011 Jun;9(6):791-800. 
108. Dai Y, Xia W, Song T, Su X, Li J, Li S, et al. MicroRNA-200b Is Overexpressed in Endometrial Adenocarcinomas and Enhances MMP2 Activity by Downregulating TIMP2 in Human Endometrial Cancer Cell Line HEC-1A Cells. Nucleic Acid Ther. 2013 Feb;23(1):29-34.

109. Reis ST, Antunes AA, Pontes J, Jr., de Sousa-Canavez JM, Dall'Oglio MF, Piantino $\mathrm{CB}$, et al. Underexpression of MMP-2 and its regulators, TIMP2, MT1-MMP and IL-8, is associated with prostate cancer. International braz $\mathrm{j}$ urol : official journal of the Brazilian Society of Urology. 2012 Mar-Apr;38(2):167-74.

110. Wellner U, Schubert J, Burk UC, Schmalhofer O, Zhu F, Sonntag A, et al. The EMT-activator ZEB1 promotes tumorigenicity by repressing stemness-inhibiting microRNAs. Nature cell biology. 2009 Dec;11(12):1487-95.

111. Saini S, Majid S, Yamamura S, Tabatabai L, Suh SO, Shahryari V, et al. Regulatory Role of mir-203 in Prostate Cancer Progression and Metastasis. Clinical cancer research : an official journal of the American Association for Cancer Research. 2011 Aug 15;17(16):5287-98.

112. Gandellini P, Folini M, Longoni N, Pennati M, Binda M, Colecchia M, et al. miR205 Exerts tumor-suppressive functions in human prostate through down-regulation of protein kinase Cepsilon. Cancer research. 2009 Mar 15;69(6):2287-95.

113. Viticchie G, Lena AM, Latina A, Formosa A, Gregersen LH, Lund AH, et al. MiR203 controls proliferation, migration and invasive potential of prostate cancer cell lines. Cell cycle. 2011 Apr 1;10(7):1121-31.

114. Schaefer A, Jung M, Mollenkopf HJ, Wagner I, Stephan C, Jentzmik F, et al. Diagnostic and prognostic implications of microRNA profiling in prostate carcinoma. International journal of cancer Journal international du cancer. 2010 Mar 1;126(5):1166-76.

115. Walter BA, Valera VA, Pinto PA, Merino MJ. Comprehensive microRNA Profiling of Prostate Cancer. Journal of Cancer. 2013;4(5):350-7.

116. Majid S, Dar AA, Saini S, Yamamura S, Hirata H, Tanaka Y, et al. MicroRNA-205directed transcriptional activation of tumor suppressor genes in prostate cancer. Cancer. 2010 Dec 15;116(24):5637-49.

117. Tucci P, Agostini M, Grespi F, Markert EK, Terrinoni A, Vousden KH, et al. Loss of p63 and its microRNA-205 target results in enhanced cell migration and metastasis in prostate cancer. Proceedings of the National Academy of Sciences of the United States of America. 2012 Sep 18;109(38):15312-7.

118. Aziz MH, Manoharan HT, Church DR, Dreckschmidt NE, Zhong W, Oberley TD, et al. Protein kinase Cepsilon interacts with signal transducers and activators of transcription 3 (Stat3), phosphorylates Stat3Ser727, and regulates its constitutive activation in prostate cancer. Cancer research. 2007 Sep 15;67(18):8828-38.

119. Park SM, Gaur AB, Lengyel E, Peter ME. The miR-200 family determines the epithelial phenotype of cancer cells by targeting the E-cadherin repressors ZEB1 and ZEB2. Genes \& development. 2008 Apr 1;22(7):894-907.

120. Casas E, Kim J, Bendesky A, Ohno-Machado L, Wolfe CJ, Yang J. Snail2 is an essential mediator of Twist1-induced epithelial mesenchymal transition and metastasis. Cancer research. 2011 Jan 1;71(1):245-54.

121. Lapointe J, Li C, Higgins JP, van de Rijn M, Bair E, Montgomery K, et al. Gene expression profiling identifies clinically relevant subtypes of prostate cancer. Proceedings of the National Academy of Sciences of the United States of America. 2004 Jan 20;101(3):8116.

122. Luo JH, Yu YP, Cieply K, Lin F, Deflavia P, Dhir R, et al. Gene expression analysis of prostate cancers. Molecular carcinogenesis. 2002 Jan;33(1):25-35.

123. Siva AC, Nelson LJ, Fleischer CL, Majlessi M, Becker MM, Vessella RL, et al. Molecular assays for the detection of microRNAs in prostate cancer. Molecular cancer. 2009;8:17. 
124. Tsuchiyama K, Ito $\mathrm{H}$, Taga M, Naganuma S, Oshinoya $\mathrm{Y}$, Nagano $\mathrm{K}$, et al. Expression of microRNAs associated with Gleason grading system in prostate cancer: miR182-5p is a useful marker for high grade prostate cancer. The Prostate. 2013 Jun;73(8):82734.

125. Ueno K, Hirata H, Shahryari V, Deng G, Tanaka Y, Tabatabai ZL, et al. microRNA183 is an oncogene targeting Dkk-3 and SMAD4 in prostate cancer. British journal of cancer. 2013 Apr 30;108(8):1659-67.

126. Mihelich BL, Khramtsova EA, Arva N, Vaishnav A, Johnson DN, Giangreco AA, et al. miR-183-96-182 cluster is overexpressed in prostate tissue and regulates zinc homeostasis in prostate cells. The Journal of biological chemistry. 2011 Dec 30;286(52):44503-11.

127. Li XL, Hara T, Choi Y, Subramanian M, Francis P, Bilke S, et al. A p21-ZEB1 complex inhibits epithelial-mesenchymal transition through the microRNA 183-96-182 cluster. Molecular and cellular biology. 2014 Feb;34(3):533-50.

128. Christofori G. New signals from the invasive front. Nature. 2006 May 25;441(7092):444-50.

129. Steele R, Mott JL, Ray RB. MBP-1 upregulates miR-29b that represses Mcl-1, collagens, and matrix-metalloproteinase-2 in prostate cancer cells. Genes \& cancer. 2010 Apr 1;1(4):381-7.

130. Navon R, Wang H, Steinfeld I, Tsalenko A, Ben-Dor A, Yakhini Z. Novel rankbased statistical methods reveal microRNAs with differential expression in multiple cancer types. PloS one. 2009;4(11):e8003.

131. Galasso M, Sandhu SK, Volinia S. MicroRNA expression signatures in solid malignancies. Cancer journal. 2012 May-Jun;18(3):238-43.

132. Hudson RS, Yi M, Esposito D, Watkins SK, Hurwitz AA, Yfantis HG, et al. MicroRNA-1 is a candidate tumor suppressor and prognostic marker in human prostate cancer. Nucleic acids research. 2012 Apr;40(8):3689-703.

133. Kojima S, Chiyomaru T, Kawakami K, Yoshino H, Enokida H, Nohata N, et al. Tumour suppressors miR-1 and miR-133a target the oncogenic function of purine nucleoside phosphorylase (PNP) in prostate cancer. British journal of cancer. 2012 Jan 17;106(2):40513.

134. Kang GH, Lee S, Lee HJ, Hwang KS. Aberrant CpG island hypermethylation of multiple genes in prostate cancer and prostatic intraepithelial neoplasia. The Journal of pathology. $2004 \mathrm{Feb} ; 202(2): 233-40$.

135. Liu L, Yoon JH, Dammann R, Pfeifer GP. Frequent hypermethylation of the RASSF1A gene in prostate cancer. Oncogene. 2002 Oct 3;21(44):6835-40.

136. Liu YN, Abou-Kheir W, Yin JJ, Fang L, Hynes P, Casey O, et al. Critical and reciprocal regulation of KLF4 and SLUG in transforming growth factor beta-initiated prostate cancer epithelial-mesenchymal transition. Molecular and cellular biology. 2012 Mar;32(5):941-53.

137. Yang J, Mani SA, Donaher JL, Ramaswamy S, Itzykson RA, Come C, et al. Twist, a master regulator of morphogenesis, plays an essential role in tumor metastasis. Cell. 2004 Jun 25;117(7):927-39.

138. Kwok WK, Ling MT, Lee TW, Lau TC, Zhou C, Zhang X, et al. Up-regulation of TWIST in prostate cancer and its implication as a therapeutic target. Cancer research. 2005 Jun 15;65(12):5153-62.

139. Yuen HF, Chua CW, Chan YP, Wong YC, Wang X, Chan KW. Significance of TWIST and E-cadherin expression in the metastatic progression of prostatic cancer. Histopathology. 2007 Apr;50(5):648-58.

140. Eide T, Ramberg H, Glackin C, Tindall D, Tasken KA. TWIST1, A novel androgenregulated gene, is a target for NKX3-1 in prostate cancer cells. Cancer cell international. 2013;13(1):4.

141. Bethel CR, Faith D, Li X, Guan B, Hicks JL, Lan F, et al. Decreased NKX3.1 protein expression in focal prostatic atrophy, prostatic intraepithelial neoplasia, and 
adenocarcinoma: association with gleason score and chromosome $8 \mathrm{p}$ deletion. Cancer research. 2006 Nov 15;66(22):10683-90.

142. Iwata T, Schultz D, Hicks J, Hubbard GK, Mutton LN, Lotan TL, et al. MYC overexpression induces prostatic intraepithelial neoplasia and loss of Nkx3.1 in mouse luminal epithelial cells. PloS one. 2010;5(2):e9427.

143. Bandres E, Cubedo E, Agirre X, Malumbres R, Zarate R, Ramirez N, et al. Identification by Real-time PCR of 13 mature microRNAs differentially expressed in colorectal cancer and non-tumoral tissues. Molecular cancer. 2006;5:29.

144. Sarver AL, Li L, Subramanian S. MicroRNA miR-183 functions as an oncogene by targeting the transcription factor EGR1 and promoting tumor cell migration. Cancer research. 2010 Dec 1;70(23):9570-80.

145. Weeraratne SD, Amani V, Teider N, Pierre-Francois J, Winter D, Kye MJ, et al. Pleiotropic effects of miR-183 96 182 converge to regulate cell survival, proliferation and migration in medulloblastoma. Acta neuropathologica. 2012 Apr;123(4):539-52.

146. Qu Y, Li WC, Hellem MR, Rostad K, Popa M, McCormack E, et al. MiR-182 and miR-203 induce mesenchymal to epithelial transition and self-sufficiency of growth signals via repressing SNAI2 in prostate cells. International journal of cancer Journal international du cancer. 2013 Aug 1;133(3):544-55.

147. Kawano Y, Kitaoka M, Hamada Y, Walker MM, Waxman J, Kypta RM. Regulation of prostate cell growth and morphogenesis by Dickkopf-3. Oncogene. 2006 Oct 19;25(49):6528-37.

148. Abarzua F, Sakaguchi M, Takaishi M, Nasu Y, Kurose K, Ebara S, et al. Adenovirus-mediated overexpression of REIC/Dkk-3 selectively induces apoptosis in human prostate cancer cells through activation of c-Jun-NH2-kinase. Cancer research. 2005 Nov 1;65(21):9617-22.

149. Taylor BS, Schultz N, Hieronymus H, Gopalan A, Xiao Y, Carver BS, et al. Integrative genomic profiling of human prostate cancer. Cancer cell. $2010 \mathrm{Jul}$ 13;18(1):1122.

150. Ding Z, Wu CJ, Chu GC, Xiao Y, Ho D, Zhang J, et al. SMAD4-dependent barrier constrains prostate cancer growth and metastatic progression. Nature. 2011 Feb 10;470(7333):269-73.

151. Ma L, Teruya-Feldstein J, Weinberg RA. Tumour invasion and metastasis initiated by microRNA-10b in breast cancer. Nature. 2007 Oct 11;449(7163):682-8.

152. Liu Y, Zhao J, Zhang PY, Zhang Y, Sun SY, Yu SY, et al. MicroRNA-10b targets E-cadherin and modulates breast cancer metastasis. Medical science monitor : international medical journal of experimental and clinical research. 2012 Aug;18(8):BR299-308.

153. Fendler A, Jung M, Stephan C, Honey RJ, Stewart RJ, Pace KT, et al. miRNAs can predict prostate cancer biochemical relapse and are involved in tumor progression. International journal of oncology. 2011 Nov;39(5):1183-92.

154. Li X, Zhang Y, Zhang Y, Ding J, Wu K, Fan D. Survival prediction of gastric cancer by a seven-microRNA signature. Gut. 2010 May;59(5):579-85.

155. Wiklund ED, Bramsen JB, Hulf T, Dyrskjot L, Ramanathan R, Hansen TB, et al. Coordinated epigenetic repression of the miR-200 family and miR-205 in invasive bladder cancer. International journal of cancer Journal international du cancer. 2011 Mar $15 ; 128(6): 1327-34$.

156. Cheng CW, Wang HW, Chang CW, Chu HW, Chen CY, Yu JC, et al. MicroRNA30 a inhibits cell migration and invasion by downregulating vimentin expression and is a potential prognostic marker in breast cancer. Breast cancer research and treatment. 2012 Aug;134(3):1081-93.

157. Barron N, Keenan J, Gammell P, Martinez VG, Freeman A, Masters JR, et al. Biochemical relapse following radical prostatectomy and miR-200a levels in prostate cancer. The Prostate. 2012 Aug 1;72(11):1193-9. 
158. Hu X, Macdonald DM, Huettner PC, Feng Z, El Naqa IM, Schwarz JK, et al. A miR200 microRNA cluster as prognostic marker in advanced ovarian cancer. Gynecologic oncology. 2009 Sep;114(3):457-64.

159. Nam EJ, Yoon H, Kim SW, Kim H, Kim YT, Kim JH, et al. MicroRNA expression profiles in serous ovarian carcinoma. Clinical cancer research : an official journal of the American Association for Cancer Research. 2008 May 1;14(9):2690-5.

160. Marchini S, Cavalieri D, Fruscio R, Calura E, Garavaglia D, Nerini IF, et al. Association between miR-200c and the survival of patients with stage I epithelial ovarian cancer: a retrospective study of two independent tumour tissue collections. The lancet oncology. 2011 Mar;12(3):273-85.

161. Yu J, Ohuchida K, Mizumoto K, Sato N, Kayashima T, Fujita H, et al. MicroRNA, hsa-miR-200c, is an independent prognostic factor in pancreatic cancer and its upregulation inhibits pancreatic cancer invasion but increases cell proliferation. Molecular cancer. 2010;9:169.

162. Carlsson J, Davidsson S, Helenius G, Karlsson M, Lubovac Z, Andren O, et al. A miRNA expression signature that separates between normal and malignant prostate tissues. Cancer cell international. 2011;11(1):14.

163. Kao CJ, Martiniez A, Shi XB, Yang J, Evans CP, Dobi A, et al. miR-30 as a tumor suppressor connects EGF/Src signal to ERG and EMT. Oncogene. 2013 Jun 3.

164. Kumarswamy R, Mudduluru G, Ceppi P, Muppala S, Kozlowski M, Niklinski J, et al. MicroRNA-30a inhibits epithelial-to-mesenchymal transition by targeting Snail and is downregulated in non-small cell lung cancer. International journal of cancer Journal international du cancer. 2012 May 1;130(9):2044-53.

165. Wang W, Lin H, Zhou L, Zhu Q, Gao S, Xie H, et al. MicroRNA-30a-3p inhibits tumor proliferation, invasiveness and metastasis and is downregulated in hepatocellular carcinoma. European journal of surgical oncology : the journal of the European Society of Surgical Oncology and the British Association of Surgical Oncology. 2013 Nov 19.

166. Behnsawy HM, Miyake H, Harada K, Fujisawa M. Expression patterns of epithelialmesenchymal transition markers in localized prostate cancer: significance in clinicopathological outcomes following radical prostatectomy. BJU international. 2013 Jan;111(1):30-7. 
APÊNDICES 


\section{Artigos científicos submetidos}

Modern Pathology

Comprehensive study of gene and microRNA expression related to epithelialmesenchymal transition in prostate cancer

\section{Congressos}

XXXIV Congresso Brasileiro de Urologia

Apresentação oral: Baixos níveis de expressão de miR-200b estão associados com estadiamento avançado e maior escore de Gleason em pacientes com câncer localizado de próstata

XXIX Congresso Brasileiro de Patologia

Apresentação oral: Baixos níveis de expressão de miR-200b estão associados com estadiamento avançado e maior escore de Gleason em pacientes com câncer localizado de próstata

25th European Congress of Pathology Apresentação de pôster: Low expression levels of miRNA 200b are related to pT3 and high Gleason score in prostate cancer

\section{Resumos publicados em anais de congresso:}

Katz, B; Reis, ST; Viana, N; Morais, D; Srougi, M; Leite, KRM. Baixos níveis de expressão de miR-200b estão associados com estadiamento avançado e maior escore de Gleason em pacientes com câncer localizado de próstata. XXXIV Congresso Brasileiro de Urologia, 2013, Natal. International Braz J Urol, 2013. v. 39.

Katz, B; Reis, ST; Dip, N; Viana, N; Morais, D; Silva, I; Srougi, M; Leite, KRM. Low expression levels of miRNA 200b are related to pT3 and high Gleason score in prostate cancer. 25th European Congress of Pathology, 2013, Lisboa. Virchow Archiv, 2013. v. 463. p. 341-341. 


\section{Prêmios}

XXIX Congresso Brasileiro de Patologia

Prêmio SBP para os 10 melhores trabalhos apresentados da sessão de apresentação oral/tema livre

\section{Apresentações futuras}

AUA 2014 Annual Meeting

Apresentação de pôster: MicroRNAs and genes related to epithelial-mesenchymal transition in prostate cancer 
differentiation state of the compartments. Conversely, DDP4 and p63 were down-regulated in the tumor glands whereas AMACR and PCA were up-regulated. In the tumor-associated stroma, CD90 and PENK were found up- and down-regulated, respectively.

Conclusion: LMD is a method of choice to sample cell population of all four glandular and stromal compartments and carry out genc expression analysis. High throughput transcriptomic studies will b performed to decipher the interactions between these compartments and define a "gland plus stroma"-based molecular Gleason score.

\section{PS-25-054}

Association of glutathione s-transferases M1 and T1 polymorphism with clinicopathological parameters in prostate cancer

U. Berber, I. Yilmaz, O. Yilmaz, A. Haholu, Z. Kucukodaci, D. Demire GATA Haydarpasha Training Hosp, Pathology, Istanbul, Turkey

Objective: We aimed to investigate the association between glutathion s-transferase (GST)-M1 and GSTT1 polymorphisms and histopathologic parameters in radical prostatectomy specimens.

Method: We developed a multiplex polymerase chain reaction an high resolution melting curve analysis method to screen GSTM and GSTT1 genotypes simultaneously in a single tube. Formallin fixed paraffin embedded archival tissues from 162 radical prostatectomy specimens were included in the study. Patient age, Gleason score, tumor volume, seminal vesicle invasion, perineural invasion, extraprostatic extension, and pathological tumor stages were analysed in different genotype groups.

Results: The frequencies of GSTM1 null genotypes were $50.6 \%$ $(82 / 162)$, and GSTT1 null genotypes were $20.4 \%(33 / 162)$. Whe compared to GSTM1 present genotype, perineural invasion $(75.6 \% \mathrm{v}$ $65.0 \%$ ) and extraprostatic extension (9.8\% vs $6.3 \%$ )were slightly more common in GSTM1 null genotype carriers, but did not reach the significancy level. No any differences were found between GSTT1 genotype groups and selected clinicopathological para meters.

Conclusion: The present study suggests that inherited absence of GSTM1 and GSTT1 genes are not associated with tumor characteristics in prostate cancer. However, further projects with exact genotyping are required to distinguish homozygote and heterozygote individuals to clarify their association with prognostic parameters in prostate cancer.

PS-25-056

Proteomics in testicular lymphoma: Case report

Poinareanu , M. Aschie, A. F. Mitroi, M. Enciu

Ovidius University, Medicine-Pathology, Constanta, Romania

Objective: Primary non-Hodgkin's lymphoma of the testis is an uncommon disease and that represent $1 \%-2 \%$ of all nonHodgkin lymphomas. It accounts for about $9 \%$ of testicular neoplasms. Histologically, $80 \%$ to $90 \%$ of primary testicular lymphomas are diffuse large-cell type with B cell phenotype, but isolated cases of other histological subtypes have been described such as Burkitt and burkitt's-like types in 10-20\% of cases, mainly in HIV+ patients.

Method: In this paper we present a case report with primary nonHodgkin testicular lymphoma in one 34 years old patient. The particularities of case are the age of patient and tumor morphological features witch can be confused with undifferentiated seminoma

Results: Differential diagnosis is made by immunohistochemistry using specific antibodies for those situations: PLAP AFP or OCT3/4 in embryonar carcinoma and CD19, CD20 and CD45RO in B cell lymphoma. Using immunohistochemistry we demonstrated tumor membership category lymphomas

Conclusion: In conclusion, this paper demonstrates the usefulness of immunohistochemistry in pathology diagnoses especially in locating rare diseases at several level.

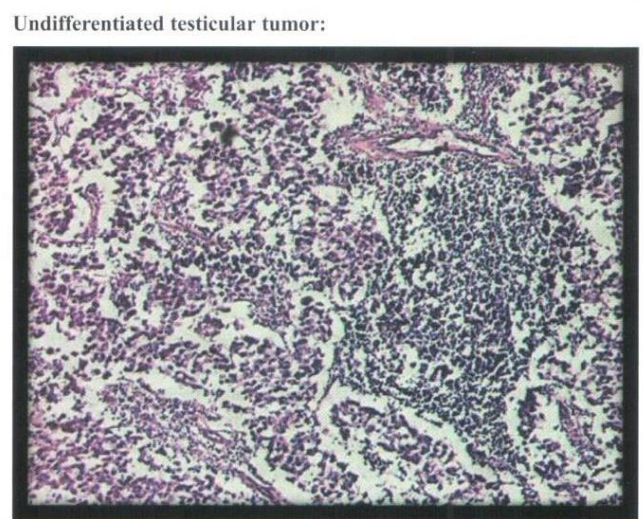

PS-25-057

Low expression levels of miRNA 200b are related to pT3 and high Gleason score in prostate cancer

B. Katz ${ }^{*}$, S. Reis, N. Dip, N. Viana, D. Morais, I. Silva, M. Srougi, K. Ramos Moreira Leite

"Universidade de São Paulo, Brazil

Objective: The ZEB/miR200 loop plays a fundamental role in epitelial-tomesenchymal transition. However, knowledge is scant about this loop in prostate cancer. Our objective is to assess the function of this loop in prostate cancer. Method: Fifty-one fresh-frozen samples from patients with localized prostate submitted to radical prostatectomy were selected. Expression levels of E-cadherin, ZEB1, ZEB2, TGF $\beta 1$, miR-200b and miR-429 were assessed using qRT-PCR. We compared the genes and miRNAs expression with Gleason score (GS), pathological staging (pT), preoperative PSA and biochemical recurrence.

Results: miR200b, miR429. E-cadherin and ZEB2 were overexpressed in the majority of patients, while TGF- $\beta 1$ and ZEB1 were predominantly underexpressed. miR-200b levels were significantly lower in $\mathrm{pT} 3$ patients comparing to $\mathrm{pT} 2$ ( 7.73 vs $23.86, P=0.02$ ), and in patients with $\mathrm{GS} \geq 8$ comparing to patients with GS $\leq 6(9.94$ vs $18.67, P=0.035)$. No association was observed regarding miR 429 and the genes with the clinicopathological parameters.

Conclusion: This is the first study to show that patients with $\mathrm{pT} 3$ prostate cancer and high GS have lower levels of miR200b. Stage and GS are the most important predictive factors for cancer progression. Our results suggest that miR $200 \mathrm{~b}$ might contribute to this process, and could be a potential prognostic marker in prostate cancer

Expression profile of the genes and miRNA in 51 patients with prostate cancer:

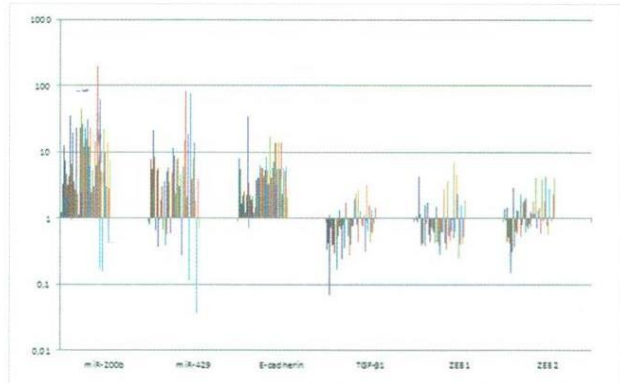




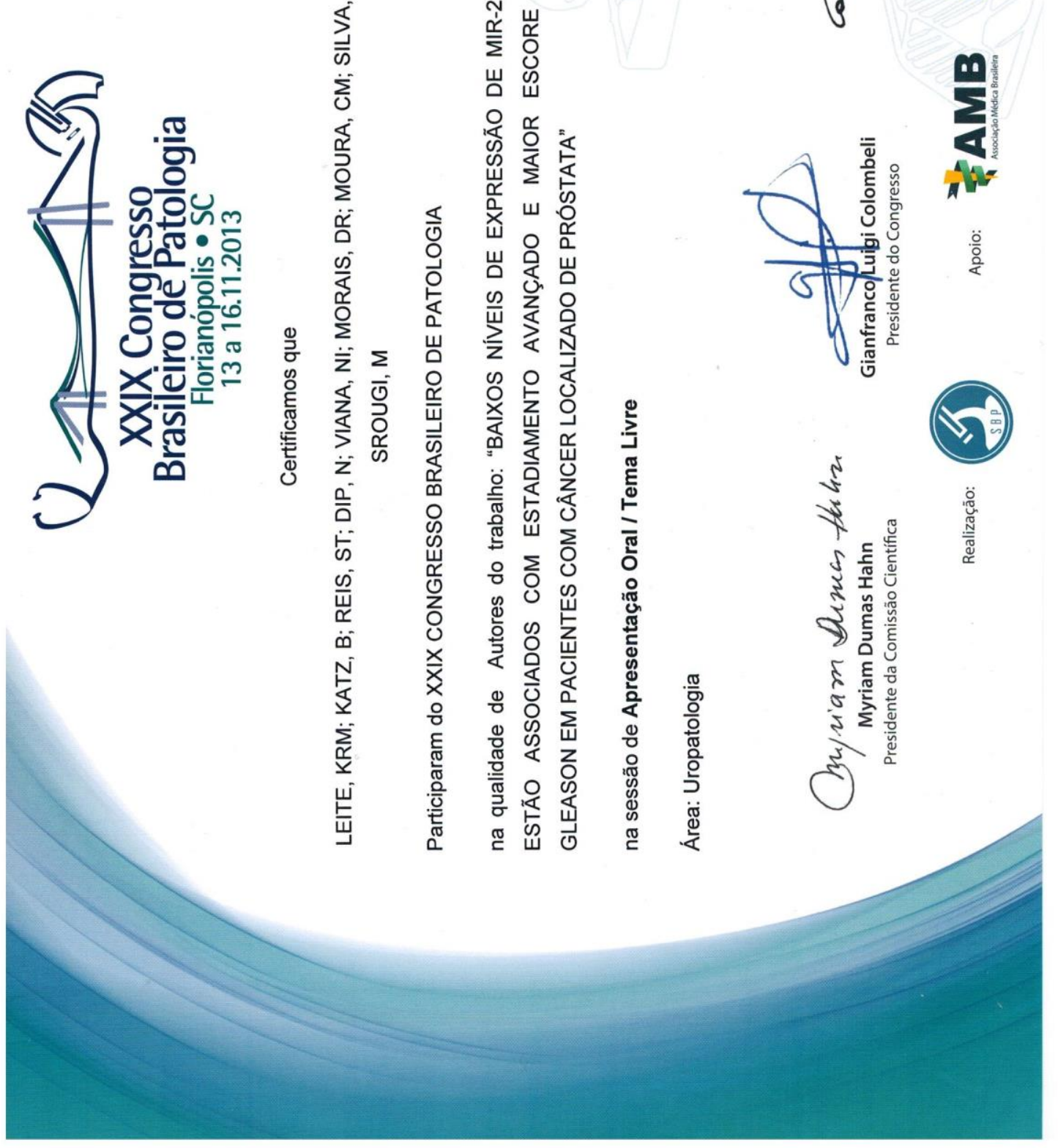



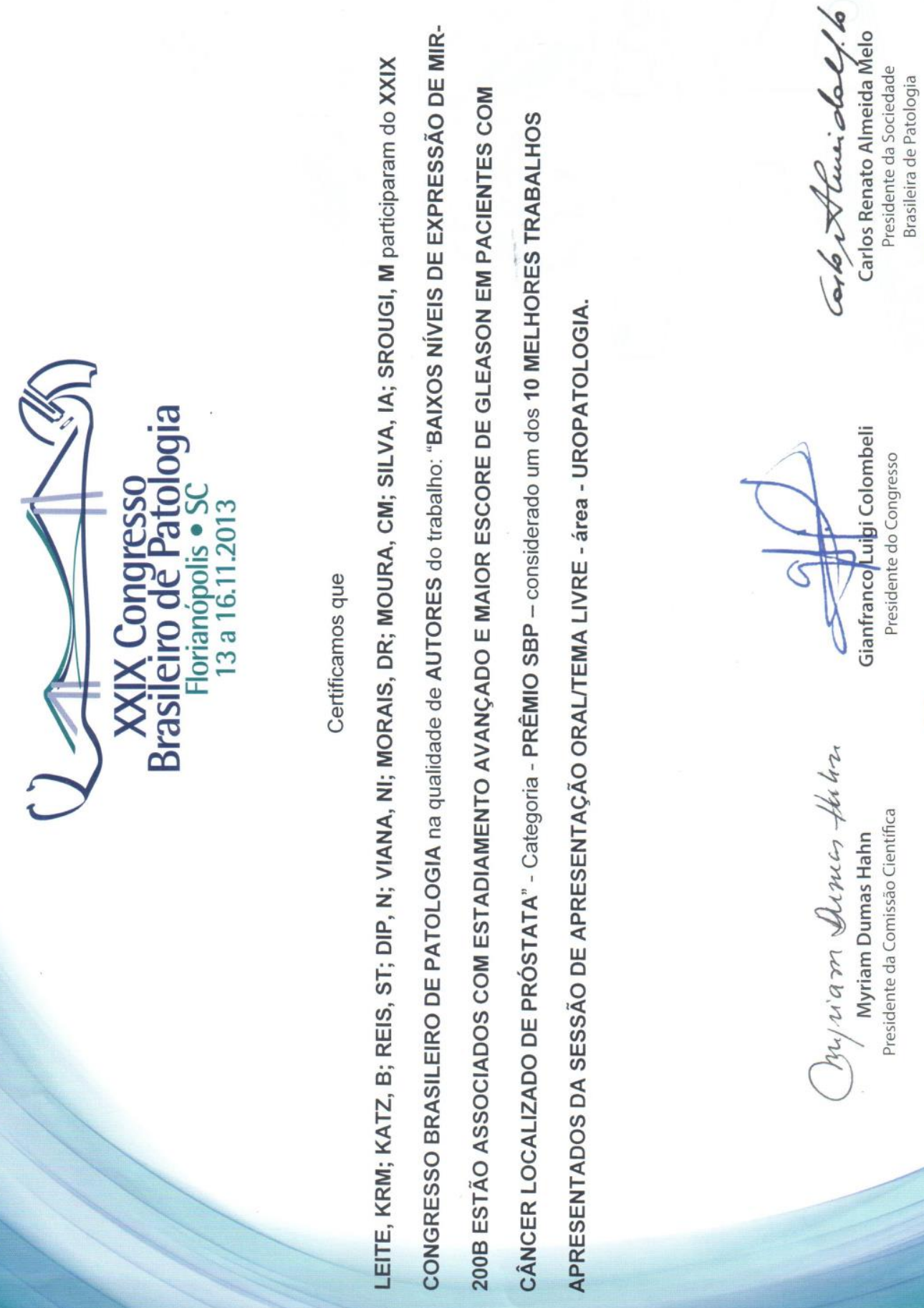

5

哭

눕
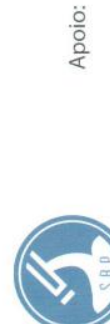

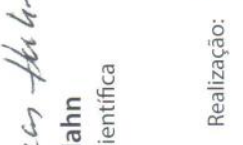

\资

จ)

ई

ह

उ 


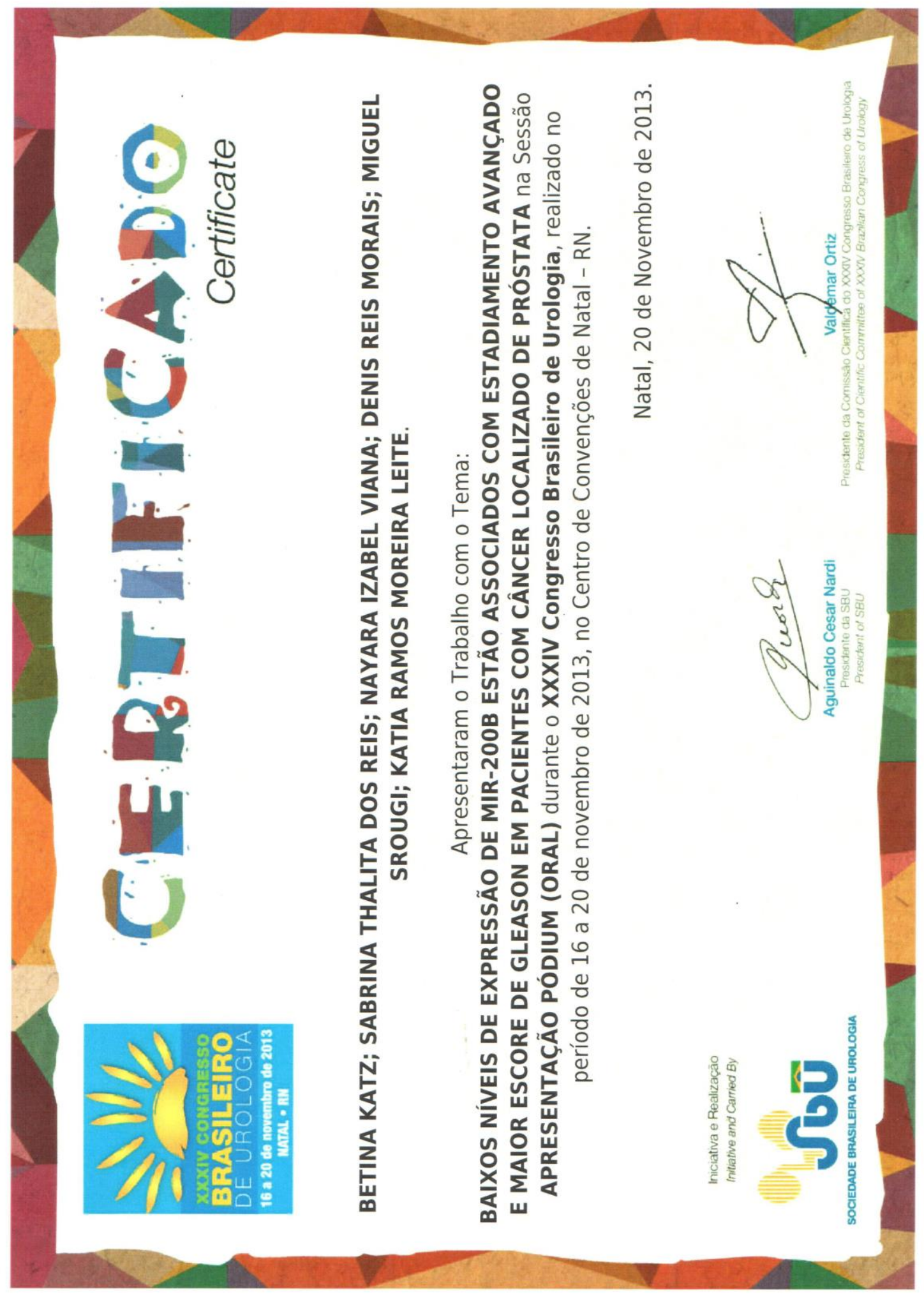


Abstracts printed from AUA2014.org

\title{
MicroRNAs and genes related to epithelial-mesenchymal transition in prostate cancer
}

Authors: Betina Katz*, Sabrina Reis, Nelson Dip, Nayara Viana, Denis Morais, Caio Moura, Iran Silva, Alexandre Iscaife, Miguel Srougi, Katia RM Leite, São Paulo, Brazil

\begin{abstract}
MP31-14 Introduction and Objectives

Prostate cancer $(\mathrm{PCa})$ is the most common cancer in men and the second leading cause of cancer-related mortality. Although most patients present with localized disease at diagnosis, $5 \%$ already have metastatic disease. One of the main mechanisms of tumor progression is the epithelial-mesenchymal transition (EMT). In EMT, epithelial cells lose intercellular adhesion and acquire a mesenchymal phenotype with invasiveness and metastatic potential. The main event is the repression of E-cadherin by transcriptional factors, including ZEB1, ZEB2, Snail, Slug and Twist. microRNAs are also involved in EMT, and one of the most important is the miR-200 family, which induces epithelial differentiation by inhibiting ZEB. Our aim was to evaluate the expression of genes and miRNAs involved in EMT in localized PCa and to correlate with clinicopathological features and outcome after surgery.
\end{abstract}

\section{Methods}

Fifty-one fresh-frozen samples from patients with localized $\mathrm{PCa}$ submitted to radical prostatectomy were selected. Gene expression of E-cadherin, N-cadherin, Vimentin, TGF $\beta$, ZEB1, ZEB2, Snail, Slug, Twist and PDGF-D and miRNA expression of miRNAs 200b, 429, $141,203,205,183,373,21,9,1,495,29 b, 30 a, 34 a, 155$ and 10b were assessed by qRTPCR. Controls were comprised by 10 cases of benign prostatic hyperplasia. The genes and miRNAs expression were compared with Gleason score (GS), pathological stage (pT), preoperative PSA and biochemical recurrence.

\section{Results}

The majority of cases showed overexpression of E-cadherin and Twist and underexpression of $\mathrm{N}$-cadherin, Vimentin, TGF $\beta$, ZEB1, Slug and PDGF-D. miRNAs 200b, 429, 141, 203, 205, 183,373 and 21 were overexpressed, while miRNAs 9, 495, 29b and 1 were underexpressed. The remaining showed a variable expression pattern. There was a significant correlation between lower expression of miR 200b, 30a and 1 and non-organ-confined disease (pT3). miRNAs 200b and 30a levels were also underexpressed in cases with GS $\geq 8$ comparing to GS $\leq 6(6.94$ vs $18.67, p=0.035)$ and in patients categorized as having high risk disease in relation to low risk (1.70 vs $6.37 ; p=0.03$ ), respectively. Yet, Vimentin and Twist were significantly overexpressed in the high risk group.

\section{Conclusions}

Localized PCa still maintains the epithelial phenotype. However, underexpression of miRNAs $200 \mathrm{~b}, 30 \mathrm{a}$ and 1 were significantly associated with more advanced stage and higher GS. The mesenchymal markers Vimentin and Twist were also overexpressed in patients with high risk disease. These miRNAs and genes could be used in the clinical practice as tumor markers to characterize tumor aggressiveness.

Date \& Time: May 18, 2014 10:30 AM-12:30 PM

Session Title: Prostate Cancer: Basic Research II Sources of Funding: FAPESP \#2012/02267-1 


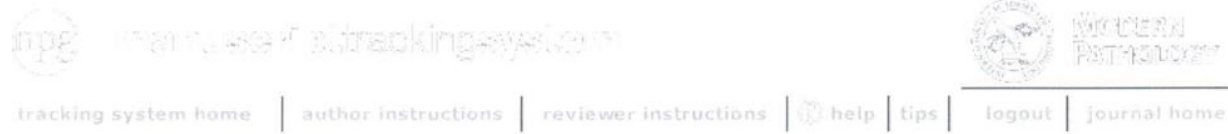

Detailed Status Information

\begin{tabular}{|c|c|}
\hline Manuscript \# & MP-2014-0365 \\
\hline Current Revision \# & 0 \\
\hline Submission Date & 9th Apr 14 13:41:13 \\
\hline Current Stage & Manuscript With Editors \\
\hline Title & $\begin{array}{l}\text { Comprehensive study of gene and microRNA expression related to epithelial- } \\
\text { mesenchymal transition in prostate cancer }\end{array}$ \\
\hline Running Title & Markers of prostate cancer progression \\
\hline Manuscript Type & Original Article \\
\hline Manuscript Comment & $\begin{array}{l}5 \text { reviewers to include: } \\
\text { Maria Ana Duhagon - mduhagon@fcien.edu.uy } \\
\text { William Catalona - wcatalona@nmff.org } \\
\text { Thomas Brabletz - Thomas.Brabletz@uniklinik-freiburg.de } \\
\text { Anindya Dutta - ad8q@virginia.edu } \\
\text { Yibin Kang - ykang@princeton.edu } \\
3 \text { reviewers to exclude: } \\
\text { Stefan Ambs - ambss@mail.nih.gov } \\
\text { Alcides Chaux - alcideschaux@uninorte.edu.py } \\
\text { Carlo Croce - carlo.croce@osumc.edu } \\
\text { This manuscript has not been presented at the USCAP annual meeting. } \\
\text { The 1st author is not a resident. }\end{array}$ \\
\hline Corresponding Author & Dr. Betina Katz (bs_katz@yahoo.com) (Universidade de Sao Paulo) \\
\hline Contributing Authors & $\begin{array}{l}\text { Miss Sabrina Reis, Miss Nayara Viana, Mr. Denis Morais, Mr. Caio Moura, Dr. } \\
\text { Nelson Dip, Mr. Iran Silva, Dr. Alexandre Iscaife, Dr. Miguel Srougi, Dr. Katia Leite }\end{array}$ \\
\hline Abstract & 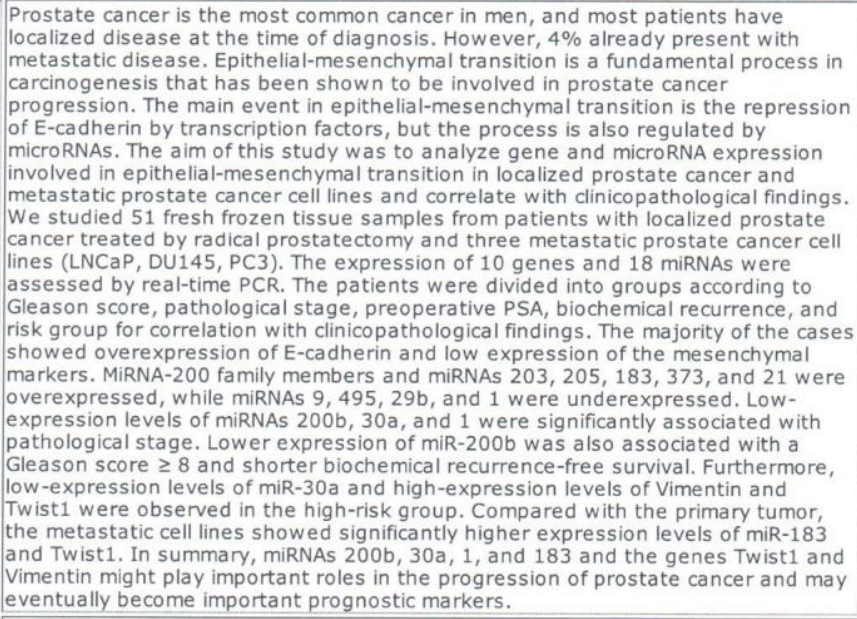 \\
\hline Keywords & prostate cancer, microRNA, epithelial-mesenchymal transition \\
\hline Conflict of Interest Statement & There is NO conflict of interest to disclose. \\
\hline Applicable Funding Source & São Paulo Research Foundation (FAPESP) - 2012/02267-1 [Katz] \\
\hline
\end{tabular}

Stage 
Comprehensive study of gene and microRNA expression related to epithelialmesenchymal transition in prostate cancer

Authors:

Betina Katz

Sabrina T. Reis ${ }^{1}$

Nayara I. Viana

Denis R. Morais

Caio M. Moura ${ }^{1}$

Nelson Dip ${ }^{1}$

Iran A. Silva

Alexandre Iscaife

Miguel Srougi ${ }^{1}$

Katia R. M. Leite ${ }^{1}$

'Division of Urology and Laboratory of Medical Investigation (LIM55), University of Sao Paulo Medical School, Sao Paulo, Brazil 
Correspondence to: Betina Katz, MD

Division of Urology and Laboratory of Medical Investigation (LIM55), University of Sao

Paulo Medical School, Av. Dr. Arnaldo 455, $2^{\circ}$ floor, room 2145, 01246-903, Sao Paulo,

Brazil

Telephone number: +551130617183

Fax number: +551130618469

bkatz@usp.br

Running title: Markers of prostate cancer progression 


\section{Abstract}

Prostate cancer is the most common cancer in men, and most patients have localized disease at the time of diagnosis. However, $4 \%$ already present with metastatic disease. Epithelial-mesenchymal transition is a fundamental process in carcinogenesis that has been shown to be involved in prostate cancer progression. The main event in epithelialmesenchymal transition is the repression of E-cadherin by transcription factors, but the process is also regulated by microRNAs. The aim of this study was to analyze gene and microRNA expression involved in epithelial-mesenchymal transition in localized prostate cancer and metastatic prostate cancer cell lines and correlate with clinicopathological findings. We studied 51 fresh frozen tissue samples from patients with localized prostate cancer treated by radical prostatectomy and three metastatic prostate cancer cell lines (LNCaP, DU145, PC3). The expression of 10 genes and 18 miRNAs were assessed by real-time PCR. The patients were divided into groups according to Gleason score, pathological stage, preoperative PSA, biochemical recurrence, and risk group for correlation with clinicopathological findings. The majority of the cases showed overexpression of E-cadherin and low expression of the mesenchymal markers. MiRNA200 family members and miRNAs 203, 205, 183, 373, and 21 were overexpressed, while miRNAs 9, 495, 29b, and 1 were underexpressed. Low-expression levels of miRNAs 200b, $30 \mathrm{a}$, and 1 were significantly associated with pathological stage. Lower expression of miR$200 \mathrm{~b}$ was also associated with a Gleason score $\geq 8$ and shorter biochemical recurrencefree survival. Furthermore, low-expression levels of miR-30a and high-expression levels of Vimentin and Twist1 were observed in the high-risk group. Compared with the primary tumor, the metastatic cell lines showed significantly higher expression levels of miR-183 and Twist1. In summary, miRNAs 200b, 30a, 1, and 183 and the genes Twist 1 and 
Vimentin might play important roles in the progression of prostate cancer and may eventually become important prognostic markers. 
Introduction

Prostate cancer ( $\mathrm{PCa})$ is one of the most common tumors in men, and it accounts for $29 \%$ of all newly diagnosed cancers ${ }^{1}$. After the adoption of PSA screening, most patients present with localized $\mathrm{PCa}$, but $4 \%$ already have metastatic disease at the time of diagnosis ${ }^{1}$. At present, clinicopathological features such as staging, Gleason score (GS), and PSA levels are good prognostic markers ${ }^{2}$ and are used to make treatment decisions: however, they are not sufficiently accurate to discriminate between tumors that will remain indolent and those that will later progress to become metastatic. Indeed, the unique biological features and heterogeneous genetic backgrounds of $\mathrm{PCa}^{3}$ can limit the efficacy of conventional clinicopathological parameters as predictive markers. For these reasons, molecular biomarkers have been increasingly investigated to help understand and predict cancer behavior.

The epithelial-to-mesenchymal transition (EMT) is a reverse biological process that plays a role in invasion and metastasis during carcinogenesis. Epithelial cell-cell adhesion is decreased, and the cells acquire a spindle-shaped, highly motile fibroblast phenotype and a greater capacity for migration and invasion ${ }^{4}$. The main feature of EMT is transcriptional silencing of E-cadherin ${ }^{5.6}$, which is controlled by the transcriptional regulators ZEB1, ZEB2, SNAI1 (Snail), SNAI2 (Slug), and TWIST1 ${ }^{5,7,8}$. Additionally, there is also upregulation of mesenchymal markers, such as Vimentin and $\mathrm{N}$-cadherin, a process that is known as cadherin switching ${ }^{9}$.

The roles of genes related to EMT in PCa are not completely understood, and previous studies describe the loss of E-cadherin ${ }^{10}$ followed by increased expression of $\mathrm{N}$ cadherin, Cadherin-11 and Vimentin ${ }^{9}$ in immunohistochemistry analysis. The expression levels of ZEB1, a crucial regulator of EMT in PCa, are related to the GS ${ }^{11}$, and Behnsawy 
et al proposed the use of EMT gene expression profiles as markers of biochemical recurrence after radical prostatectomy ${ }^{12}$.

MicroRNAs (miRNAs), a new class of non-coding, regulatory RNAs, have been shown to participate in many processes related to the development and progression of cancer, including EMT ${ }^{13}$. One of the main miRNAs involved in EMT is the miR-200 family, which is a potent inducer of epithelial differentiation. This group comprises miR-200a, miR$200 \mathrm{~b}, \mathrm{miR}-429$, miR-200c, and miR-141, which are generated from two transcripts. The first three are derived from chromosome 1, while the latter two are derived from chromosome 12. The members of this group are highly related in sequence, indicating that they likely target a similar complement of messenger RNAs ${ }^{14}$.

Among the targets of the miR-200 family are ZEB1 and ZEB2 ${ }^{15-17}$. miR-200 members inhibit the expression of ZEB at the post-transcriptional level by binding to highly conserved target sites in their $3^{\prime}$ UTRs ${ }^{18,19}$. Interestingly, miR-200 members are transcriptional targets of ZEB1 and ZEB2. The close functional link between the ZEB factors and the miR-200 family in a double-negative feedback loop is known as the ZEB/miR-200 feedback loop ${ }^{18}$, in which the activation of one group negatively affects the expression of the other group. Depending on the extracellular signals, this loop can switch from one side to the other side and stabilize either the epithelial or mesenchymal phenotype. Other miRNAs have also been shown to participate in EMT, targeting SNA/1 (miR-29b, miR-30a, miR-34a) ${ }^{20,21}$, and SNA/2 (miR-34a, miR-1, miR-200b) ${ }^{22,23}$. However, few studies have assessed miRNAs involved in EMT in PCa.

Our aim is to decipher the role of genes and miRNAs related to EMT in PCa to identify a profile that defines PCa behavior. 


\section{Materials and Methods}

Patient selection

Between 2000 and 2002, tissue for biobank research was collected from 419 patients with localized PCa who underwent radical prostatectomy in our institution. All patients were treated by the same surgeon, and all pathological specimens were analyzed by the same uropathologist. The patients were followed up for a mean time period of 63.06 months.

From the 419 samples, 51 patients were selected. The exclusion criteria were previous therapy or neoadjuvant treatment, absence of clinical information or loss to follow-up, and less than $75 \%$ tumor tissue in the sample collected for the biobank.

As a control, non-neoplastic tissue was obtained from surgical specimens from 10 patients who underwent transurethral resection for benign prostatic hyperplasia (BPH). Members of the control group were required to fulfill the following criteria: prostate volume $<50 \mathrm{~cm}^{3}$ on ultrasound, PSA levels $<2,5 \mathrm{ng} / \mathrm{ml}$, and no malignancy in the pathological specimen.

\section{Prostate tissue samples}

All fresh-frozen PCa samples were obtained from our prostate biobank, and informed consent was obtained from all patients. This study was approved by the institutional board of ethics. The fresh-frozen tumors originated from radical prostatectomy specimens, and a $1 \mathrm{~cm}^{3}$ fragment was isolated from the suspicious area and immediately snap-frozen at $-80^{\circ} \mathrm{C}$. The remaining tissue was fixed in $10 \%$ formalin, routinely processed, and stained with hematoxylin and eosin for histological examination. The samples were subsequently reviewed and graded using the modified Gleason grading system ${ }^{24}$, and the stage was determined following TNM 2010. 
Cell lines

The prostate cancer cell lines LNCaP, DU145, and PC3 were obtained from the American Type Culture Collection (ATCC). LNCaP, DU145, and PC3 were maintained in RPMI, DMEM, and MEM media (Invitrogen, Carlsbad, CA, EUA), respectively. All media were supplemented with $10 \%$ fetal bovine serum and a $1 \%$ antibiotic/antimycotic solution (Sigma, St. Louis, MO, USA), and the cultures were incubated at $37^{\circ} \mathrm{C}$ in an atmosphere of $5 \% \mathrm{CO}_{2}$

RNA and miRNA isolation and amplification

Both RNA and miRNA were isolated from prostate tissues and cell lines using the Ambion mirVana ${ }^{\mathrm{TM}}$ kit (Austin, TX, USA) according to the manufacturer's protocol. RNA and miRNA were quantified using the Nanodrop ND-1000 spectrophotometer (Nanodrop), aliquoted, and stored briefly at $-80^{\circ} \mathrm{C}$ until use in experiments.

cDNA was generated from RNA and miRNA using a TaqMan® RNA Reverse Transcription Kit and TaqMan® MicroRNA Reverse Transcription Kit, respectively. The cDNA was stored at $-20{ }^{\circ} \mathrm{C}$ until use. For gene and miRNA amplification, a TaqMan Reagent Kit was used with the 7500 Fast Real-Time PCR System (Applied Biosystems $®$, Foster City, CA, USA). The reactions were performed in duplicate, and B2M ( $\beta-2$ microglobulin) and RNU-48 were used as endogenous controls for genes and miRNAs, respectively.

Gene and miRNA expression levels were obtained by relative quantification using the $2^{-\Delta \Delta c t}$ method. The formula employed is $\triangle \Delta C T=d C T_{1}-d C T_{2}$, where $d_{C T}=C T$ of the target (tumor sample) - CT of the mean of the endogenous control (tumor sample), and $\mathrm{dCT}_{2}=\mathrm{CT}$ of the mean of the normal controls (benign prostate tissue) - CT of the mean of the endogenous control (benign prostate tissue). For evaluation of the metastatic cell lines the "control" $\left(\mathrm{dCT}_{2}\right)$ was considered to be the pT2 tumors. The final result was obtained by 
applying the $2^{-\Delta \Delta c t}$ method. Findings greater or lesser than 1 were considered to indicate overexpression or underexpression, respectively. All values were standardized relative to the normal control values, which were represented as a value of 1 .

Gene and miRNA selection

The choice of miRNAs and genes evaluated in this study was based on their role in the EMT process in various types of cancer. We performed a literature search via PubMed and Web of Science using the terms "epithelial-mesenchymal transition", "cancer", and "miRNA". Based on the data published in the literature, we selected 18 miRNAs that targeted the most important genes involved in EMT. The data are presented in Table 1.

Statistical Analysis

Groups

To compare the clinicopathological features among patients with localized $\mathrm{PCa}$, the patients were divided into groups based on their $G S$ ( $G S \leq 6$ vs $G S \geq 8$ ), pathological stage ( $\mathrm{pT} 2$ vs pT3), pre-operative PSA ( $<10 \mathrm{vs} \geq 10 \mathrm{ng} / \mathrm{mL}$ ), and absence or presence of biochemical recurrence, defined as PSA $\geq 0,02 \mathrm{ng} / \mathrm{mL}$. The patients were also classified into low-risk and high-risk disease groups according to the presence of any unfavorable feature. In this scenario, the expression values in the tumor tissue were compared to those in the benign prostate tissue.

For the evaluation of metastatic tumors, three metastatic PCa cell lines were analyzed together and designated as the metastatic group. The expression levels of the genes and miRNAs between the cell group and pT3 tumors were compared in relation to pT2 tumors, which were considered the "control" group. The rationale was that the pathological stage might represent a practical evidence of EMT, and by using this method, 
we could evaluate which EMT markers are involved in the progression of a localized tumor to metastasis.

\section{Statistical tests}

The Mann-Whitney $U$ and $T$ tests were used to compare the GS, pathologica stage, pre-operative PSA levels, biochemical recurrence, and risk groups. The distribution of gene and miRNA expression levels was skewed, and the data were log-transformed for analysis. Kaplan-Meier curves were constructed to analyze biochemical recurrence-free survival. The statistical significance for all tests, as assessed by calculating two-sided $P$ values, was set at $<0.05$

\section{Results}

Patient data

The mean age of the patients was 65 years. The mean and median GS were 7.3 and 7 , respectively. Twenty-two patients (43\%) were stage pT2, and 29 (57\%) patients were stage pT3. Seventeen $(33 \%)$ patients had biochemical recurrence in a mean followup period of 63.06 months. Patients in the control group were older, with a mean age of 71.9 years. The data are illustrated in Table 2

miRNA and gene expression profiling in localized $\mathrm{PCa}$

miRNAs 200a, 200b, 200c, 429, 141, 205, 203, 21, 183, and 373 were overexpressed in 35 (69\%), 47 (92\%), 38 (74\%), 39 (77\%), $42(82 \%), 44(86 \%), 38(74 \%)$, $51(100 \%), 38(74 \%)$, and $33(64 \%)$ samples, respectively. miRNAs $1,29 \mathrm{~b}, 9$, and 495 were underexpressed in $41(80 \%), 41(80 \%), 36(71 \%)$, and $42(82 \%)$ samples, respectively. miRNAs $34 \mathrm{a}, 155,30 \mathrm{a}$, and $10 \mathrm{~b}$ showed a variable pattern of expression: miR-34a and miR-155 were underexpressed in $55 \%$ and $57 \%$ of the samples, respectively, and miR-30a and miR-10b were overexpressed in $51 \%$ of the samples. 
E-cadherin was overexpressed in 50 cases $(98 \%)$. The genes $\mathrm{N}$-cadherin, TGFB1, and ZEB1 were underexpressed in $36(71 \%)$ patients, while SNA/2 and Vimentin were underexpressed in $42(82 \%)$ and $41(80 \%)$ patients, respectively. ZEB2, SNA11, and PDGFD showed variable patterns of expression. On the other hand, TWIST1 was the only EMT-induced gene that showed overexpression in the majority of cases $(73 \%)$.

miRNAs and genes associated with clinicopathological features

Tables 3 and 4 illustrate the data regarding miRNA and gene expression in relation to clinicopathological features, respectively. Low levels of miR-200b, miR-30a, and miR-1 were associated with pT3 disease. Of the 18 miRNAs studied, three were significantly underexpressed in $\mathrm{pT} 3$ disease (miR-200b -7.73 vs $23.86, P=0.02 ; \mathrm{miR}-30 \mathrm{a}-1.73$ vs 3.79, $P=0.048$; and miR-1 -0.72 vs $1.97, P=0.04$ ). However, regarding the genes, we could not find any association between their expression and pathological stage.

To assess the association of GS with the miRNAs and genes selected in our study, we decided to exclude tumors with a GS of 7 because of their uncertain behavior and heterogeneity from a clinical point of view. Therefore, we evaluated only tumors with GS at the well differentiated and poorly differentiated ends of the spectrum (low grade, GS $\leq 6$; high grade, $G S \geq 8)$. Thirteen patients $(26 \%)$ had a $G S$ of 7 and were consequently excluded. Fifteen patients (29\%) had a GS $\leq 6$ and $23(45 \%)$ had a GS $\geq 8$. We found that miR-200b expression was significantly lower in patients with a $G S \geq 8$ when compared to patients with a $G S \leq 6(6.94$ vs $18.67, P=0.035)$. No association was found between GS and the other miRNAs and genes.

When patients were grouped according to low-risk and high-risk disease, miR-30a was found to be associated with risk group. Patients with high-risk disease had significantly lower levels of miR-30a compared to patients in the low-risk group (1.70 vs 6.37, $P=0.039$ ). Furthermore, the expression of Vimentin and TWIST1 genes was also 
associated with risk (Table 6). High levels of Vimentin and TWIST1 were significantly associated with high-risk disease $(0.27$ vs $0.90, P=0.017 ; 1.81$ vs $8.89, P=0.018)$.

Pre-operative PSA levels and biochemical recurrence were not associated with any of the markers studied.

Due to the significant association between miRNAs 200b, 30a, and 1 with pathological stage and their potential as prognostic markers, a survival analysis was performed. We compared patients with high expression levels to those with low expression levels of each miRNA; the mean expression level of the miRNA defined these two groups. Kaplan-Meier analysis revealed that patients with lower levels of miR-200b had significantly shorter biochemical recurrence-free survival compared to patients with higher levels of miR-200b ( $P=0.049)$ (Figure 1). Patients with expression levels lower than 14.69 (the mean expression level) recurred in an average of 95 months vs 133 months for cases with levels higher than 14.69 . There was no significant difference between miR-30a and miR-1.

Moreover, miR-183 and TWIST1 expression levels were significantly higher in metastatic PCa cell lines compared to the levels in patients with pT3 disease and highgrade tumors (Table 5). In cell lines, the miR-183 and Twist1 levels were 2.64 and 3.54 respectively, while in pT3 tumors, their levels were 40.41 and 14.45 , respectively $(P=0.009$ and $P=0.049$, respectively).

\section{Discussion}

The importance of the EMT in carcinogenesis has been extensively studied in the last few years, and it is now considered one of the main mechanisms responsible for tumor progression and metastatic dissemination. Our study aimed to evaluate the significance of the expression patterns of multiple miRNAs and genes involved in EMT in PCa. This is the first study in the literature to explore the major miRNAs and their target genes in clinical 
specimens of localized prostate cancer. We have also assessed whether there were differences in both miRNAs and target genes in metastatic cell lines, with the aim of gaining a better understanding of the progression of the disease. Our findings are summarized in Figure 2, which shows the main miRNAs and genes involved in EMT in the progression of prostate carcinogenesis.

We have shown that miR-200b, miR-30a, and miR-1 were significantly underexpressed in non-organ-confined tumors and could constitute interesting prognostic factors. A recent study supports our findings by showing that miR-200b and miR-1 induce $\mathrm{MET}$ in mouse and human PCa cells and are important regulators in prostatic tumorigenesis and tumor progression ${ }^{23}$.

miR-200b was overexpressed in PCa specimens, and this finding is in agreement with previous studies on $\mathrm{PCa}{ }^{25,26}$. The members of the miR-200 family are the most important miRNAs involved in EMT ${ }^{27}$, and studies in PCa cells have shown that miR-200b inhibits EMT, growth, and metastasis ${ }^{23,28}$. We hypothesize that miR-200b has the greatest potential to become a prognostic marker because lower expression of miR-200b was significantly associated with a high GS, pT3 disease, and shorter biochemical recurrencefree survival. The role of miR-200b has been described in other tumors, and its downregulation is related to advanced disease stage ${ }^{29}$ and shorter overall survival ${ }^{31-33}$ Regarding the miR-200 family, miR-200a was the only member previously described as being associated with biochemical recurrence in PCa. Barron et al found that miR-200a levels were reduced in patients who relapsed by studying miR-200a expression in formalin-fixed paraffin-embedded tissue from patients with pT3 disease ${ }^{30}$. On the contrary, Ambs et al described that higher levels of miR-200a and miR-200b were associated with higher stage in $\mathrm{PCa}^{26}$. 
We found that miR-1 was downregulated in the primary tumor compared to benign prostate tissue, and this finding is in agreement with the literature ${ }^{26,34}$. It is thought that miR-1 plays a role in EMT through different mechanisms in $\mathrm{PCa}$ : by directly regulating Slug ${ }^{23}$; through epigenetic effects, such as histone methylation and acetylation ${ }^{35}$; and through other independent targets that act in proliferation, migration, and invasion, such as KIF2A, FOXP1, HDAC4, and PNP ${ }^{34}$. In our study, miR-1 expression levels were significantly reduced in non-organ confined disease compared to organ confined disease. This is the second study to describe a potential role of miR-1 in prostate cancer as a prognostic marker. Hudson et al previously found that lower expression levels of miR-1 were associated with earlier biochemical recurrence in $\mathrm{PCa}^{35}$.

Data regarding the role of miR-30a in PCa are scarce and contradictory. miR-30a showed a variable pattern of expression, with half of the patients showing overexpression, while the other half showed underexpression. miR-30a was described as being downregulated in the study conducted by Porkka et $\mathrm{al}^{38}$, while Carlsson et al reported the upregulation of this miRNA ${ }^{39}$. Recently, Kao et al showed that the ETS-related gene (ERG), which is the most frequently overexpressed oncogene in $\mathrm{PCa}$, is a direct target of miR-30 and that overexpression of miR-30 in PCa cells suppresses EMT phenotypes and inhibits cell migration and invasion ${ }^{40}$. miR-30 family also inhibits cell migration, invasiveness, and metastasis in vitro in other tumors, such as lung, breast, and hepatocellular cancer ${ }^{21,41-43}$, by targeting SNAI1 ${ }^{21,41}$ and Vimentin ${ }^{42,43}$. In this study, the relationship observed between decreased expression of miR-30, advanced pathological stage, and high-risk disease confirms miR-30 as a tumor suppressor miRNA in PCa. Cheng et al observed that low levels of miR-30a were predictors of advanced stage and lymph node metastasis in invasive breast cancer ${ }^{42}$. Wang et al showed that low 
expression levels of miR-30a were significantly associated with a higher incidence of portal vein tumor thrombus in hepatocellular carcinoma ${ }^{43}$.

Regarding the genes, we observed overexpression of E-cadherin in virtually all cases, and the majority of the mesenchymal markers, including $\mathrm{N}$-cadherin, TGFB1, ZEB1, Vimentin, and SNA/2, were downregulated. This gene expression profile strongly suggests that localized $\mathrm{PCa}$ maintains the epithelial phenotype despite tumor differentiation and increasing stage. However, TWIST1 was overexpressed in $73 \%$ of the cases. TWIST1 is a helix-loop-helix transcription factor that activates EMT through indirect inhibition of E-cadherin ${ }^{44}$. TWIST1 has been shown to be overexpressed in PCa on immunohistochemistry assays and positively correlated with the GS ${ }^{45,46}$. It is interesting that a gene with such importance in EMT and with prognostic value in $\mathrm{PCa}$ is overexpressed in localized tumors. The early overexpression of TWIST1 may be attributed to its regulation by the NKX3-1 gene ${ }^{47}$. Eide et al demonstrated that TWIST1 is a target of NKX3-1, a tumor suppressor that was found to be underexpressed in the early stages of $\mathrm{PCa}{ }^{48,49}$. However, the early upregulation of TWIST1 does not appear to be sufficient to initiate the EMT process. According to Casas et al, TWIST1 induces SNA/2 to promote EMT by binding to the conserved E-box in the proximate SNA/2 promoter ${ }^{50}$. These authors showed that depletion of SNA/2 completely blocks the ability of TWIST1 to suppress E-cadherin and induces morphological changes associated with EMT. We show that high levels of TWIST1, as well as Vimentin, are significantly associated with patients in the high-risk group. In a recent study, Behnsawy et al ${ }^{12}$ showed that high expression levels of TWIST1 and Vimentin evaluated by immunohistochemistry is an independent factor related to shorter biochemical recurrence-free survival, suggesting that these genes might be potential markers of biochemical recurrence after radical prostatectomy. The association between Vimentin and biochemical recurrence in PCa was also reported by 
Zhang et al ${ }^{51}$; moreover, Vimentin is a target of miR-30a, and both showed an inverse association with high-risk disease.

When we examined the metastatic cell lines, we found that the expression levels of TWIST1 and miR-183 were also significantly higher in the metastatic cell lines than in the pT3 tumors.

TWIST1 appears to play a role in various steps of EMT, and its role in the progression of $\mathrm{PCa}$ from $\mathrm{BPH}$ to high-grade prostatic intraepithelial neoplasia (PIN), low grade $\mathrm{PCa}$, and high grade PCa was demonstrated by Yuen et al ${ }^{46}$. These authors also demonstrated that the nuclear reactivity scores of the primary cancers in individuals with metastatic disease were significantly higher than those without metastasis and were able to predict metastatic potential. In the study by Kwok et al, TWIST1 expression was higher in tissues derived from metastatic lesions from bones and lymph nodes ${ }^{45}$. The role of TWIST1 in this later step of EMT might be explained by the activation of its target, miR10b. miR-10b not only represses E-cadherin ${ }^{52}$ but also inhibits the translation of the HOXD10 protein, permitting the expression of the pro-metastatic gene product, $\mathrm{RHOC}^{53}$.

The miR-183 cluster has already been shown to be upregulated in PCa tissue ${ }^{54-59}$ in addition to 13 different tumors ${ }^{60}$. The miR-182-96-183 cluster is located in the same chromosomal region (7q32.2) ${ }^{61}$ and consists of 3 members: miR-183, miR-182, and miR96. The role of the miR-183 cluster in EMT is not completely understood, and it appears to have a context-dependent function. There are contradictory descriptions in the literature, with some studies showing that miR-183 promotes migration and invasion ${ }^{57,62,63}$, while others indicate that it inhibits migration, invasion, and metastasis ${ }^{64-66}$. Ueno et al observed that higher expression levels of miR-183 were significantly associated with higher PSA, higher stage and shorter overall survival after RP. Two targets of miR-183, DKK3 and SMAD4, were described in PCa by the same authors ${ }^{57}$, and both are inhibitors of PC3 cell 
growth ${ }^{67.68}$. This oncogenic role of miR-183 could be explained by the regulation of 2 important tumor suppressor genes, EGR1 and PTEN, which were identified by Sarver et al in colon cancer and synovial sarcoma cell lines ${ }^{62}$. However, Qu et al showed that reexpression of one of the members of the miR-183 cluster, miR-182, in a prostate cancer cell line (EPT1) induced MET features and acquisition of the oncogenic characteristics through repression of SNAI2 ${ }^{64}$. In addition, miR-183 and miR-96 repressed SNAI2, ZEB1, ITGB1, and KLF4 in colorectal cancer cell lines ${ }^{65}$.

It is important to understand that EMT influences tumor progression in different steps through several markers. Here, we described a comprehensive study of miRNAs and genes related to EMT in PCa and found that the expression levels of miR-200b, miR30a, miR-1, TWIST1 and Vimentin could be used in decision-making processes related to primary or adjuvant treatments in the future.

Disclosure/Conflict of Interest: This work was supported by FAPESP (Fundação de Amparo à Pesquisa do Estado de Sao Paulo) under protocol number 2012/02267-1. The authors declare no conflict of interest. 


\section{References}

1. Siegel R, Naishadham D, Jemal A. Cancer statistics, 2013. CA: a cancer journal for clinicians 2013;63:11-30.

2. Quinn DI, Henshall SM, Haynes AM, et al. Prognostic significance of pathologic features in localized prostate cancer treated with radical prostatectomy: implications for staging systems and predictive models. Journal of clinical oncology : official journal of the American Society of Clinical Oncology 2001;19:3692-705.

3. Mackinnon AC, Yan BC, Joseph LJ, Al-Ahmadie HA. Molecular biology underlying the clinical heterogeneity of prostate cancer: an update. Archives of pathology \& laboratory medicine 2009;133:1033-40.

4. Thiery JP, Acloque H, Huang RY, Nieto MA. Epithelial-mesenchymal transitions in development and disease. Cell 2009;139:871-90.

5. Huber MA, Kraut N, Beug H. Molecular requirements for epithelial-mesenchymal transition during tumor progression. Current opinion in cell biology 2005;17:548-58. 6. Halbleib JM, Nelson WJ. Cadherins in development: cell adhesion, sorting, and tissue morphogenesis. Genes \& development 2006:20:3199-214.

7. Moreno-Bueno G, Cubillo E, Sarrio D, et al. Genetic profiling of epithelial cells expressing E-cadherin repressors reveals a distinct role for Snail, Slug, and E47 factors in epithelial-mesenchymal transition. Cancer research 2006;66:9543-56.

8. Batlle $E$, Sancho $E$, Franci $C$, et al. The transcription factor snail is a repressor of E-cadherin gene expression in epithelial tumour cells. Nature cell biology $2000 ; 2: 84-9$.

9. Tomita $K$, van Bokhoven A, van Leenders GJ, et al. Cadherin switching in human prostate cancer progression. Cancer research 2000;60:3650-4.

10. Putzke AP, Ventura AP, Bailey AM, et al. Metastatic progression of prostate cancer and e-cadherin regulation by zeb1 and SRC family kinases. The American journal of pathology 2011;179:400-10.

11. Graham TR, Zhau HE, Odero-Marah VA, et al. Insulin-like growth factor-1dependent up-regulation of ZEB1 drives epithelial-to-mesenchymal transition in human prostate cancer cells. Cancer research 2008;68:2479-88

12. Behnsawy HM, Miyake H, Harada K, Fujisawa M. Expression patterns of epithelialmesenchymal transition markers in localized prostate cancer: significance in clinicopathological outcomes following radical prostatectomy. BJU international 2013;111:30-7.

13. Bartel DP. MicroRNAs: genomics, biogenesis, mechanism, and function. Cell $2004 ; 116: 281-97$

14. Bendoraite A, Knouf EC, Garg KS, et al. Regulation of miR-200 family microRNAs and ZEB transcription factors in ovarian cancer: evidence supporting a mesothelial-toepithelial transition. Gynecologic oncology 2010:116:117-25

15. Gregory PA, Bert AG, Paterson EL, et al. The miR-200 family and miR-205 regulate epithelial to mesenchymal transition by targeting ZEB1 and SIP1. Nature cell biology 2008;10:593-601.

16. Korpal M, Lee ES, Hu G, Kang Y. The miR-200 family inhibits epithelialmesenchymal transition and cancer cell migration by direct targeting of E-cadherin transcriptional repressors ZEB1 and ZEB2. The Journal of biological chemistry 2008;283:14910-4.

17. Park SM, Gaur AB, Lengyel E, Peter ME. The miR-200 family determines the epithelial phenotype of cancer cells by targeting the E-cadherin repressors ZEB1 and ZEB2. Genes \& development 2008;22:894-907. 
18. Burk U, Schubert J, Wellner U, et al. A reciprocal repression between ZEB1 and members of the miR-200 family promotes EMT and invasion in cancer cells. EMBO reports 2008:9:582-9.

19. Bracken CP, Gregory PA, Kolesnikoff N, et al. A double-negative feedback loop between ZEB1-SIP1 and the microRNA-200 family regulates epithelial-mesenchymal transition. Cancer research 2008:68:7846-54

20. Ru P, Steele R, Newhall P, Phillips NJ, Toth K, Ray RB. miRNA-29b suppresses prostate cancer metastasis by regulating epithelial-mesenchymal transition signaling Molecular cancer therapeutics 2012;11:1166-73.

21. Zhang J, Zhang H, Liu J, et al. miR-30 inhibits TGF-beta1-induced epithelial-tomesenchymal transition in hepatocyte by targeting Snail1. Biochemical and biophysical research communications 2012:417:1100-5.

22. Siemens H, Jackstadt R, Hunten S, et al. miR-34 and SNAIL form a doublenegative feedback loop to regulate epithelial-mesenchymal transitions. Cell cycle 2011;10:4256-71

23. Liu YN, Yin JJ, Abou-Kheir W, et al. MiR-1 and miR-200 inhibit EMT via Slugdependent and tumorigenesis via Slug-independent mechanisms. Oncogene 2013:32:296 -

306

24. Epstein JI, Allsbrook WC, Jr., Amin MB, Egevad LL, Committee IG. The 2005 International Society of Urological Pathology (ISUP) Consensus Conference on Gleason Grading of Prostatic Carcinoma. The American journal of surgical pathology 2005;29:1228-42

25. Kong D, Li Y, Wang Z, et al. miR-200 regulates PDGF-D-mediated epithelialmesenchymal transition, adhesion, and invasion of prostate cancer cells. Stem Cells 2009:27:1712-21

26. Ambs S, Prueitt RL, Yi M, et al. Genomic profiling of microRNA and messenger RNA reveals deregulated microRNA expression in prostate cancer. Cancer research 2008;68:6162-70

27. Paterson EL, Kolesnikoff N, Gregory PA, Bert AG, Khew-Goodall Y, Goodall GJ. The microRNA-200 family regulates epithelial to mesenchymal transition. TheScientificWorldJournal 2008;8:901-4.

28. Williams LV, Veliceasa D, Vinokour E, Volpert OV. miR-200b inhibits prostate cancer EMT, growth and metastasis. PloS one 2013;8:e83991.

29. Kurashige J, Kamohara H, Watanabe M, et al. MicroRNA-200b regulates cell proliferation, invasion, and migration by directly targeting ZEB2 in gastric carcinoma. Ann Surg Oncol 2012;19 Suppl 3:S656-64.

30. Barron N, Keenan J, Gammell P, et al. Biochemical relapse following radica prostatectomy and miR-200a levels in prostate cancer. The Prostate 2012:72:1193-9. 31. Marchini S, Cavalieri D, Fruscio R, et al. Association between miR-200c and the survival of patients with stage I epithelial ovarian cancer: a retrospective study of two independent tumour tissue collections. The lancet oncology 2011;12:273-85

32. Nam EJ, Yoon H, Kim SW, et al. MicroRNA expression profiles in serous ovarian carcinoma. Clinical cancer research : an official journal of the American Association for Cancer Research 2008;14:2690-5.

33. Hu X, Macdonald DM, Huettner PC, et al. A miR-200 microRNA cluster as

prognostic marker in advanced ovarian cancer. Gynecologic oncology 2009;114:457-64

34. Kojima S, Chiyomaru T, Kawakami K, et al. Tumour suppressors miR-1 and miR-

133a target the oncogenic function of purine nucleoside phosphorylase (PNP) in prostate cancer. British journal of cancer 2012;106:405-13. 
35. Hudson RS, Yi M, Esposito D, et al. MicroRNA-1 is a candidate tumor suppressor and prognostic marker in human prostate cancer. Nucleic acids research 2012;40:3689and $\mathrm{p}$.

36. Liu L, Yoon JH, Dammann R, Pfeifer GP. Frequent hypermethylation of the RASSF1A gene in prostate cancer. Oncogene 2002;21:6835-40.

37. Kang GH, Lee S, Lee HJ, Hwang KS. Aberrant CpG island hypermethylation of multiple genes in prostate cancer and prostatic intraepithelial neoplasia. The Journal of pathology 2004;202:233-40.

pathology $2004 ; 202: 233-40$.
38. Porkka KP, Pfeiffer MJ, Waltering KK, Vessella RL, Tammela TL, Visakorpi T

MicroRNA expression profiling in prostate cancer. Cancer research 2007:67:6130-5.

39. Carlsson J, Davidsson S, Helenius G, et al. A miRNA expression signature that separates between normal and malignant prostate tissues. Cancer cell international

2011;11:14.

40. Kao CJ, Martiniez A, Shi XB, et al. miR-30 as a tumor suppressor connects

EGF/Src signal to ERG and EMT. Oncogene 2013.

41. Kumarswamy R, Mudduluru G, Ceppi $P$, et al. MicroRNA-30a inhibits epithelial-tomesenchymal transition by targeting Snai1 and is downregulated in non-small cell lung cancer. International journal of cancer Journal international du cancer 2012;130:2044-53. 42. Cheng $\mathrm{CW}$, Wang $\mathrm{HW}$, Chang $\mathrm{CW}$, et al. MicroRNA-30a inhibits cell migration and invasion by downregulating vimentin expression and is a potential prognostic marker in breast cancer. Breast cancer research and treatment 2012;134:1081-93.

43. Wang W, Lin H, Zhou L, et al. MicroRNA-30a-3p inhibits tumor proliferation,

invasiveness and metastasis and is downregulated in hepatocellular carcinoma. European journal of surgical oncology : the journal of the European Society of Surgical Oncology and the British Association of Surgical Oncology 2013.

44. Yang J, Mani SA, Donaher JL, et al. Twist, a master regulator of morphogenesis, plays an essential role in tumor metastasis. Cell 2004;117:927-39.

45. Kwok WK, Ling MT, Lee TW, et al. Up-regulation of TWIST in prostate cancer and its implication as a therapeutic target. Cancer research 2005;65:5153-62. 46. Yuen HF, Chua CW, Chan YP, Wong YC, Wang X, Chan KW. Significance of Histopathology 2007; 50:648-58.

47. Eide T, Ramberg H, Glackin C, Tindall D, Tasken KA. TWIST1, A novel androgenregulated gene, is a target for NKX3-1 in prostate cancer cells. Cancer cell international 2013;13:4.

48. Bethel CR, Faith D, Li X, et al. Decreased NKX3.1 protein expression in focal prostatic atrophy, prostatic intraepithelial neoplasia, and adenocarcinoma: association with gleason score and chromosome 8p deletion. Cancer research 2006;66:10683-90. 49. Iwata T, Schultz D, Hicks J, et al. MYC overexpression induces prostatic intraepithelial neoplasia and loss of Nkx3.1 in mouse luminal epithelial cells. PloS one 2010;5:e9427.

50. Casas E, Kim J, Bendesky A, Ohno-Machado L, Wolfe CJ, Yang J. Snail2 is an essential mediator of Twist1-induced epithelial mesenchymal transition and metastasis. Cancer research 2011:71:245-54.

51. Zhang Q, Helfand BT, Jang TL, et al. Nuclear factor-kappaB-mediated transforming growth factor-beta-induced expression of vimentin is an independent predictor of biochemical recurrence after radical prostatectomy. Clinical cancer research : an official journal of the American Association for Cancer Research 2009;15:3557-67.

52. Liu Y, Zhao J, Zhang PY, et al. MicroRNA-10b targets E-cadherin and modulates breast cancer metastasis. Medical science monitor : international medical journal of experimental and clinical research 2012;18:BR299-308. 
53. Ma L, Teruya-Feldstein J, Weinberg RA. Tumour invasion and metastasis initiated by microRNA-10b in breast cancer. Nature 2007:449:682-8.

54. Schaefer A, Jung M, Mollenkopf HJ, et al. Diagnostic and prognostic implications of microRNA profiling in prostate carcinoma. International journal of cancer Journal international du cancer 2010;126:1166-76.

55. Tsuchiyama $\mathrm{K}$, Ito $\mathrm{H}$, Taga $\mathrm{M}$, et al. Expression of microRNAs associated with Gleason grading system in prostate cancer: miR-182-5p is a useful marker for high grade prostate cancer. The Prostate 2013;73:827-34.

56. Siva AC, Nelson LJ, Fleischer CL, et al. Molecular assays for the detection of microRNAs in prostate cancer. Molecular cancer 2009;8:17.

57. Ueno $\mathrm{K}$, Hirata $\mathrm{H}$, Shahryari $\mathrm{V}$, et al, microRNA-183 is an oncogene targeting Dkk-

3 and SMAD4 in prostate cancer. British journal of cancer 2013;108:1659-67.

58. Mihelich BL, Khramtsova EA, Arva N, et al. miR-183-96-182 cluster is

overexpressed in prostate tissue and regulates zinc homeostasis in prostate cells. The Journal of biological chemistry 2011;286:44503-11.

59. Larne O, Martens-Uzunova E, Hagman Z, et al. miQ--a novel microRNA based diagnostic and prognostic tool for prostate cancer. International journal of cancer Journal international du cancer 2013;132:2867-75.

60. Zhang QH, Sun HM, Zheng RZ, et al. Meta-analysis of microRNA-183 family expression in human cancer studies comparing cancer tissues with noncancerous tissues. Gene 2013;527:26-32.

61. Bandres $E$, Cubedo $E$, Agirre $X$, et al. Identification by Real-time PCR of 13 mature microRNAs differentially expressed in colorectal cancer and non-tumoral tissues. Molecular cancer 2006:5:29.

62. Sarver AL, Li L, Subramanian S. MicroRNA miR-183 functions as an oncogene by targeting the transcription factor EGR1 and promoting tumor cell migration. Cancer research 2010;70:9570-80.

63. Weeraratne SD, Amani V, Teider N, et al. Pleiotropic effects of miR-183 96 182 converge to regulate cell survival, proliferation and migration in medulloblastoma. Acta neuropathologica 2012;123:539-52.

64. Qu Y, Li WC, Hellem MR, et al. MiR-182 and miR-203 induce mesenchymal to epithelial transition and self-sufficiency of growth signals via repressing SNAI2 in prostate cells. International journal of cancer Journal international du cancer 2013;133:544-55.

65. Li XL, Hara T, Choi Y, et al. A p21-ZEB1 complex inhibits epithelial-mesenchyma transition through the microRNA 183-96-182 cluster. Molecular and cellular biology 2014:34:533-50.

66. Wellner U, Schubert J, Burk UC, et al. The EMT-activator ZEB1 promotes tumorigenicity by repressing stemness-inhibiting microRNAs. Nature cell bi 2009;11:1487-95.

67. Kawano Y, Kitaoka M, Hamada Y, Walker MM, Waxman J, Kypta RM. Regulation of prostate cell growth and morphogenesis by Dickkopf-3. Oncogene 2006;25:6528-37. 68. Abarzua F, Sakaguchi M, Takaishi M, et al. Adenovirus-mediated overexpression of REIC/Dkk-3 selectively induces apoptosis in human prostate cancer cells through activation of C-Jun-NH2-kinase. Cancer research 2005:65:9617-22.

69. Taylor BS, Schultz N, Hieronymus $\mathrm{H}$, et al. Integrative genomic profiling of human prostate cancer. Cancer cell 2010;18:11-22.

70. Ding Z, Wu CJ, Chu GC, et al. SMAD4-dependent barrier constrains prostate cancer growth and metastatic progression. Nature 2011;470:269-73.

71. Boll K, Reiche K, Kasack K, et al. MiR-130a, miR-203 and miR-205 jointly repress key oncogenic pathways and are downregulated in prostate carcinoma. Oncogene 2013:32:277-85 
72. Tucci P, Agostini M, Grespi F, et al. Loss of p63 and its microRNA-205 target results in enhanced cell migration and metastasis in prostate cancer. Proceedings of the National Academy of Sciences of the United States of America 2012;109:15312-7.

73. Majid S, Dar AA, Saini S, et al. MicroRNA-205-directed transcriptional activation of tumor suppressor genes in prostate cancer. Cancer 2010;116:5637-49.

74. Gandellini P, Folini M, Longoni N, et al. miR-205 Exerts tumor-suppressive

functions in human prostate through down-regulation of protein kinase Cepsilon. Cance research 2009:69:2287-95

75. Dorff TB, Flaig TW, Tangen CM, et al. Adjuvant androgen deprivation for high-risk prostate cancer after radical prostatectomy: SWOG S9921 study. Journal of clinical oncology : official journal of the American Society of Clinical Oncology 2011;29:2040-5 76. Schubert M, Joniau S, Gontero P, et al. The role of adjuvant hormonal treatment after surgery for localized high-risk prostate cancer: results of a matched multinstitutional analysis. Advances in urology 2012;2012:612707.

77. McVey GP, McPhail S, Fowler S, McIntosh G, Gillatt D, Parker CC. Initial management of low-risk localized prostate cancer in the UK: analysis of the British Association of Urological Surgeons Cancer Registry. BJU international 2010;106:1161-4. 78. Klotz L, Zhang L, Lam A, Nam R, Mamedov A, Loblaw A. Clinical results of longterm follow-up of a large, active surveillance cohort with localized prostate cancer. Journa of clinical oncology : official journal of the American Society of Clinical Oncology 2010;28:126-31

79. Loeb S, Bjurlin MA, Nicholson J, et al. Overdiagnosis and Overtreatment of Prostate Cancer. European urology 2014 


\section{Figure legends}

Figure 1. Kaplan-Meier biochemical recurrence-free survival curve based on miR-200b mean expression $(P=0.049$, Log rank test). Patients with miR-200b expression levels $\leq$ 14.690 showed significantly shorter biochemical recurrence-free survival.

Figure 2. Main miRNAs and genes involved in epithelial-mesenchymal transition in prostate cancer. Expression levels of miRNAs 200b, 30a and 1 decrease when the tumor acquires high grade features, while expression levels of TWIST1 and Vimentin increase When the tumor becomes metastatic, an increase in the expression levels of miR-183 and TWIST1 is observed. $B R=$ Biochemical Recurrence 
Table 1. Selection of miRNAs and their main targets

\begin{tabular}{|c|c|c|}
\hline microRNA & Target gene & Reference \\
\hline miR-200a & $\begin{array}{l}\text { ZEB1 } \\
\text { ZEB2 }\end{array}$ & $\begin{array}{l}\text { Bracken et al, 2008; } \\
\text { Gregory et al, 2008; } \\
\text { Korpal et al, 2008 }\end{array}$ \\
\hline miR-200b & $\begin{array}{l}\text { ZEB1 } \\
\text { ZEB2 } \\
\text { SNAI2 } \\
\text { PDGFD }\end{array}$ & $\begin{array}{c}\text { Bracken et al, 2008; } \\
\text { Gregory et al, 2008; } \\
\text { Korpal et al, 2008; Kong et } \\
\text { al, 2009; Liu et al, } 2012\end{array}$ \\
\hline miR-200c & $\begin{array}{l}\text { ZEB1 } \\
\text { ZEB2 }\end{array}$ & $\begin{array}{l}\text { Bracken et al, 2008; } \\
\text { Gregory et al, 2008; } \\
\text { Korpal et al, 2008 }\end{array}$ \\
\hline miR-429 & $\begin{array}{l}\text { ZEB1 } \\
\text { ZEB2 }\end{array}$ & $\begin{array}{l}\text { Bracken et al, 2008; } \\
\text { Gregory et al, 2008; } \\
\text { Korpal et al, 2008 }\end{array}$ \\
\hline miR-141 & $\begin{array}{l}\text { ZEB1 } \\
\text { ZEB2 }\end{array}$ & $\begin{array}{l}\text { Burk et al, 2008; Gregory } \\
\text { et al, 2008; Korpal et al, } \\
2008\end{array}$ \\
\hline miR-205 & $\begin{array}{l}\text { ZEB1 } \\
\text { ZEB2 }\end{array}$ & Gregory et al, 2008 \\
\hline $\mathrm{miR}-203$ & $\begin{array}{l}\text { ZEB1 } \\
\text { ZEB2 } \\
\text { SNAI2 }\end{array}$ & $\begin{array}{l}\text { Wellner et al, 2009; Saini } \\
\text { et al, 2011; Zhang et al, } \\
\text { 2011; Qu et al, } 2013\end{array}$ \\
\hline $\mathrm{miR}-183$ & ZEB1 & Wellner et al, 2009 \\
\hline miR-1 & SNAI2 & $\begin{array}{c}\text { Liu et al, 2012; Tominaga } \\
\text { et al, } 2012\end{array}$ \\
\hline miR-29b & SNAIl & Ru et al, 2012 \\
\hline miR-9 & E-cadherin & Ma et al, 2010 \\
\hline miR-21 & SNAII & Bornachea et al, 2012 \\
\hline miR-495 & E-cadherin & $\begin{array}{c}\text { Hwang-Verslues et al, } \\
2011\end{array}$ \\
\hline miR-30a & $\begin{array}{c}\text { SNAIl } \\
\text { Vimentin }\end{array}$ & $\begin{array}{c}\text { Kumarswamy et al, 2011; } \\
\text { Cheng et al, 2012; }\end{array}$ \\
\hline miR-34a & $\begin{array}{l}\text { ZEB1 } \\
\text { SNAI1 } \\
\end{array}$ & $\begin{array}{c}\text { Siemens et al, 2011; Hahn } \\
\text { et al, } 2013\end{array}$ \\
\hline miR-155 & TGFB1* & $\begin{array}{c}\text { Kong et al, 2008; } \\
\text { Johansson et al, } 2013\end{array}$ \\
\hline miR-10b & $\begin{array}{l}\text { E-cadherin } \\
\text { TWIST1* }\end{array}$ & $\begin{array}{l}\text { Ma et al, 2007; Liu et al, } \\
2012\end{array}$ \\
\hline miR-373 & Involved in metastasis & $\begin{array}{l}\text { Huang et al, 2008; Yang et } \\
\text { al, } 2009\end{array}$ \\
\hline
\end{tabular}


Table 2. Clinicopathological Features of 51 Patients with Localized Prostate Cancer Treated by Radical Prostatectomy

\begin{tabular}{|c|c|c|c|}
\hline Clinicopathological Features & $\begin{array}{c}\text { PCa Cases } \\
\text { (51) }\end{array}$ & $\begin{array}{c}\text { Control } \\
\text { (10) }\end{array}$ & $\boldsymbol{P}$ \\
\hline \multicolumn{4}{|l|}{ Age, years } \\
\hline Mean (SD) & $65( \pm 7.5)$ & $71,9( \pm 8.4)$ & \\
\hline Median & 66 & 72 & \\
\hline Min-Max & $49-77$ & $59-88$ & 0.012 \\
\hline \multicolumn{4}{|l|}{ Clinical Stage (N, \%) } \\
\hline $\mathrm{T} 1 \mathrm{c}$ & $22(45)$ & & \\
\hline T2a & $13(27)$ & & \\
\hline $\mathrm{T} 2 \mathrm{~b}$ & $9(18)$ & & \\
\hline $\mathrm{T} 2 \mathrm{c}$ & $5(10)$ & & \\
\hline \multicolumn{4}{|l|}{ PSA, ng/dL } \\
\hline Mean & $8.19(4.3)$ & $1.05(0.5)$ & \\
\hline Median & 9 & 1.25 & \\
\hline Min-Max & $4.1-20$ & $0.06-1.58$ & \\
\hline$<10(\mathrm{~N}, \%)$ & $39(76)$ & & 0,000 \\
\hline$\geq 10(\mathrm{~N}, \%)$ & $12(24)$ & & \\
\hline \multicolumn{4}{|l|}{ Gleason Score (N, \%) } \\
\hline Median GS & 7 & & \\
\hline Score $\leq 6$ & $15(30)$ & & \\
\hline Score 5 & 2 & & \\
\hline Score 6 & 13 & & \\
\hline Score 7 & $13(25)$ & & \\
\hline Score $\geq 8$ & $23(45)$ & & \\
\hline Score 8 & 18 & & \\
\hline Score 9 & 3 & & \\
\hline Score 10 & 2 & & \\
\hline \multicolumn{4}{|l|}{ Pathologic T Stage (N, \%) } \\
\hline pT2 & $22(43)$ & & \\
\hline pT3 & $29(57)$ & & \\
\hline \multicolumn{4}{|l|}{ Tumor recurrence (N, \%) } \\
\hline Yes & $17(33)$ & & \\
\hline No & $34(67)$ & & \\
\hline
\end{tabular}




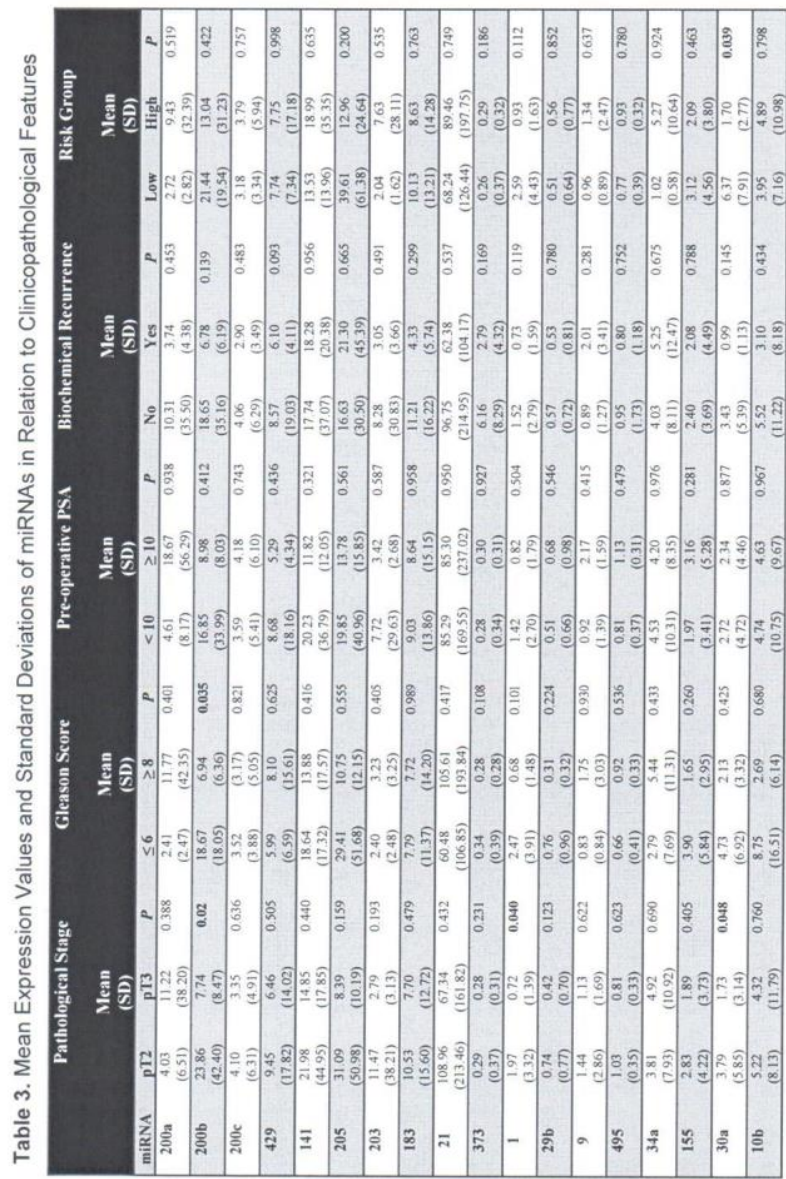




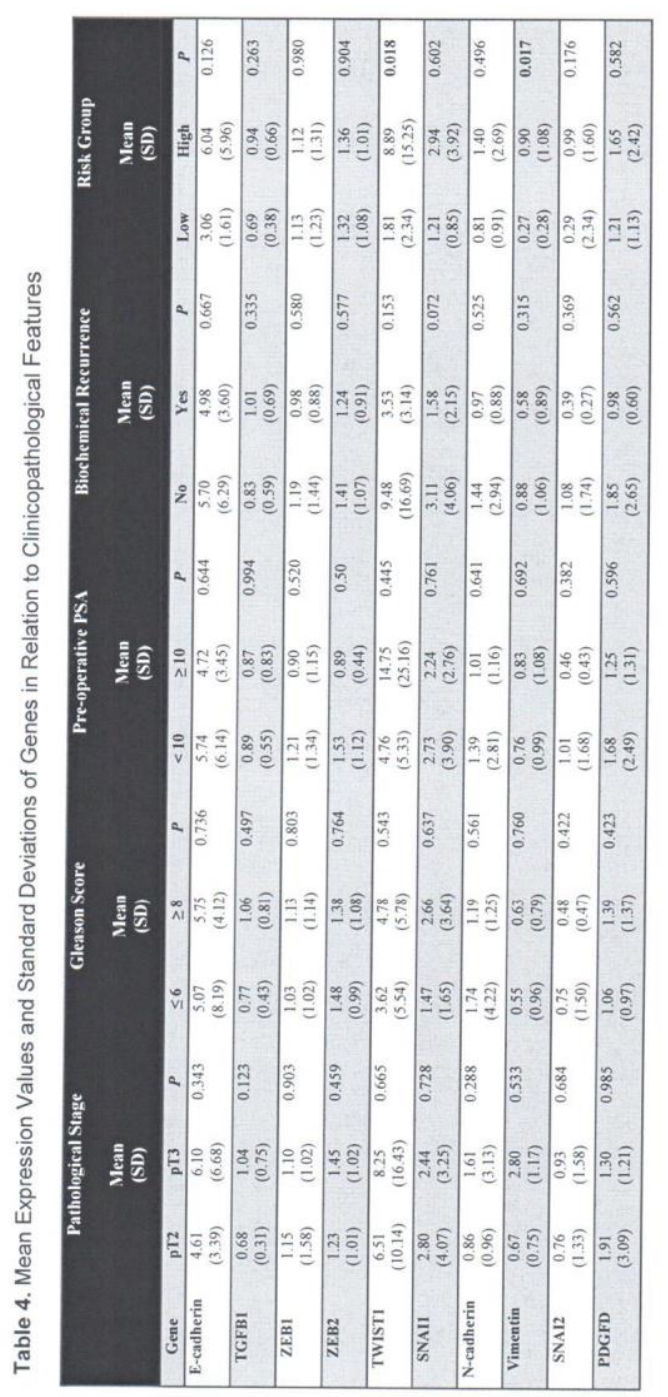




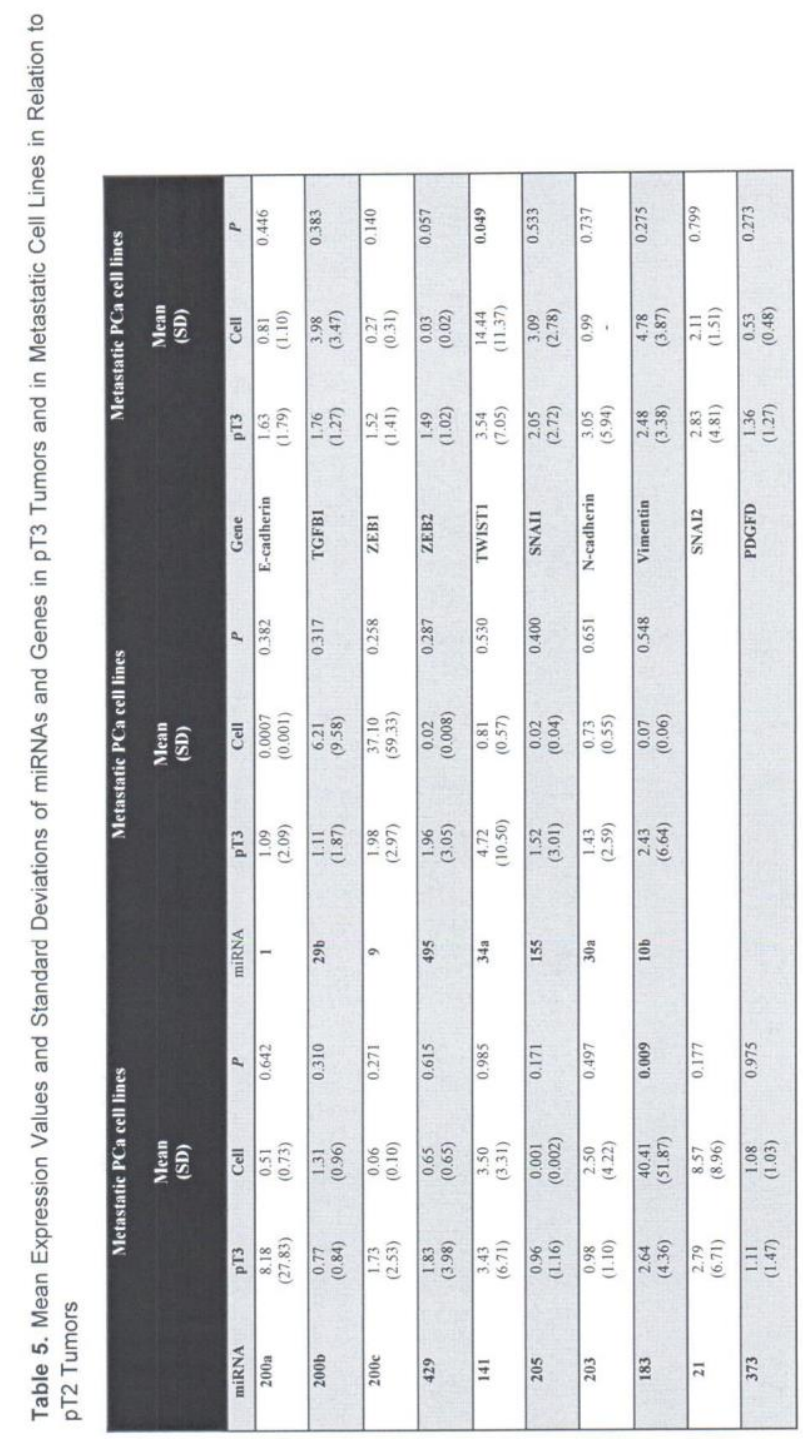




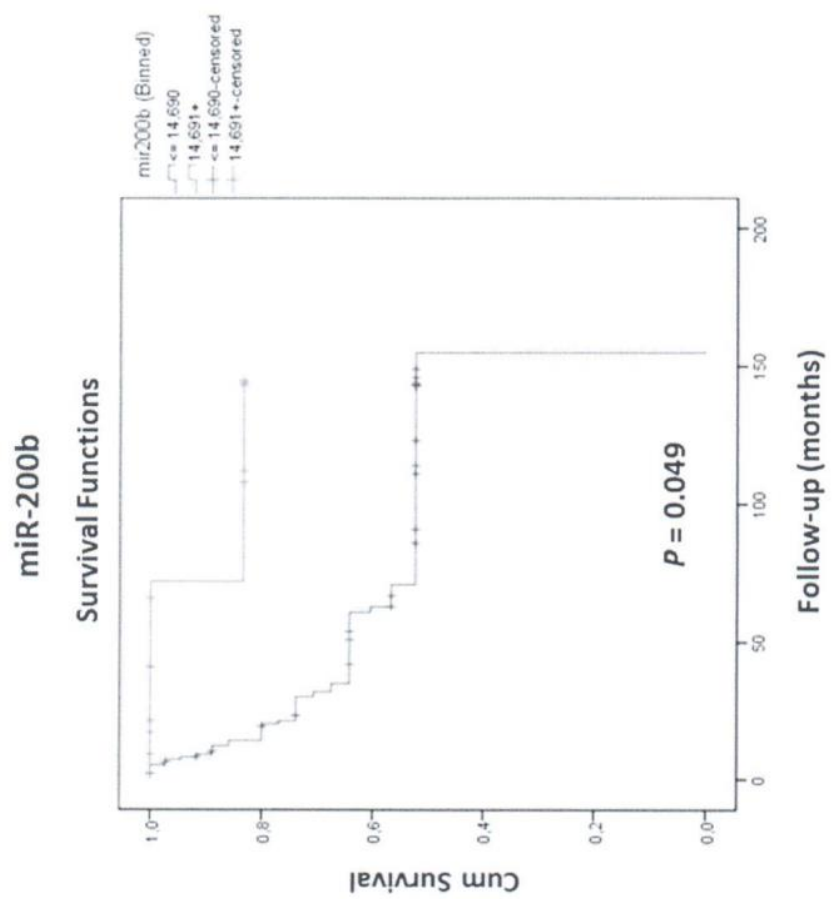




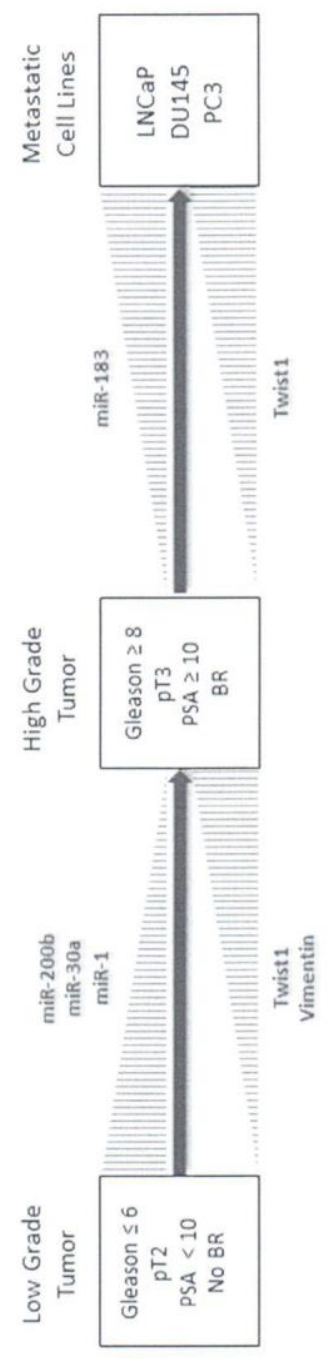




\section{Hospital das Clínicas da FMUSP}

Comissão de Ética para Análise de Projetos de Pesquisa - CAPPesq

\section{PROJETO DE PESQUISA}

Título: ESTUDO DOS GENES E MICRO RNA RELACIONADOS À TRANSIÇÃO EPITÉLIOMESENQUIMAL NO ADENOCARCINOMA DE PRÓSTATA

Pesquisador Responsável: Katia Ramos Moreira Leite

Pesquisador Executante: Betina Katz

Versão: 1

Co-autores: Sabrina Thalita dos Reis, Marcos Francisco Dall'Oglio, Miguel Srougi

Finalidade Acadêmica: Doutorado

Instituição: HCFMUSP

Departamento: CIRURGIA - Disciplina de Urologia

\section{PARECER CONSUBSTANCIADO DO CEP}

Número do Parecer: 5907

Data da Relatoria: 07.03 .12

Apresentação do Projeto: $O$ câncer de próstata é o tumor mais comum em homens e a segunda causa de óbito por câncer no Brasil (www.inca.gov.br), sendo responsável por $11 \%$ das mortes decorrentes de câncer no sexo masculino, similar ao que ocorre no câncer de mama no sexo feminino, o qual é responsável por $15 \%$ das mortes por câncer em mulheres. A transição epitélio-mesenquimal (TEM) é um programa biológico celular reversível que permite a transição parcial ou completa entre dois fenótipos. A célula epitelial, que normalmente interage com a membrana basal, perde a capacidade de aderência intercelular e, através de uma série de processos moleculares, assume um fenótipo mesenquimal . Ao obter tais caracteristicas, a célula adquire um aumento da capacidade migratória e invasora, da resistência à apoptose e da produção de componentes da matriz extracelular (MEC). A ativação de fatores de transcrição, a expressão de proteínas da superfície celular, a expressão de proteínas do citoesqueleto, a produção de enzimas degradantes da MEC e as alterações na expressão de certos microRNAs são fenômenos envolvidos na TEM.Assim sendo, a escassez de dados sobre este tema e a sua relevância para a progressão tumoral tornam necessária uma investigação mais ampla e completa dos fatores envolvidos na transição epitélio-mesenquimal, incluindo os miRNAs, no câncer de próstata. Devido escassez de dados sobre este tema e a sua relevância para a progressão tumoral tornam necessária uma investigação mais ampla e completa dos fatores envolvidos na transição epitélio-mesenquimal, incluindo os miRNAs, no câncer de próstata.

Objetivo da Pesquisa: Objetivos 1) Análise da expressão dos genes e micro RNAs envolvidos no processo de transição epitéliomesenquimal em espécimes de câncer de próstata localizado de pacientes submetidos à prostatectomia radical. 2)Correlação do perfil de expressão dos genes e micro RNAs com graduação histológica de Gleason, estadiamento patológico e recidiva bioquímica.

Avaliação dos Riscos e Benefícios: Não há risco para o paciente, apenas será utilizado um fragmento da próstata que foi retirado durante a cirurgia. Não há benefícios diretos para os participantes, apenas ao final do estudo saberemos se os resultados de 


\section{Hospital das Clínicas da FMUSP}

Comissão de Ética para Análise de Projetos de Pesquisa - CAPPesq

nossa pesquisa poderão diferenciar pacientes com alto e baixo risco de recorrência da doença.

Comentários e Considerações sobre a Pesquisa: A pesquisa é inédita e relevante e os pesquisadores têm condições de levá-la a bom termo.

Recomendações: Não há recomendações imediatas.

Conclusões ou Pendências e Lista de Inadequações: O protocolo pode ser aprovado.

Situação do Parecer: APROVADO

Necessita Apreciação da CONEP: Não

Considerações Finais a critério do CEP: Aprovado

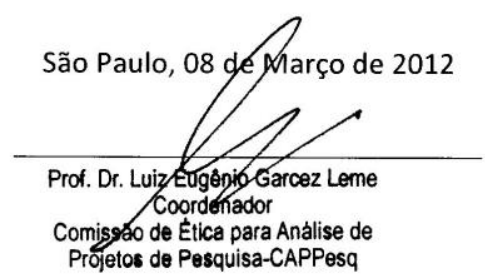

